\title{
Seismic Instrumentation Plan for the Hawaiian Volcano Observatory
}

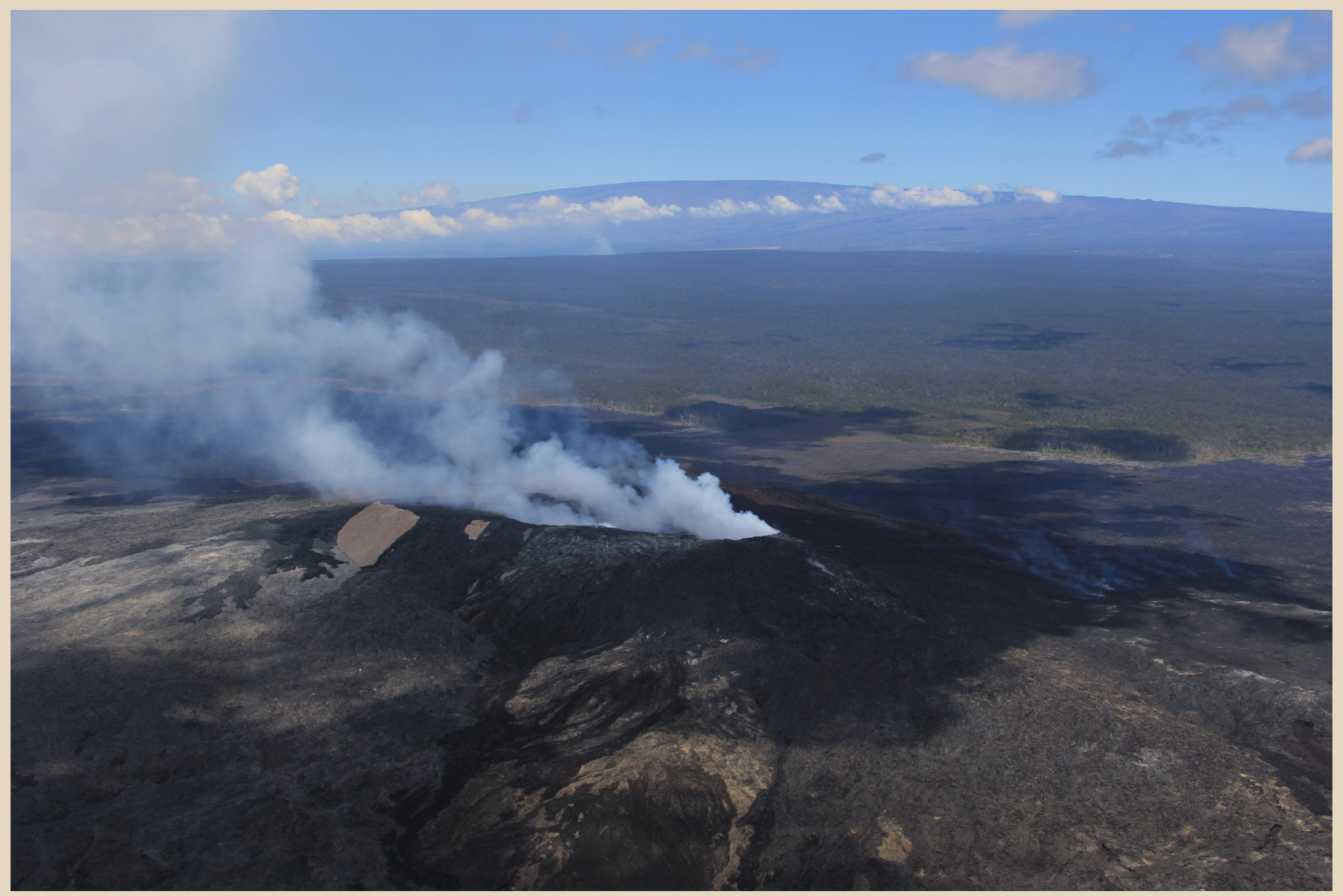

Scientific Investigations Report 2014-5179 
FRONT COVER

Two volcanic plumes from the Kilauea magmatic system with Mauna Loa in the background on the Island of Hawai i. Foreground: P'u'u 'Ō'ō vent with the June 27, 2014, lava tube steaming to the right. Middle ground: Volcanic plume from the pit crater within Halema `uma`u at the summit of Kilauea. The distance between P'u`u 'Ō'ō and Halema`uma`u is 11.5 miles (18.5 kilometers). Background: Mauna Loa is seen on the horizon with the Northeast Rift Zone on the right horizon and the Southwest Rift Zone on the left horizon. The distance between P'u'u 'O' $\bar{o}$ and the summit of Mauna Loa is 32 miles (51.5 kilometers). There is more than 10,000 feet ( 3,048 meters) of vertical relief between $P^{\prime} u^{\prime} u^{~ '} \bar{O}{ }^{\circ} \bar{o}$ and Mauna Loa. (U.S. Geological Survey photograph by Tim Orr.) 


\section{Seismic Instrumentation Plan for the Hawaiian Volcano Observatory}

By Weston A. Thelen

Scientific Investigations Report 2014-5179 


\section{U.S. Department of the Interior SALLY JEWELL, Secretary}

\section{U.S. Geological Survey Suzette M. Kimball, Acting Director}

U.S. Geological Survey, Reston, Virginia: 2014

For product and ordering information: World Wide Web: http://www.usgs.gov/pubprod Telephone: 1-888-ASK-USGS

For more information on the USGS - the Federal source for science about the Earth, its natural and living resources, natural hazards, and the environment: World Wide Web: http://www.usgs.gov

Telephone: 1-888-ASK-USGS

Any use of trade, firm, or product names is for descriptive purposes only and does not imply endorsement by the U.S. Government.

Although this report is in the public domain, permission must be secured from the individual copyright owners to reproduce any copyrighted material contained within this report.

Suggested citation:

Thelen, W.A., 2014, Seismic instrumentation plan for the Hawaiian Volcano Observatory: U.S. Geological Survey Scientific Investigations Report 2014-5179, 43 p., http://dx.doi.org/10.3133/sir20145179. 


\section{Contents}

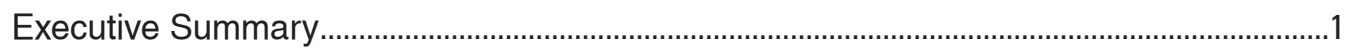

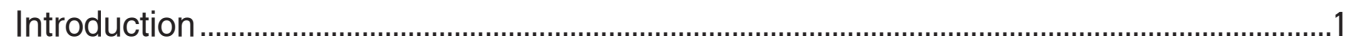

Current Status of Seismic Monitoring .............................................................................

Network Analysis with Detection and Location Thresholds ................................................8

Methodology to Calibrate Local Magnitude and Calculate Detection and Location

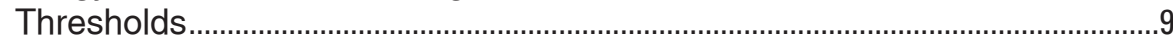

Theoretical Detection Thresholds and Quality Location Thresholds ..........................10

Seismic Monitoring Gap of the Hawaiian Volcano Observatory..........................................19

Methodology for Determining the Seismic Monitoring Gap ..........................................19

Characterizing the Seismic Monitoring Gap ..............................................................19

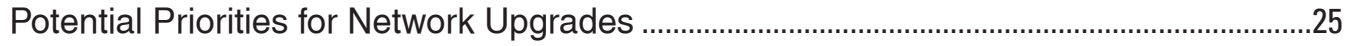

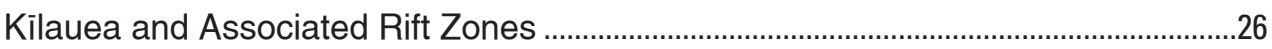

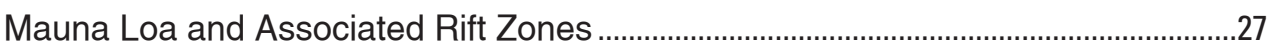

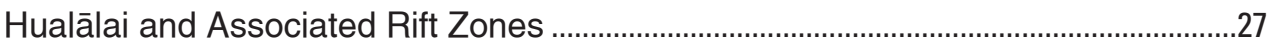

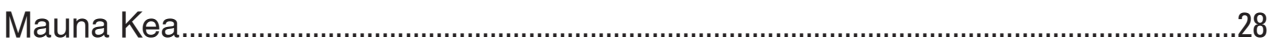

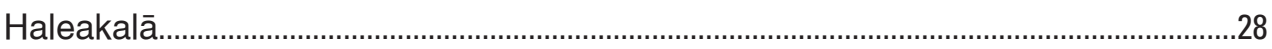

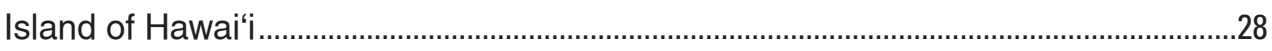

Maui, Kaho'olawe, Lāna‘i, Moloka‘i, O‘ahu, Kaua‘i and Ni'ihau ....................................28

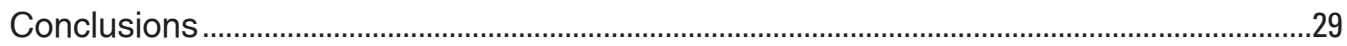

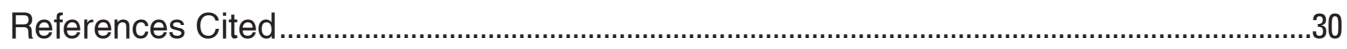

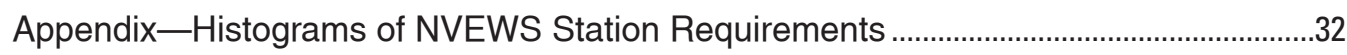

\section{Figures}

1. Map showing active volcanoes of the Island of Hawai'i as defined by the National Volcanic Early Warning System report..........................................................................

2. Map of the Island of Hawai'i showing seismic stations. Red stations are maintained

by the Hawaiian Volcano Observatory .......................................................................

3. Seismic station map of Kilauea Caldera, on the Island of Hawai' i ...............................5

4. Seismic station map of Kïlauea's lower East Rift Zone on the Island of Hawai'i.........6

5. Seismic station map of the Islands of Moloka'i, Maui, Lāna'i and Kaho'olawe.............6

6. Seismic station map of the Islands of O'ahu, Kaua'i and Ni'ihau...................................7

7. Map of infrasound arrays on the on the Island of Hawaili ...............................................

8. Map showing current National Volcanic Early Warning System report quality level status for the Island of Hawai'i..................................................................................11

9. Bar graph summarizing the theoretical magnitude of detection for earthquakes in each respective region of the State of Hawaii ..........................................................11

10. Bar graph summarizing the theoretical magnitude of quality location for earthquakes in each respective region of the State of Hawaii.......................................12

11. Map showing theoretical magnitude of detection threshold for earthquakes in the State of Hawaii ...........................................................................................................12

12. Map showing theoretical magnitude of quality location (TML) threshold for earthquakes in the State of Hawaii . 
13. Map showing theoretical magnitude of detection threshold for earthquakes at the Island of Hawai'i.

14. Map showing theoretical magnitude of quality location threshold for earthquakes at the Island of Hawai'i

15. Map showing theoretical magnitude of detection threshold for Kilauea's south flank on the Island of Hawai'i .

16. Map showing theoretical magnitude of quality location threshold for earthquakes at Killauea's south flank on the Island of Hawai'i.

17. Map showing theoretical magnitude of detection threshold for earthquakes at Mauna Loa on the Island of Hawai'i

18. Map showing theoretical magnitude of quality location threshold for earthquakes at Mauna Loa on the Island of Hawai'i.

19. Map showing theoretical magnitude of detection threshold for earthquakes at Hualālai on the Island of Hawai' $i$

20. Map showing theoretical magnitude of quality location threshold for earthquakes at Hualālai on the Island of Hawai' $i$

21. Map showing theoretical magnitude of detection threshold for earthquakes at Haleakalā on the Island of Maui ...

22. Map showing theoretical magnitude of quality location threshold for earthquakes at Haleakalā on the Island of Maui .

23. Map of the Island of Hawai'i showing the rift zones of Kilauea, Mauna Loa, and Hualālai Volcanoes

24. Maps showing different stages in determining the number of seismic stations necessary to meet the requirements of National Volcanic Early Warning System quality level 4 at Kìlauea, Mauna Loa, Mauna Kea, and Hualālai Volcanoes ...21

25. Maps showing final results of two different estimates of the number of stations necessary to satisfy the requirements of a National Volcanic Early Warning System quality level 4 seismic network on Kïlauea, Mauna Loa, Mauna Kea, and Hualālai

26. Bar graph showing total number of additional stations needed in each respective region of the State of Hawaii to meet the optimal level of seismic monitoring as recommended by the National Volcanic Early Warning System report...............26

27. Graphs showing total number of seismic stations needed to meet National Volcanic Early Warning System quality level 2 status in study areas on the Islands of Hawai'i and Maui

28. Graphs showing total number of seismic stations needed to meet National Volcanic Early Warning System quality level 3 status in study areas on the Islands of Hawai'i and Maui

29. Graphs showing total number of short-period stations needed to meet National Volcanic Early Warning System quality level 3 status in study areas on the Islands of Hawai'i and Maui.

30. Graphs showing total number of broadband stations needed to meet National Volcanic Early Warning System quality level 3 status in study areas on the Islands of Hawai'i and Maui.

31. Graphs showing total number of seismic stations needed to meet National Volcanic Early Warning System quality level 4 status in study areas on the Islands of Hawai'i and Maui .....

32. Graphs showing total number of short-period stations needed to meet National Volcanic Early Warning System quality level 4 status in study areas on the Islands of Hawai'i and Maui. 
33. Total number of broadband stations needed to meet National Volcanic Early Warning System quality level 4 status in study areas on the Islands of Hawai'i and Maui.

34. Graphs showing total number of strong-motion stations needed to meet National Volcanic Early Warning System quality level 4 status in study areas on the Islands of Hawai'i and Maui...

35. Graphs showing total number of seismic stations needed to meet National Volcanic Early Warning System optimal quality level in study areas on the Islands of Hawai'i and Maui

36. Graphs showing total number of short-period stations needed to meet National Volcanic Early Warning System optimal quality level in study areas on the Islands of Hawai'i and Maui...

37. Graphs showing total number of broadband stations needed to meet National Volcanic Early Warning System optimal quality level in study areas on the Islands of Hawai'i and Maui

38. Graphs showing total number of strong-motion stations needed to meet National Volcanic Early Warning System optimal quality level in study areas on the Islands of Hawai'i and Maui...

\section{Tables}

1. Contributions of partner networks to the overall Hawaiian Volcano Observatory seismic network.

2. Summary of National Volcanic Early Warning System threat levels for Hawaiian volcanoes with year of last known eruption in parentheses .....................................2

3. Summary of instrumentation report for seismic networks ...............................................

4. Summary of the total number of additional stations needed to reach each National Volcanic Early Warning System quality level for Hawaiian volcanoes .................23

5. Summary of the total number of additional short-period stations needed to reach each National Volcanic Early Warning System quality level for Hawaiian volcanoes .

6. Summary of the total number of additional broadband stations needed to reach each National Volcanic Early Warning System quality level for Hawaiian volcanoes

7. Summary of the total number of additional strong-motion stations needed to reach National Volcanic Early Warning System quality level 4 for Hawaiian volcanoes.

8. Summary of the total number of seismic stations needed to achieve an optimal configuration for Hawaiian volcanoes as defined by the National Volcanic Early Warning System report 
This page intentionally left blank. 


\title{
Seismic Instrumentation Plan for the Hawaiian Volcano Observatory
}

\author{
By Weston A. Thelen
}

\section{Executive Summary}

The seismic network operated by the U.S. Geological Survey's Hawaiian Volcano Observatory (HVO) is the main source of authoritative data for reporting earthquakes in the State of Hawaii, including those that occur on the State's six active volcanoes (Kīlauea, Mauna Loa, Hualālai, Mauna Kea, Haleakalā, Lō'ihi). Of these volcanoes, Kīlauea and Mauna Loa are considered "very high threat" in a report on the rationale for a National Volcanic Early Warning System (NVEWS) (Ewert and others, 2005). This seismic instrumentation plan assesses the current state of HVO's seismic network with respect to the State's active volcanoes and calculates the number of stations that are needed to upgrade the current network to provide a seismic early warning capability for forecasting volcanic activity. Further, the report provides proposed priorities for upgrading the seismic network and a cost assessment for both the installation costs and maintenance costs of the improved network that are required to fully realize the potential of the early warning system.

HVO has operated seismometers on the Island of Hawai' $i$ since 1912. Currently, the seismic network includes more than 70 stations from four different organizations. Generally, the Island of Hawai' $i$ has most of the seismic stations in the network (and most of the activity), with the density of seismic stations increasing from the northern part of the island to the south-southeast. The strength of the current network, based on theoretical detection and location capabilities, is at the summit of Kîlauea Volcano and Kīlauea's upper East Rift Zone and $\mathrm{Pu}^{\prime} \mathrm{u}{ }^{\prime} \overline{\mathrm{O}}^{`} \overline{\mathrm{o}}$ - where few, if any, upgrades need to be made to the seismic network. The network in the region between Kîlauea and Mauna Loa is slightly weaker, as is the summit of Mauna Loa. In general, the rift zones of each volcano are more poorly monitored seismically than the summits and thus require a greater number of stations to achieve a volcanic early warning capability for monitoring seismicity.

Priorities for new seismic installations on the volcanoes depend on several factors, including current activity, historical activity, population exposure, and current network quality. On Kîlauea, new installations on the middle East Rift Zone, lower East Rift Zone, and lower Southwest Rift Zone appear to be the highest priorities. On Mauna Loa, improvements to the summit seismic network should be prioritized based on the analysis of the data, followed by the installation of a sparse network on both rift zones. Once installed, the next priority would be to create denser seismic networks on the rift zones, particularly where eruptions could quickly threaten populated areas (middle Northeast Rift Zone, lower Southwest Rift Zone). On Hualālai, analysis of the data indicates that the Northwest Rift Zone is the most important priority, particularly where it runs through the population center of Kalaoa. Hualālai's South Rift Zone appears to be the lowest priority for additional seismic instrumentation of any rift zone on Kīlauea, Mauna Loa, or Hualālai because of its low historical activity and lack of population exposure. Mauna Kea and Haleakalā have less active historical eruptive activity and thus have more modest proposed upgrades to seismic instrumentation.

The installation of new seismic stations is only the first part of building a volcanic early warning capability for seismicity in the State of Hawaii. Additional personnel will likely be required to study the volcanic processes at work under each volcano, analyze the current seismic activity at a level sufficient for early warning, build new tools for monitoring, maintain seismic computing resources, and maintain the new seismic stations.

\section{Introduction}

The U.S. Geological Survey (USGS) Hawaiian Volcano Observatory (HVO) has been the main organization responsible for monitoring volcanoes on the Island of Hawai' $i$ since its inception in 1912 (contributions of partner networks are shown in table 1). The State of Hawaii has as many as six volcanoes that can be considered "active" across all the Hawaiian Islands (fig. 1). In a report by Ewert and others (2005; hereafter called the NVEWS report) that described the rationale for a National Volcano Early Warning System (NVEWS), the "threat level" was assessed for all U.S. volcanoes based on historical activity, volcanic ash production, population exposure, and aircraft exposure, along with many other factors. Amongst Hawaiian volcanoes, Kīlauea and Mauna Loa were assigned to the highest of five threat levels, Hualālai was in the second highest threat level, and Haleakalā and Mauna Kea were placed in the third highest threat level. Lō'ihi (southeast of the Island of Hawai' $i$ ) was unranked because of its remote and underwater nature (table 2). Since the threat levels have been assigned, significant new research has shown that Kīlauea has an explosive history, which was not fully appreciated in the NVEWS report (for example, Fiske and others, 2009). With the population exposure of both visitors to 
Table 1. Contributions of partner networks to the overall Hawaiian Volcano Observatory seismic network.

\begin{tabular}{lcl}
\hline \multicolumn{1}{c}{ Organization } & $\begin{array}{c}\text { Number of } \\
\text { instruments }\end{array}$ & Types of instruments \\
\hline $\begin{array}{c}\text { National Strong Mo- } \\
\text { tion Program }\end{array}$ & 31 & Triggered strong motion \\
$\begin{array}{c}\text { Pacific Tsunami Warn- } \\
\text { ing Center }\end{array}$ & 17 & Broadband, strong motion \\
$\begin{array}{l}\text { Puna Geothermal } \\
\text { Global Seismograph } \\
\text { Network }\end{array}$ & 7 & Borehole shortperiod \\
\hline
\end{tabular}

Table 2. Summary of National Volcanic Early Warning System (NVEWS) threat levels for Hawaiian volcanoes (Ewert and others, 2005) with year of last known eruption in parentheses.

[NA, not applicable]

\begin{tabular}{llc}
\hline NVEWS threat level & \multicolumn{1}{c}{ Volcano } & Optimal quality \\
\hline Very high threat & Kīlauea (2014+) & 4 \\
& Mauna Loa (1984) & \\
High threat & Hualālai (1801) & 4 \\
Moderate threat & Mauna Kea (2460 B.C.) & 3 \\
& Haleakalā ( 1480) & \\
Not ranked & Lō'ihi (1996) & NA \\
\hline
\end{tabular}

Hawai'i Volcanoes National Park and residents in the nearby town of Volcano, this explosive history makes Kîlauea one of the most dangerous volcanoes in the United States. The relatively large number of active and dangerous volcanoes in the State of Hawaii within a relatively small geographic area necessitates a strategy for monitoring these volcanoes to protect the life and property of visitors and residents.

One of the oldest and most diagnostic monitoring techniques for assessing volcanic activity is seismology. HVO has operated seismometers of various types since 1912 and has been producing a modern seismic catalog since October 1, 1959 (Klein and Wright, 2000). Some of the first prototype electromagnetic seismometers were built and tested at HVO in the late 1950s; these had dramatically improved sensitivity compared to other seismometers at the time (Okubo and others, 2013). The first telemetered seismograph was also pioneered at HVO. It was placed 3 kilometers $(\mathrm{km})$ away from HVO and hardwired back to the observatory (Okubo and others, 2013). HVO followed the computer revolution, switching to new computer processing systems for seismic data in 1970 (punch cards), 1979 (Eclipse/HYPOINVERSE), 1985 (Caltech/USGS Seismic Processing, CUSP), and 2009 (Advanced National Seismic System Quake Monitoring System, AQMS) (Okubo and others, 2013). The seismic network was entirely converted to digital recording and telemetry between 2011 and 2013. The conversion to digital recording

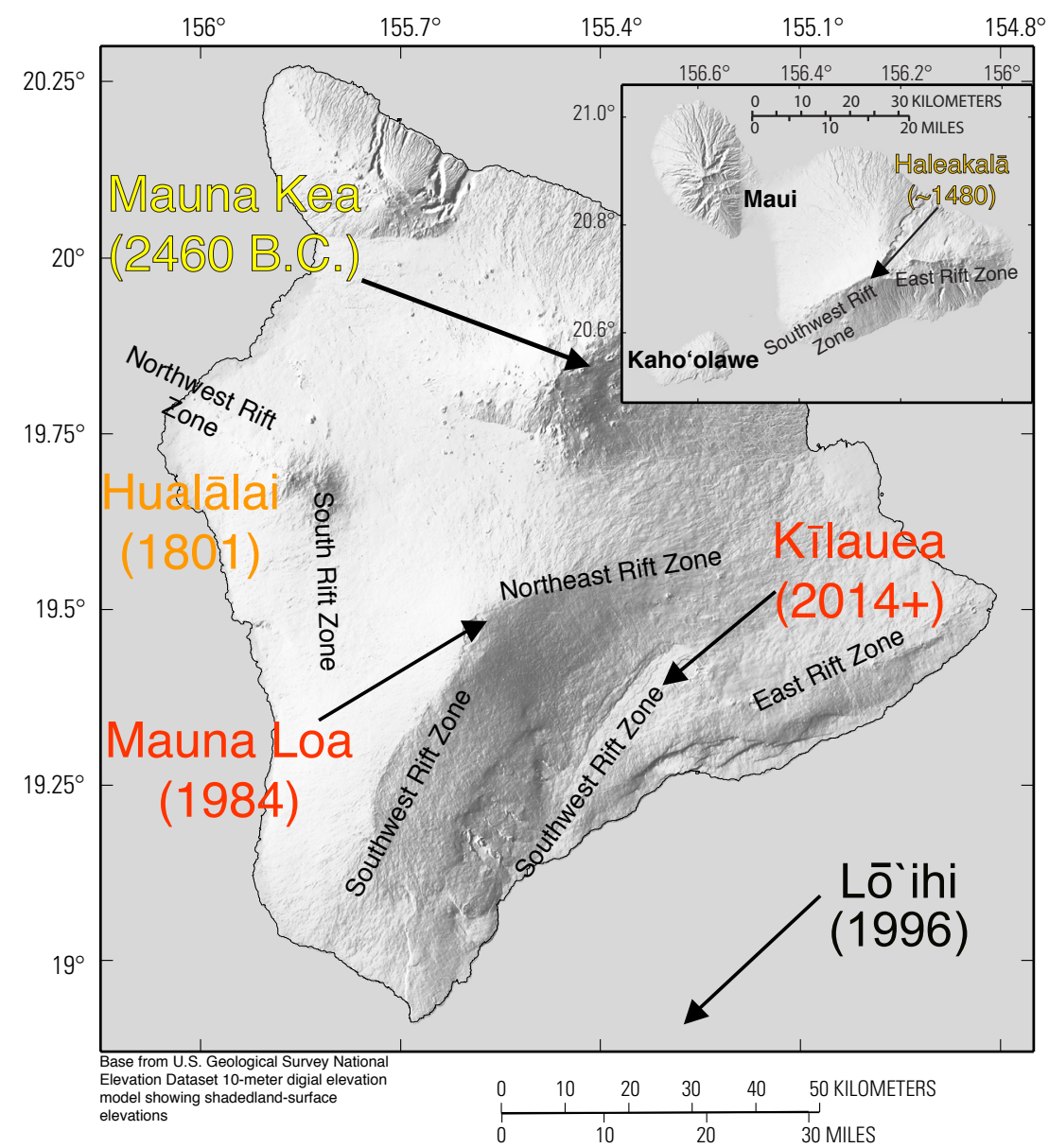

Figure 1. Map showing active volcanoes of the Island of Hawai'i as defined by the National Volcanic Early Warning System (NVEWS) report (Ewert and others, 2005). Years of last eruption are included in parentheses below the volcano name. Red labels denote very high threat volcanoes, orange labels denote high threat volcanoes, and yellow labels denote moderate threat volcanoes. Lō'ihi submarine volcano was not considered as part of the NVEWS report due to its remote, offshore location and lower volcanic risk. 
Table 3. Summary of instrumentation report for seismic networks (Moran and others, 2008).

[M, magnitude; km, kilometers, LP, long period; VLP, very long period, $3 \mathrm{D}$, three dimensional]

\begin{tabular}{|c|c|c|}
\hline Quality level & Capabilities & Requirement \\
\hline Level 1 & $\begin{array}{l}\text { Detect } M>1.5 \text { earthquakes, } \\
\text { Crudely locate } M>3 \text { earthquakes }\end{array}$ & $\begin{array}{l}2 \text { seismic stations within } 50 \mathrm{~km} \text {, } \\
5 \text { seismic stations within } 200 \mathrm{~km}\end{array}$ \\
\hline Level 2 & $\begin{array}{l}\text { Detect } M>1 \text { earthquakes, } \\
\text { Crudely located } M>2 \text { earthquakes, } \\
\text { Determine event type, } \\
\text { Detect energetic seismic tremor, } \\
\text { Detect LP earthquakes, } \\
\text { Detect } M>1 \text { event families }\end{array}$ & $\begin{array}{l}2 \text { seismic stations within } 10 \mathrm{~km} \text {, } \\
5 \text { seismic stations within } 50 \mathrm{~km}\end{array}$ \\
\hline Level 3 & $\begin{array}{l}\text { Detect } M>0.5 \text { earthquakes, } \\
\text { Accurately locate } M>1 \text { earthquakes, } \\
\text { Determine event type, } \\
\text { Detect seismic tremor, } \\
\text { On-scale recording on } 1 \text { station, } \\
\text { Detect VLP earthquakes, } \\
\text { Calculate fault-plane solutions, } \\
\text { Determine b-values, } \\
\text { Detect LP earthquakes, } \\
\text { Detect } M>0.5 \text { event families, } \\
\text { Detect traveltime changes }\end{array}$ & $\begin{array}{l}2-3 \text { seismic stations within } 5 \mathrm{~km} \text {, including } 1 \text { broad- } \\
\text { band station; } 6-8 \text { seismic stations within } 20 \mathrm{~km}\end{array}$ \\
\hline Level 4 & $\begin{array}{l}\text { Detect and locate } M>0 \text { earthquakes, } \\
\text { Determine event type, } \\
\text { Crudely locate seismic tremor, } \\
\text { On-scale recording on } 1 \text { station, } \\
\text { Locate VLP earthquakes, } \\
\text { Calculate fault plane solutions, } \\
\text { Calculate moment tensors, } \\
\text { Calculate b-values, } \\
\text { Changes in S-wave splitting, } \\
\text { Construct 3-D velocity model, } \\
\text { Track relative movements of source, } \\
\text { Explosion detection (infrasound) }\end{array}$ & $\begin{array}{l}\text { 2-3 seismic stations within } 5 \mathrm{~km} \text {, including } 2 \\
\text { broadband stations and } 1 \text { strong-motion station; } \\
12-20 \text { seismic stations within } 20 \mathrm{~km} \text { including } 6 \\
\text { broadband stations }\end{array}$ \\
\hline
\end{tabular}

improved signal fidelity and dynamic range over previous analog systems. Along with the digital conversion, several new broadband and strong-motion sensors replaced existing short-period instruments, allowing the seismic network to better record a range of amplitudes and frequencies of both large tectonic earthquakes and small volcanic earthquakes.

Although the NVEWS report ranked volcanoes according to threat, and assigned high-priority targets for monitoring, it did not specify exactly what those monitoring networks should include. Moran and others (2008; henceforth called the Moran report) provided instrumentation recommendations for seismic, geodetic, gas, hydrologic, and remote sensing networks at different NVEWS threat levels. In this report, the quality of the seismic networks were divided into four levels, with 1 being the lowest quality network, and 4 being the highest quality network (table 3 ). In general, quality increases with the number of total stations, the number of broadband stations, and the number of strong-motion stations. Here we define a short-period station as a site having a seismometer with a corner frequency greater than $1 \mathrm{hertz}(\mathrm{Hz})$. Similarly, a strongmotion site is a seismic station that has an accelerometer that can record large ground motions on-scale. A broadband station is a site that has a seismometer installed with signal sensitivity greater than 40 seconds (s). As a seismic network improves in quality, more capabilities are available for monitoring (table 3). This includes a better capability of detecting smaller seismicity, the ability to distinguish and characterize source processes of different event types, volcanic moment tensor calculation, seismic tremor detection and location, and three dimensional (3-D) velocity mapping.

The capabilities associated with each level of network dictate the theoretical capabilities, not the capabilities that currently exist. Along with network upgrades must come upgrades in staff to implement the techniques that are possible. If network growth occurs without additions in analysis staff, science staff, technical staff, and information technology staff, then the techniques that are possible will remain in the research realm, and the goal of NVEWS - an improved early warning system for forecasting volcanic eruptions-will not be achieved. Much work needs to be done to have all of the theoretical capabilities available in real-time. 
The goal of this report is to present an instrumentation plan for HVO in a framework of capabilities. More specifically, recommendations of numbers of stations required for a specific region are based on quantitative estimates of how many stations are required to locate, say, a magnitude $(M) 1$ earthquake on Kīlauea's lower East Rift Zone or how many additional stations are required to generate well-constrained focal mechanisms for $M 2$ earthquakes on the Southwest Rift Zone of Mauna Loa. These capabilities come from the quality of the network, which is discussed in the Moran report and are summarized in table 3 . In general, these recommendations are most applicable to stratovolcanoes, which for the most part can be thought of as point sources to monitor. Hawaiian volcanoes must be treated fundamentally differently. Although eruptions do occur from their summits, eruptions also originate along rift zones that emanate from the summit area. Monitoring these long rift zones in similar ways to the summit of the volcano means that the number of stations to provide a certain capability on a Hawaiian-style volcano will be significantly larger than the number of stations required for a stratovolcano. On the other hand, the proximity of active volcanoes on the Island of Hawai'i may allow a single station to provide monitoring for two volcanoes in certain areas. In addition to determining how many seismometers will be required to meet certain performance criteria, this report will also present magnitude-of-detection and earthquake-location quality metrics to identify the weaknesses and strengths of the current network.

Although $\mathrm{HVO}$ has a requirement as a Tier 1 Advanced National Seismic System (ANSS) network to provide earthquake information for the State of Hawaii, most of this report will focus on planning for enhanced capabilities for the five subaerial active volcanoes. Even a modest improvement of seismic networks around the active volcanoes on Hawai' $i$ and Maui will also improve HVO's ability to detect and study tectonic earthquakes not directly associated with volcanic processes in these areas. For areas that are at moderate to high seismic risk, as all of the Islands of Hawai' $i$ except Kaua' $i$ are, the ANSS requires a magnitude of completeness $\left(M_{\mathrm{c}}\right.$; the magnitude value above which a seismic catalog follows a Gutenburg-Richter relationship; for example, Weimer and Wyss, 2000) of 2.5. Although it is possible given the current network to locate events of this size, obtaining quality locations is difficult because network geometry is limited by island geography.

This report discusses the current status of the seismic network at HVO. First the status is discussed in terms of the network quality level (NQL), which is a broad measure of network quality and one used in reports describing NVEWS (Ewert and others, 2005; Moran and others, 2008). Also discussed are the current strengths and weaknesses of the network in more spatial detail by considering the theoretical detection and location thresholds of the network. With an eye to the future, a calculation is made of monitoring gap between the current network and the different NQLs. Using the theoretical detection and location thresholds as a guide, priorities are proposed for each region and volcano to bridge the gap between the current status and the target NQL.

\section{Current Status of Seismic Monitoring}

HVO currently operates a seismic network of 72 seismic stations (as of July 2014) on the Island of Hawai' $i$ (figs. 2 through 6). HVO partners with the Pacific Tsunami Warning Center (PTWC, network code PT), the Global Seismographic Network (GSN, network code IU), Puna Geothermal Ventures (PGV), and the USGS National Strong Motion Network (NSMP, network code NP) in the operation of a regional Hawaiian seismic network consisting of 86 continuous stations and 45 triggered stations, with all groups sharing data in near real time (table 1). The types of stations and their locations are dictated by the diverse missions of each contributing organization. The PTWC is interested in rapid tsunami detection, especially as it pertains to Hawaii, and thus their network consists of broadband and strong-motion sensors recording continuously across all of the Hawaiian Islands. The GSN is interested in the detection of global seismicity, and thus they have two very sensitive and extremely well-built stations. The NSMP network is designed to record shaking associated with large earthquakes and consists of only strong-motion stations. The stations in the NSMP network are distributed in populated places and only report their data when triggered by strong shaking. The PGV network was built to monitor geothermal power production in the lower East Rift Zone of Kīlauea and thus has a limited spatial extent of exclusively short-period borehole sites. The stations maintained by HVO are confined to the Islands of Hawai' $i$ and Maui, dominantly in areas that have volcanic activity. The HVO network consists of broadband, short-period, and strong-motion stations. By importing data from our partners' stations, HVO is able to monitor seismicity on all of the Hawaiian Islands from Kaua' $i$ to Hawai' $i$.

Infrasound monitoring is an emerging field in volcanology and has been shown to have a range of uses in explosion detection (for example, De Angelis and others, 2012), lava lake monitoring (Fee and others, 2010), and fissure eruption tracking (for example, Badger and others, 2013). The Moran report suggested the inclusion of infrasound in the design of a quality level 4 network. Specifically the report proposed two collocated infrasound-seismic sites within $5 \mathrm{~km}$ of the volcano with two infrasound sensors at each site. In 2013, HVO installed three infrasound arrays, each collocated with a seismic site and each with four infrasound sensors in an array configuration (fig. 7). Since 2013, one infrasound array has been removed because of approaching lava. The array configuration allows the detection of weak infrasonic signals from more than $20 \mathrm{~km}$ away (Thelen, W.A, and Cooper, J., unpublished data). HVO also imports continuous data from two additional arrays from the Infrasound Lab at the University of Hawai'i (ISLA; fig. 7). The combined capabilities of the five 


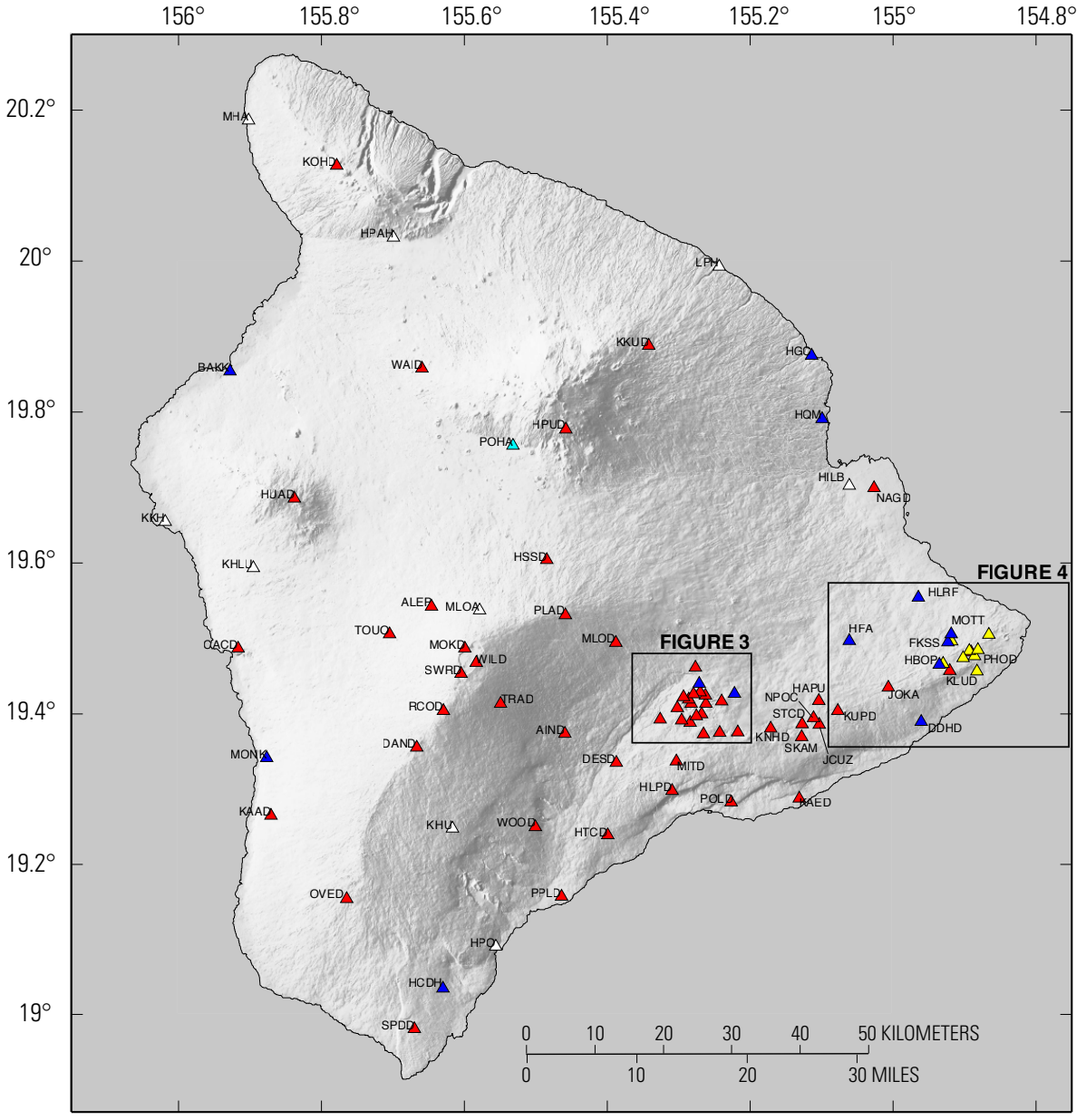

Base from U.S. Geological Survey National Elevation Dataset 10-meter digial elevation model showing shadedland-surface elevations

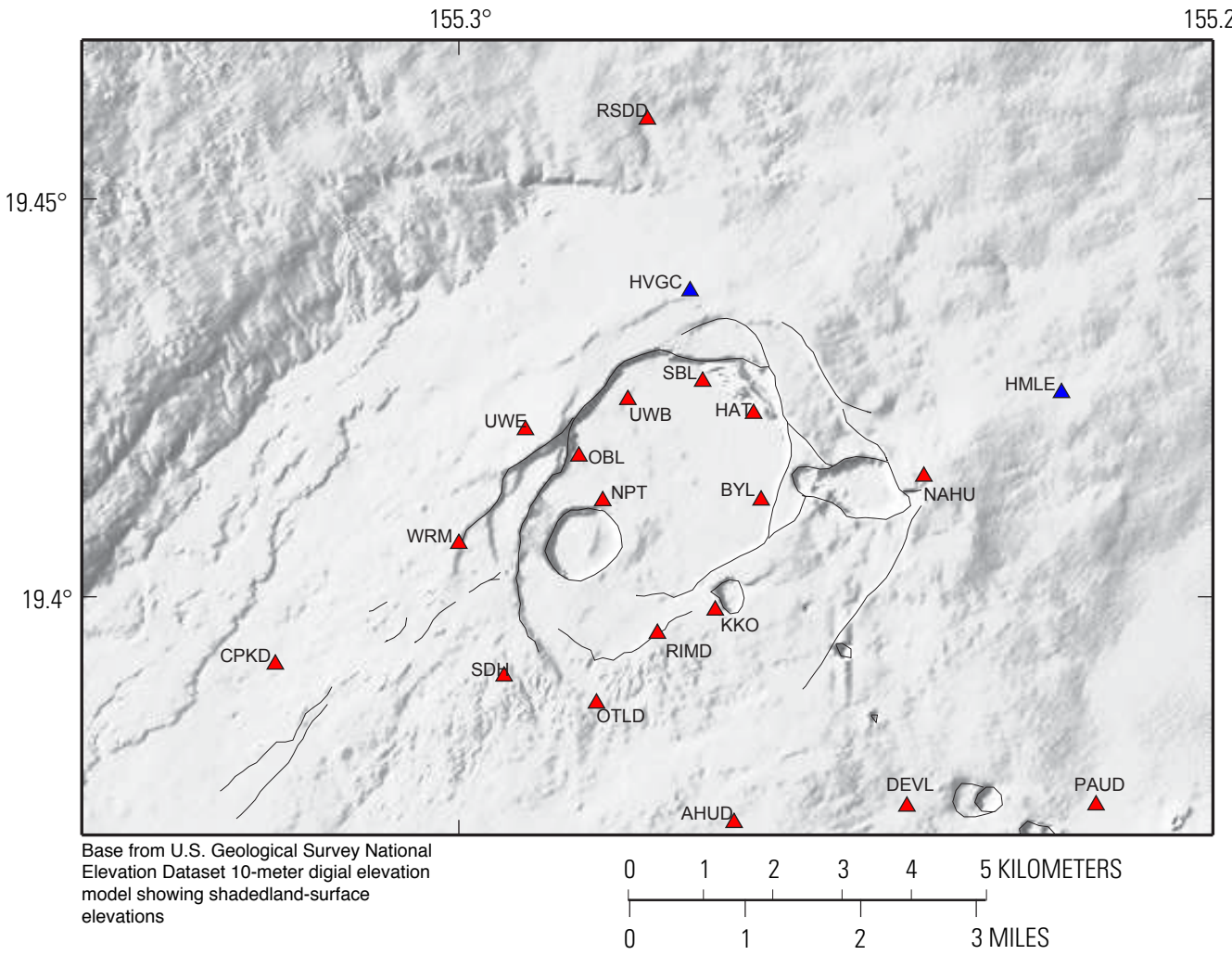

Figure 2. Map of the Island of Hawai'i showing seismic stations. Red stations are maintained by the Hawaiian Volcano Observatory, white stations by the Pacific Tsunami Warning Center, blue stations by the Global Seismographic Network, and yellow stations by Puna Geothermal. Blue stations are also U.S. Geological Survey "netquakes" stations, which influence determining the location of an earthquake but not the detection of that earthquake. Also see discussion in text.
Figure 3. Seismic station map of Kïlauea Caldera, on the Island of Hawai'i. Symbols are the same as on figure 2 . 


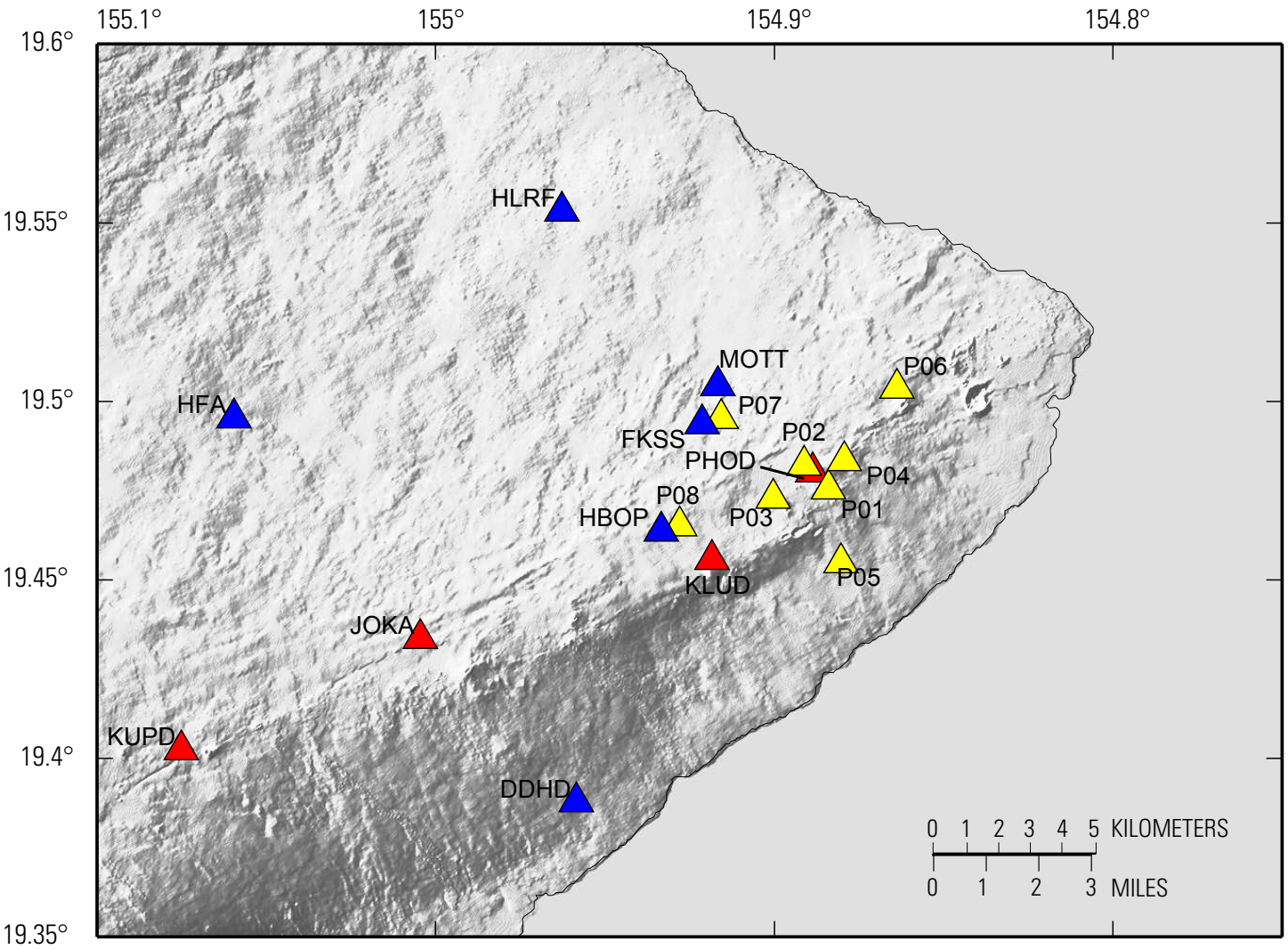

Figure 4. Seismic station map of Kïlauea's lower East Rift Zone on the Island of Hawai'i. Symbols are the same as on figure 2.

Base from U.S. Geological Survey Nationa

Elevation Dataset 10-meter digial elevation

model showing shadedland-surface

elevations

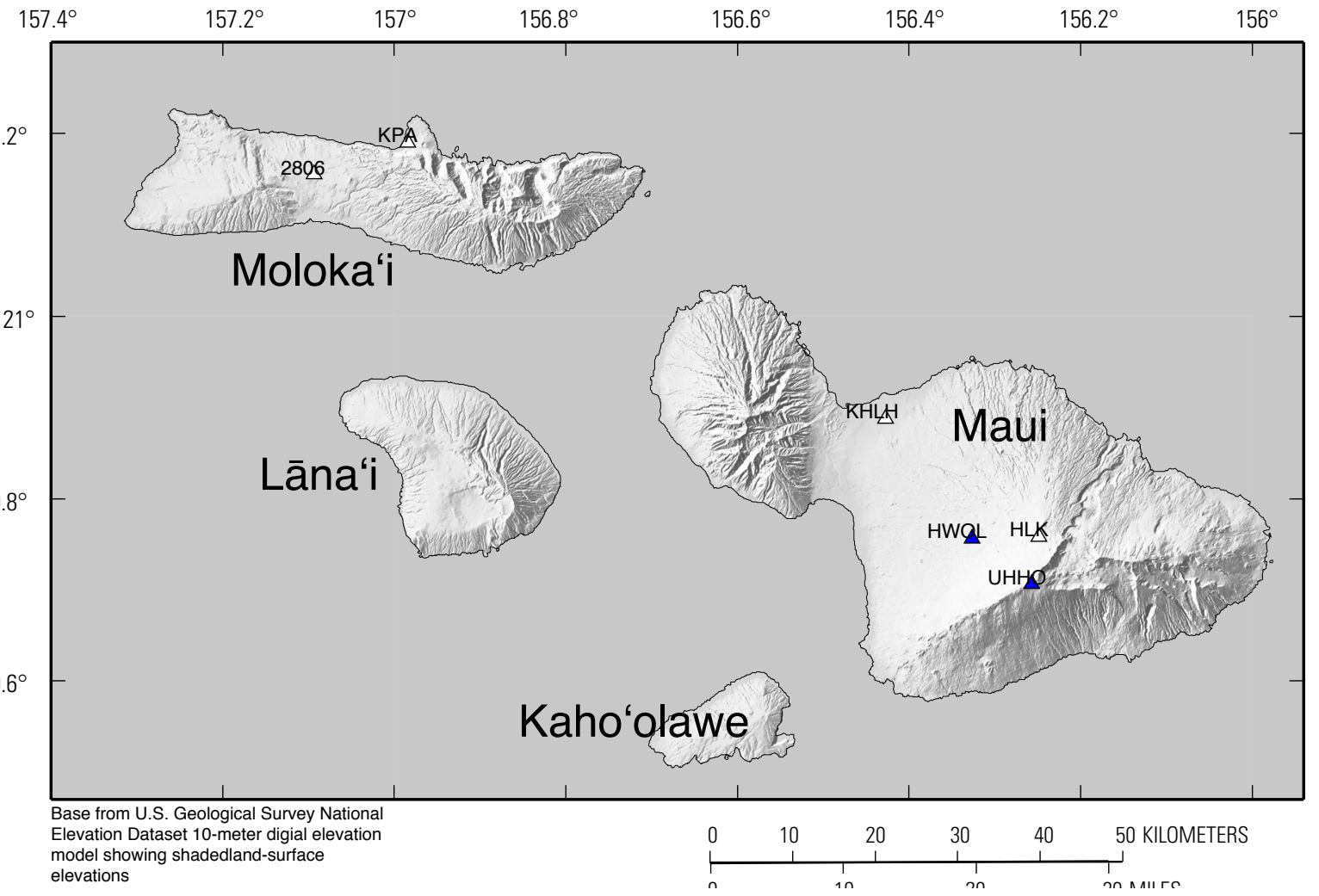

Figure 5. Seismic station map of the Islands of Moloka'i, Maui, Lāna'i and Kaho'olawe. Symbols are the same as on figure 2. 


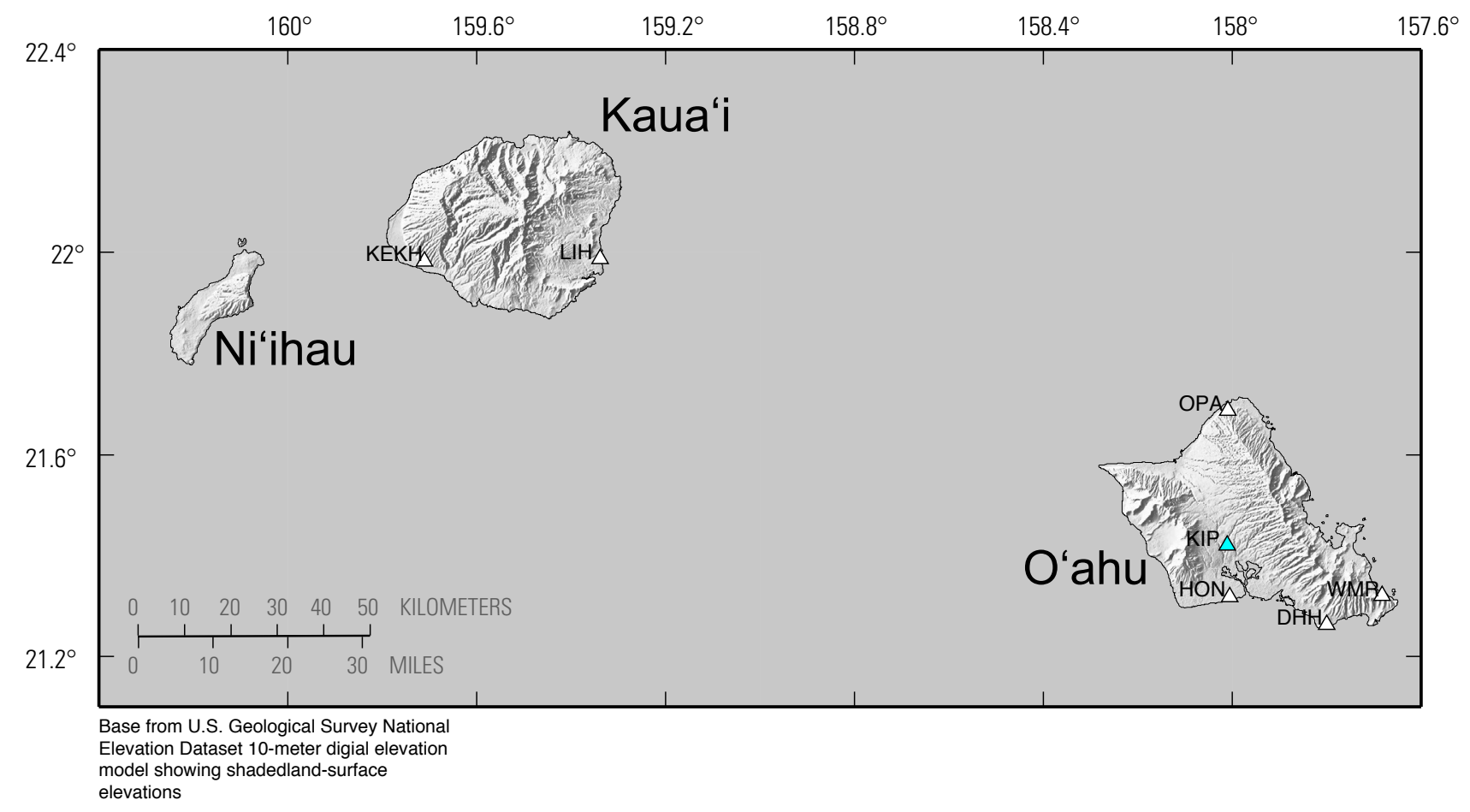

Figure 6. Seismic station map of the Islands of O'ahu, Kaua'i and Ni'ihau. Symbols are the same as on figure 2.

infrasound arrays on the Island of Hawai' $i$ give us more than the capabilities afforded by the layout suggested in the Moran report and thus we do not consider any additional infrasound sites in this report.

The current state of seismic monitoring can be cast into the NVEWS NQLs as defined in the Moran report (table 3). In general, a quality level 1 network can locate magnitude 3 earthquakes and greater and detect earthquakes down to about magnitude 1.5. Such a network only needs 2 seismic stations within $50 \mathrm{~km}$ of the volcanic target and 5 stations within 200 $\mathrm{km}$. A quality level 2 network can locate earthquakes above magnitude 2 , detect earthquakes above magnitude 1 , determine event type, and detect energetic tremor. A quality level 2 network has two seismic stations within $10 \mathrm{~km}$ of the volcanic target and five seismic stations within $50 \mathrm{~km}$ of the seismic target. A quality level 3 network has a location and detection threshold of approximately 1 and 0.5 , respectively. A quality level 3 network, in addition to the capabilities of a quality level 2 network, can determine velocity medium changes, calculate focal mechanisms, and detect very long period earthquakes (VLPs) and tremor. To achieve these capabilities, a quality level 3 network must have two to three seismic stations within $5 \mathrm{~km}$ of the volcanic target, including a single broadband. A quality level 3 network also must have six to eight stations within $20 \mathrm{~km}$ of the volcanic target. A quality level 4 network, in addition to the capabilities of the quality level 3 network, can crudely locate seismic tremor and VLPs, record all signals on scale with at least one station, detect relative location changes, and calculate moment tensors, 3 -D velocity models, and shear-wave splitting. A quality level 4 network, the highest defined quality, is defined as having two to three seismic stations within $5 \mathrm{~km}$ of the volcanic target, including two broadband stations and one strong-motion station. A quality level 4 network also has 12 to 20 seismic stations within 20 $\mathrm{km}$ of the volcanic target, including 6 broadband stations.

Assessing the network in terms of a quality level gives a quick sense of the strengths and weaknesses of the network, although the reason for relative network strength is not necessarily obvious (for example, too few broadband or strong-motion sensors). To define a network quality, I made a grid across the Island of Hawai ${ }^{6} i$, with grid spacing of 0.01 degree in latitude/longitude. At each grid point, I assess the number of continuous short-period instruments, strong-motion instruments, and continuous broadband instruments within 5 $\mathrm{km}$ and within $20 \mathrm{~km}$ of the grid node. Triggered stations were not considered in the Moran report and will not be considered in this analysis. Those values are then compared against the requirements in table 3, and each grid node is assigned a quality level (1-4). Those grid nodes are then contoured to produce a summary map (fig. 8).

Within the HVO network, quality level 4 networks exist at the summit of Kîlauea and around $\mathrm{Pu}^{\prime} u$ ' ' $\overline{\mathrm{O}}^{‘} \overline{\mathrm{o}}$. (fig. 8). The summit of Mauna Loa is quality level 3, as is Kîlauea's East Rift Zone between the summit and $\mathrm{Pu}^{\prime} u{ }^{\prime}{ }^{\prime} \bar{O}^{‘}$ o and Kîlauea's upper Southwest Rift Zone. Quality level 2 networks exist on Kîlauea's lower East Rift Zone, middle and lower Southwest Rift Zone, and the upper reaches of Mauna Loa. Minor areas of quality level 2 exist on Hualālai and Mauna Kea. The rest of the regions on Kīlauea, Mauna Loa, Hualālai, Mauna Kea, and Haleakalā are quality level 1. Based on the NVEWS report and the Moran report, the network quality level (1-4) should be tied to the volcanic threat level (very low threat, low threat, 


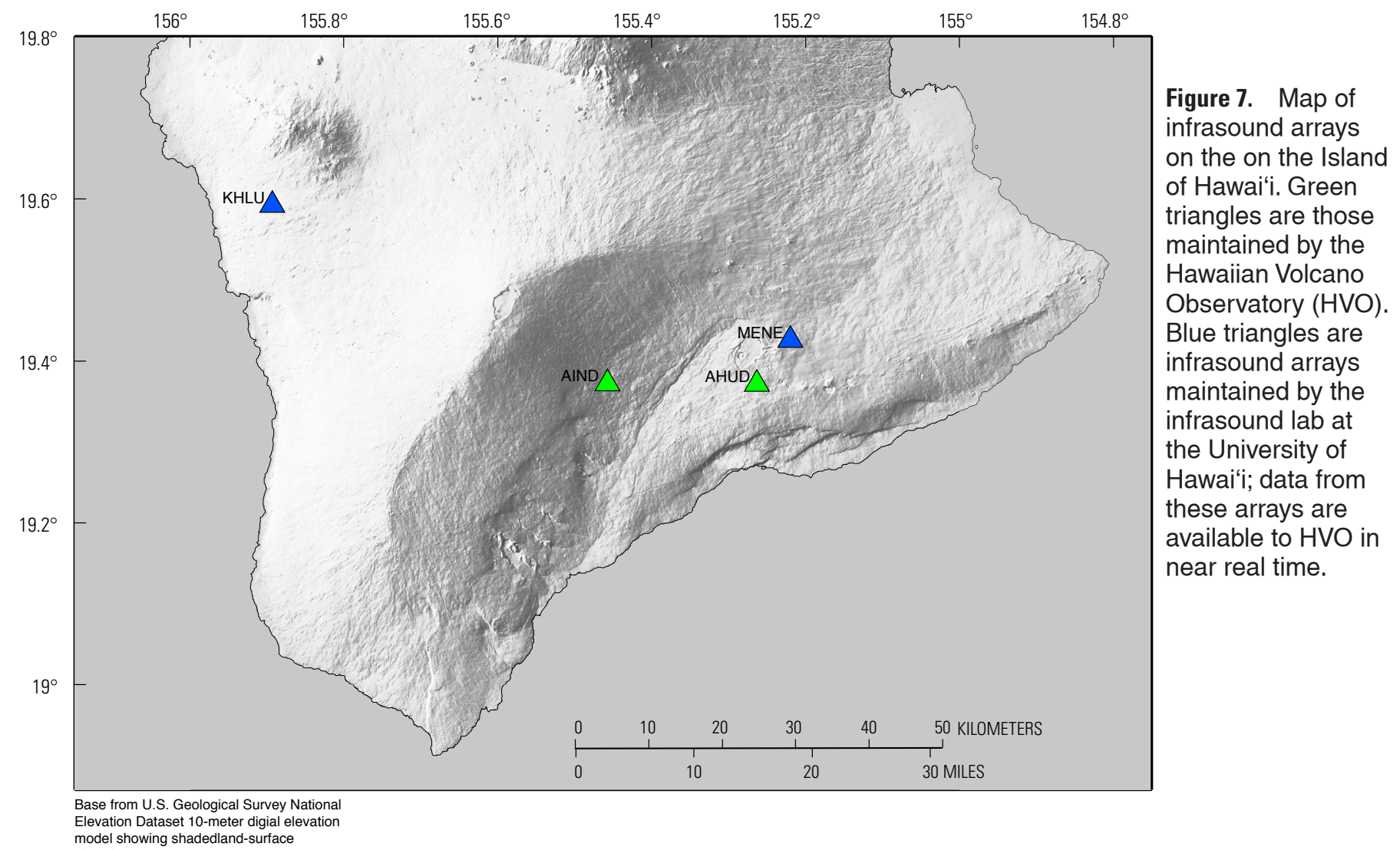

moderate threat, high threat, very high threat). For example, all very high threat volcanoes (Kîlauea and Mauna Loa) and high threat volcanoes (Hualālai) are best instrumented with NVEWS quality level 4 networks (table 2). Similarly, moderate threat volcanoes (Mauna Kea and Haleakalā) should only be instrumented with quality level 3 networks. The following sections explore exactly how many stations are needed to bring these volcanoes up to a recommended level and then prioritize the locations of future station installations.

\section{Network Analysis with Detection and Location Thresholds}

Location is one of the most basic parameters of an earthquake. When an earthquake is small or occurs in a sparse part of a seismic network, obtaining a location may not be possible because the earthquake was not recorded by enough stations; however, detection may still be possible. Detections can be extremely important as the first indicator of changes in volcanic activity. In the previous section, I assigned quality levels to different parts of the network, which rely on the number of different types of instruments within a certain radius. Although the number of stations (and thus the number of observations) does improve the results of any subsequent analysis, identifying the detection and location thresholds of the network is also as important. The detection threshold of a network measures the sensitivity of the network without considering of the type of instrument or geometry of the seismic network. The location threshold also measures the network sensitivity without consideration to the type of instrument but also considers the azimuthal coverage of the network around an earthquake source.

Most automated earthquake-detection algorithms (for example, CarlStaTrig-CarlSubTrig) require that an earthquake be detected on 2 to 4 stations so as to minimize the number of false triggers. At HVO, subsets of stations based on geography are typically configured to require triggers on at least two stations. Many of these small events are not included in a curated seismic catalog, because there are not quality arrivals recorded on enough stations to determine a location or there simply are not enough resources to analyze every single event. However, small-magnitude earthquakes may be the first sign of unrest in a volcanic crisis, and therefore detections are useful to track by a metric such as event counts.

An earthquake location can be calculated using as few as 4 phase arrivals to constrain the 4 unknowns of 3-D position and origin time. However, locations with few phase arrivals often have large errors in epicenter and depth. Additional phase arrivals will generally decrease errors in location and magnitude, although it is also important to have arrivals from stations that adequately surround the epicenter. The "azimuthal gap," the maximum difference in azimuth from the epicenter among stations that have phase arrivals for the event, is the metric used to quantify how well an epicenter is surrounded by stations. If stations are only on one side of an event, then the epicentral solution can be biased in the direction of the 
stations. Following Moran (2004), I adopt the standard that a quality (well-constrained) earthquake location is one that has 8 phase arrivals with no more than a 135-degree gap between seismic stations recording the event.

The metric most often used to assess the quality of a network is the magnitude of completeness. This metric is dependent on two things - (1) a sufficient number of earthquakes to calculate a magnitude versus cumulative occurrence of earthquakes plot and (2) a Gutenburg-Richter relationship in those earthquakes (that is, 10 times as many $M 1$ earthquakes as $M 2$ earthquakes, 10 times as many $M 2$ earthquakes as $M 3$ earthquakes, and so on). In areas of low seismicity, requirement 1 is not often met and thus a different method must be used that can be consistently applied in a broad geographic area, even where there is little or no historical seismicity. In addition, volcanoes often violate requirement 2 , as has been shown in certain areas of Kîlauea (Wyss and others, 2001).

Instead of the magnitude of completeness, I use the methodology of Moran (2004) to calculate a theoretical magnitude of detection threshold (TMD) and a theoretical magnitude of quality location threshold (TML). A quality location is defined as eight station observations with an azimuthal gap less than 135 degrees. This approach has the benefit of not assuming a certain earthquake behavior or needing a certain level of seismicity in an area. Instead, the entire network can be assessed once the Richter (local) magnitude relation for the network is found.

\section{Methodology to Calibrate Local Magnitude and Calculate Detection and Location Thresholds}

The Richter magnitude (also known as the local magnitude, $M_{\mathrm{L}}$ ) was initially formulated as the following:

$$
M_{\mathrm{L}}=\log A-\log A_{0}(\Delta),
$$

where $A$ is the maximum displacement in millimeters ( $\mathrm{mm})$ at the station of interest for the earthquake of interest, and is a calibration term for a standard earthquake where is the epicentral distance between the earthquake and station in kilometers (Richter, 1958). The second term can also be thought of as a distance correction. It follows the form:

$$
A(\Delta)=A_{0} \Delta^{-\beta} e^{\frac{-\pi f \Delta}{v Q}}
$$

where $A_{0}$ is the initial amplitude at distance 1 , is the geometrical spreading, $f$ is the frequency, $v$ is the $\mathrm{S}$-wave velocity, and $Q$ is the quality factor. By taking the logarithm, combining variables and assuming a constant $f$, becomes:

$$
\log A_{0}(\Delta)=a \log (\Delta)+b \Delta+c,
$$

where $a$ encompasses the effect of geometrical spreading, $b$ is associated with attenuation and $c$ calibrates the $M_{\mathrm{L}}$ with respect to a standard earthquake. The value of $b$ ranges from
$9 \mathrm{e}^{-4}$ in Tanzania (Langston and others, 1998) to $3 \mathrm{e}^{-3}$ in central California (Bakun and Joyner, 1984). For simplicity, I ignore $b$ because it has an insignificant effect on the final magnitude with respect to other errors in the analysis, especially at short (less than $100 \mathrm{~km}$ ) distances. The equation becomes:

$$
\log A_{0}(\Delta)=a \log (\Delta)+c .
$$

Plugging this equation into the local magnitude changes the equation to:

$$
M_{\mathrm{L}}=\log A-a \log (\Delta)-c
$$

which is the same form used in Moran (2004). Rearranging this equation to solve for the slope and intercept results in:

$$
\log A=-a \log (\Delta)+\left(M_{\mathrm{L}}-c\right)
$$

To calculate the $a$ and $c$ value that is specific to the State of Hawaii, I built a high-quality dataset of amplitude values subject to the following constraints:

1. Only earthquakes above $M 2.0$,

2. Only reviewed earthquakes with more than 20 arrivals with signal to noise ratios above 10 ,

3. Only earthquakes shallower than $15 \mathrm{~km}$ (encompasses most volcanic earthquakes),

4. Only amplitude values with signal to noise ratios larger than 50 , and

5. Only earthquakes between January 1, 2012, and July 1,2013, where the responses of the entire network are well known and the network has been mostly converted to digital.

The resulting dataset consists of 14,079 amplitudes spanning distance ranges between 0 and $562 \mathrm{~km}$. Most arrivals are within the 1 to $100 \mathrm{~km}$ range, which reflects the concentration of both earthquakes and high network density on the Island of Hawai' $i$ and further validates the decision to ignore $b$. The observations beyond $100 \mathrm{~km}$ are from stations on neighboring islands, which only have qualifying observations for the largest of earthquakes.

To calibrate the local magnitude scale for the State of Hawaii, I calculate the slope, $a$, of the hypocentral radius versus amplitude in log-log space for each earthquake. I take the median of those slopes to get a final $a$. The value of $c$ can then be calculated by considering a calibrating earthquake. I use the standard used by Richter (1958), which is that a M3.0 earthquake has an amplitude of 480 nanometers $(\mathrm{nm})$ at a distance of $100 \mathrm{~km}$.

Now that the local magnitude scale is calibrated for the State of Hawaii, it needs to be transformed into what I will call a threshold magnitude $\left(M_{\mathrm{T}}\right)$. Based on the calculation of $a$ and $c$ above, $M_{\mathrm{T}}$ is defined as:

$$
M_{\mathrm{T}}=\log A-1.54 \log (\Delta)-2.75 .
$$

In this application we are seeking to theoretically calculate the minimum magnitude of detection and quality location 
and thus the first term in the threshold magnitude can be thought of as the smallest amplitude that a station can trigger on. It is chosen empirically based on detection and location thresholds in active areas. Due dominantly to the presence of microseism, the value of $A$ is chosen to be 10 across the entire State of Hawaii. A higher value could have been chosen for certain areas (that is, the Kīlauea Caldera) to compensate for the ubiquitous presence of tremor; however, I chose not to in order to keep consistency among regions.

To calculate these thresholds across the State of Hawaii, I first set up a grid across the area of interest with grid spacing between 0.1 and 0.5 degrees in latitude/longitude, depending on the region ( 0.01 for the Island of Hawai $i, 0.05$ for all other islands). For the calculation of $M_{\mathrm{T}}$, I use the distance to the xth station, not the epicentral distance. For the calculation of the TMD, I use the distance of the second closest station to a given grid node. In essence, this means that an event must be detected on more than one station to distinguish an earthquake from a local source of noise. For the calculation of the TML, is the closest station that satisfies the following two conditions: (1) eight or more closer stations and (2) a gap of less than 135 degrees between stations. These conditions follow from the report by Moran (2004).

This approach assumes that all stations have equivalent sensitivities, which is clearly false. For example, stations near the caldera of Kîlauea record continuous tremor, resulting in a higher background and lower sensitivity. Similarly, stations along the coast are often subject to wind and wave noise that reduces sensitivity. Sensitivity is also reduced in areas of high cultural noise, which is common on many stations across the islands (for example, PHOD, HILB, RSDD). Lastly, the analysis neglects to take into account depth, which can both enhance and degrade the TML and TMD, depending on the location of an earthquake. Nevertheless, these estimates may be low by as much as a magnitude unit depending on the nature and strength of the noise source. It is thus more useful to look at the maps of detection threshold and location threshold in a relative sense to gauge strengths and weaknesses of the current seismic network.

\section{Theoretical Detection Thresholds and Quality Location Thresholds}

Results of the analysis of TMD and TML are compared for different regions in figures 9 and 10. Clearly the islands other than Hawai'i have larger TMD and TML than other areas. Within the Island of Hawai' $i$, the region with the lowest TMD and TML is Kilauea Caldera. Although this gives a sense of the relative strength of different regions of the network, assessing maps of TMD and TML gives more detail about each area. Regions of high TMD on the TMD maps (figs. 9, 11, 13, 15, 17, 19, and 21) show areas that need additional instrumentation. Regions of high TML on the TML maps (figs. 10, 12, 14, 16, 18, 20, and 22) show the areas that should be targeted to improve the azimuthal distribution of seismometers in a given area.

The TMD is surprisingly low on the Islands of Kaua' $i$, O'ahu, and Maui, which all have at least two stations (figs. 9 and 11). The TMD theoretical limits of M1.4 in south Maui to M2.1 in Kaua' $i$ are likely too low, as most of the islands above suffer from a high degree of cultural, wave, and wind noise. However, a lack of seismicity on the islands other than Hawai $i$ makes it difficult to calibrate TML or TMD. On Kaua'i, Moloka'i, Lāna' $i$ and smaller islands, the TML ranges between 2.1 and 2.6, except in a couple areas. The TML is relatively low (less than M2) in the core of $\mathrm{O}^{\prime}$ ahu and on the southwest side of Maui (figs. 10 and 12). The low TML zone in Maui is due to Maui's proximity to the Island of Hawai'i network. TMD thresholds for Haleakalā are about M1.5, whereas the TML is greater than $M 2$ for the eastern part of the volcano and as low as M1.6 to the west of the volcano's summit (figs. 11, 12, 21, and 22). TMLs for islands other than Hawai' $i$ are likely too low due to the high degree of cultural, wave, and wind noise.

On the Island of Hawai' $i$, the TMD is lowest where stations are spaced closely together (figs. 9 and 13). Low TMDs are present at Kīlauea's summit, Kīlauea's East Rift Zone (M-1.1-0; fig. 15) and Mauna Loa's summit (M-0.1-0.1; fig. 17). The regions of lowest TMDs on Kỉlauea are places of continuous tremor (Kīlauea's summit) or significant cultural noise (Puna Geothermal Ventures), and thus these low TMD values are never realized. The highest TMDs on the Island of Hawai' $i$ (M1.1) are found on the north tip of the island, progressively improving southward and eastward (fig. 13). On Hualālai, the areas of highest TMD are to the west of the summit (M0.9) and lowest to the southeast (M0.3-0.5; fig. 19). The TMD for Lō'ihi is between 0.5 and 1 ; however, high station noise near the coast suggests that this is an unlikely minimum (fig. 13).

The TML on the Island of Hawai' $i$ shows a different pattern than the TMD owing to a dependence on station geometry (figs. 10 and 14). TML values less than magnitude 0 encompass a large region bordered to the north by the Ka'oiki Fault Zone, Kīlauea' summit and upper East Rift Zone and extending south to the Hilina and Hōlei Palis (fig. 16). The summit of Mauna Loa also has a region around it with TML values less than 0 (fig. 18). By far the highest TML values on the Island of Hawai' $i$ are near the coast with values ranging in excess of magnitude 2, which is a result of the 135-degree minimumgap requirement. Large TML values are especially conspicuous near South Point and along the coastline to the north that spans Hawi to Honoka'a (fig. 14). On Kīlauea, the largest TML values are at the ends of the rift zones where they approach the coast and on the middle East Rift Zone near Heiheiahulu (fig. 16). On Mauna Loa, the zones of highest TML are at the end of the Southwest Rift Zone (greater than M2), and at the end of the Northeast Rift Zone ( $\sim M 0.75$; fig. 18). On Hualālai, the TML benefits from having the nearby Mauna Loa network are clear, with the zones of lowest TML lying southeast of the summit of Hualālai (less than M0.5; fig. 20). High TML values are present to the northwest of the summit (M1.5-2.3+; fig. 20). 


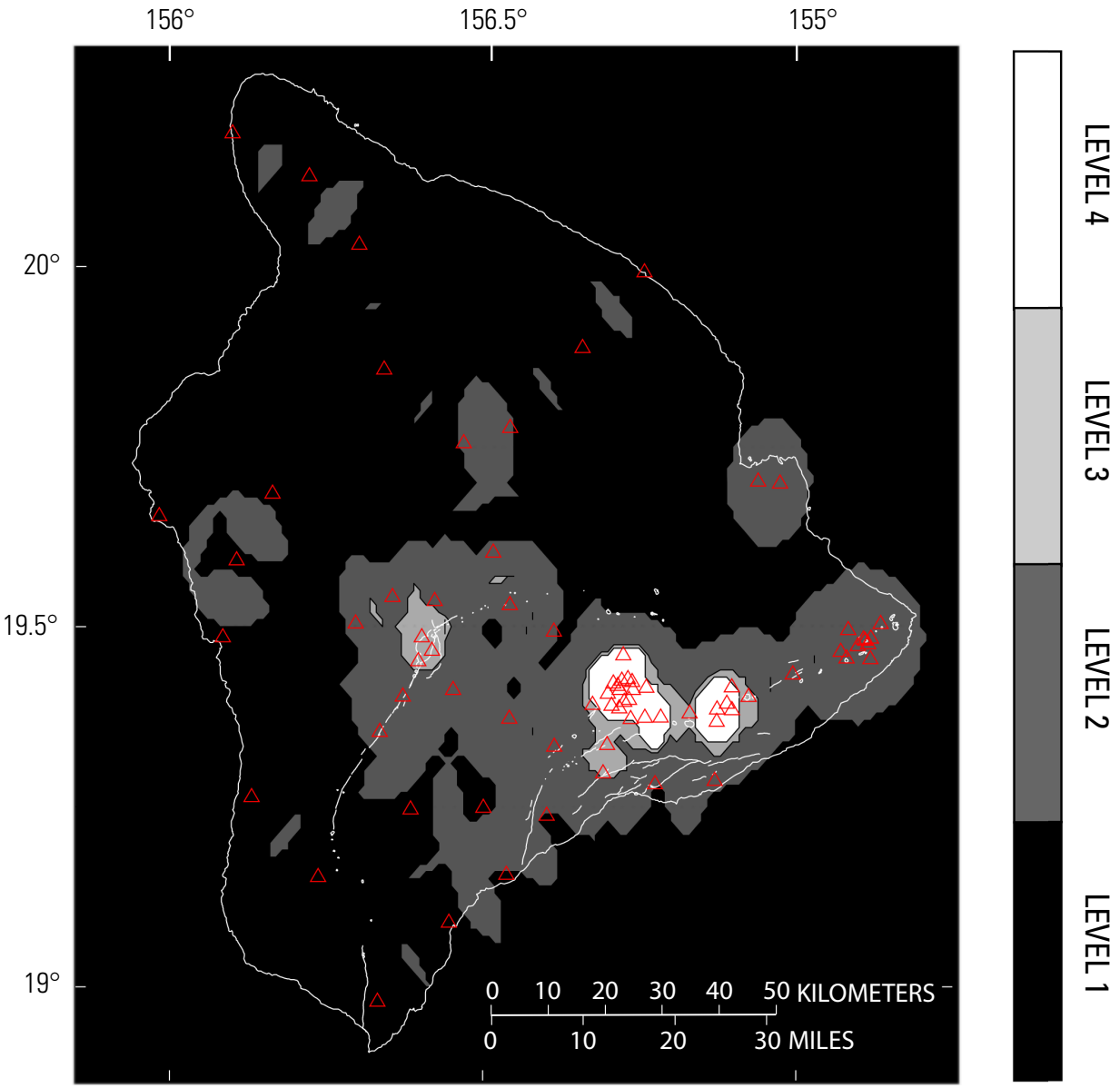

Figure 8. Map showing current National Volcanic Early Warning System (NVEWS) report (Ewert and others, 2005) quality level status for the Island of Hawai'i. Red triangles are current continuously operating seismic network stations.

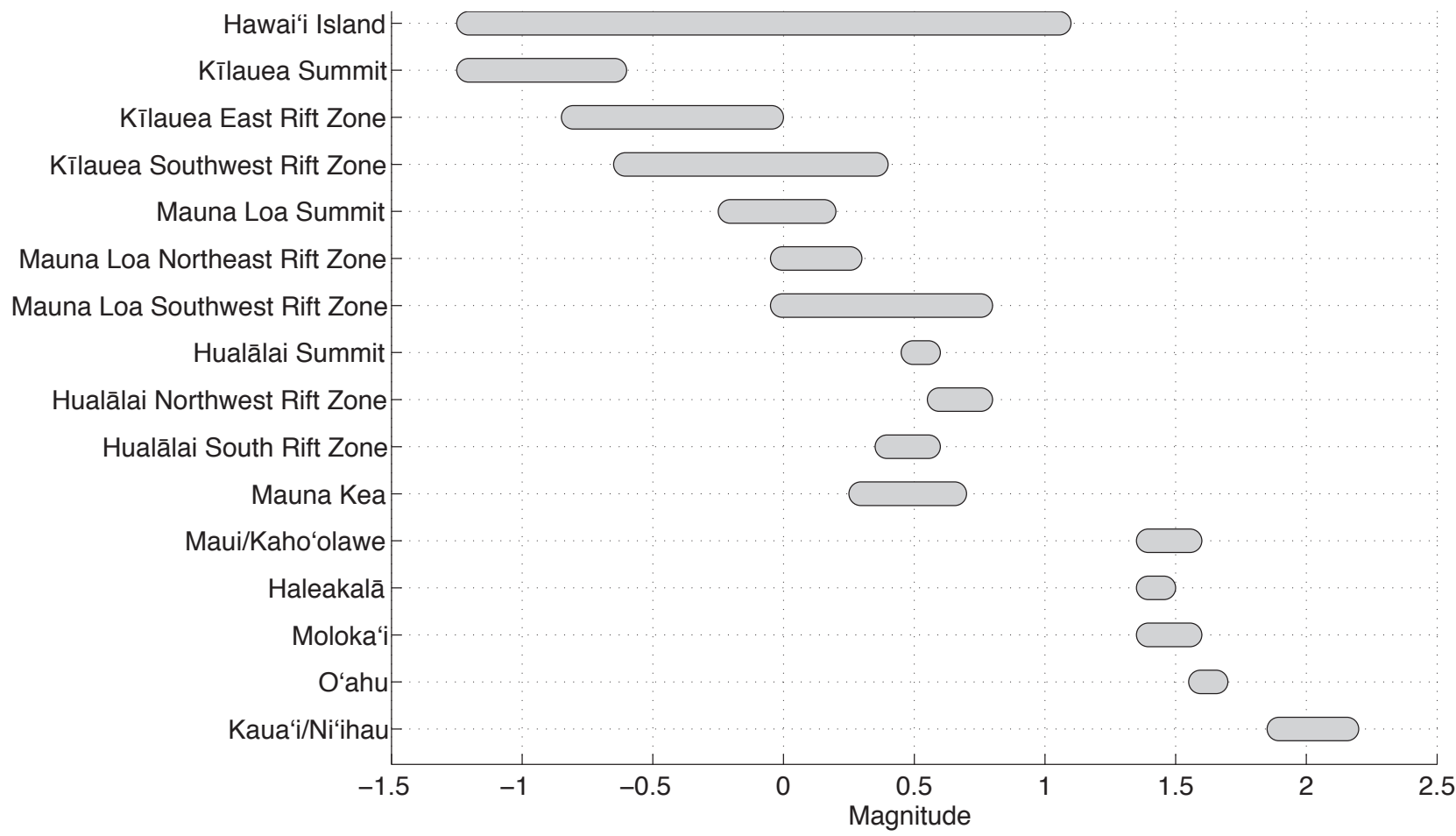

Figure 9. Bar graph summarizing the theoretical magnitude of detection (TMD) for earthquakes in each respective region of the State of Hawaii. Gray bars represent the range of TMD in a given area. The geographic extent of the rift zones is defined in figure 23. 


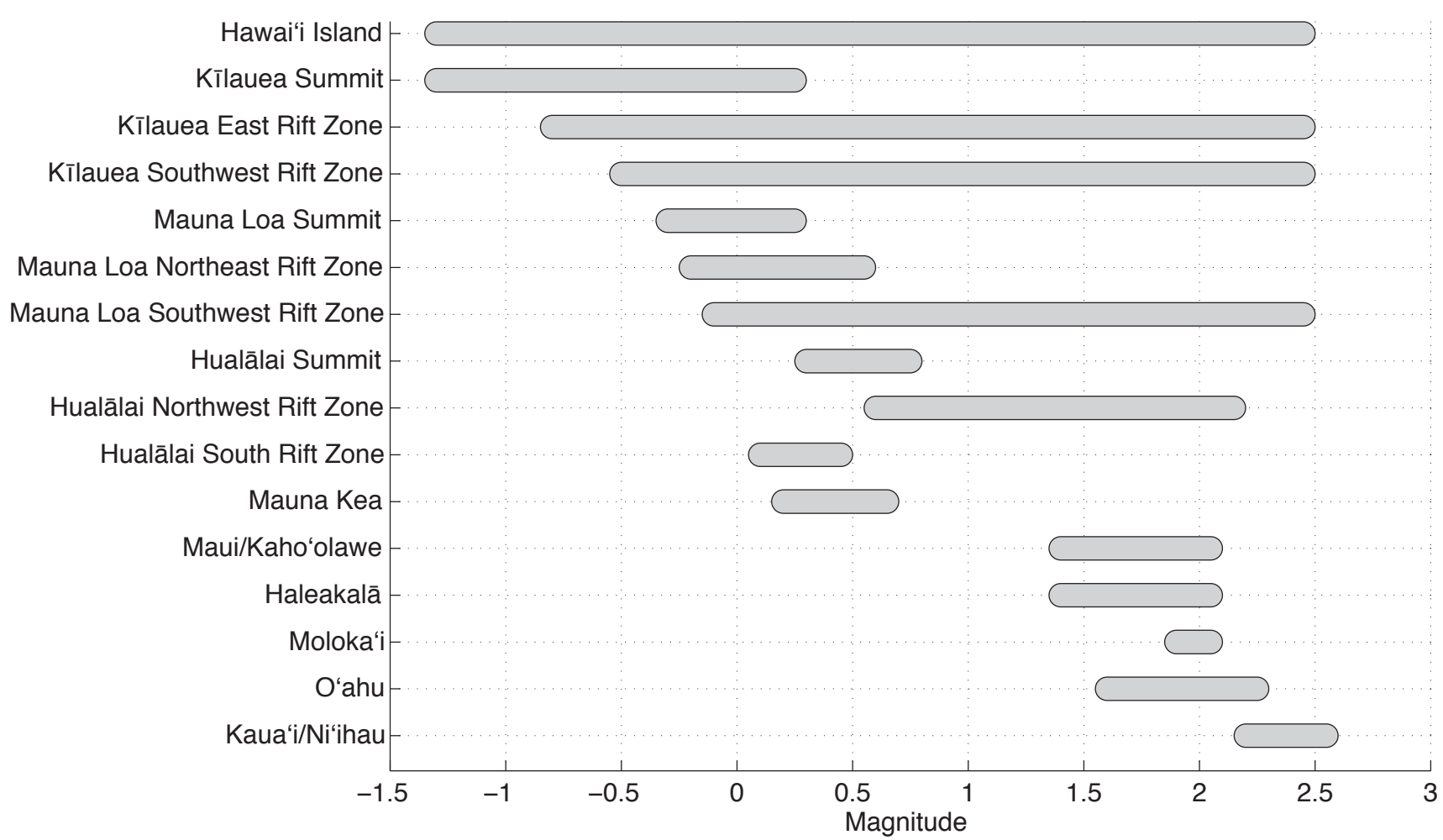

Figure 10. Bar graph summarizing the theoretical magnitude of quality location (TML) for earthquakes in each respective region of the State of Hawaii. Gray bars represent the range of TML in a given area. Many of the high TML values are where the respective region extends past the perimeter of stations in the seismic network. The geographic extent of the rift zones is defined in figure 23.

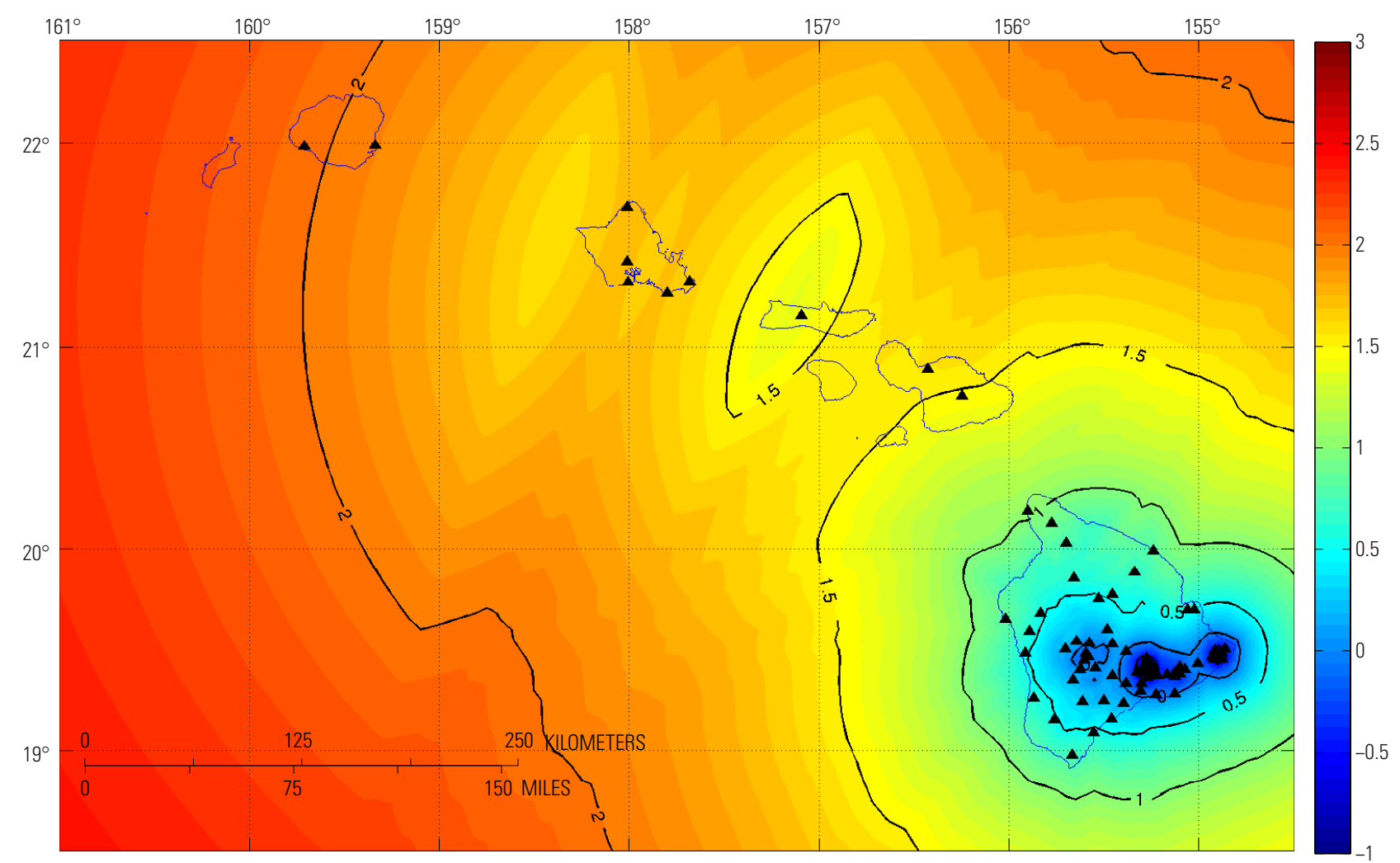

Figure 11. Map showing theoretical magnitude of detection (TMD) threshold for earthquakes in the State of Hawaii. Scale at right indicates magnitude. 


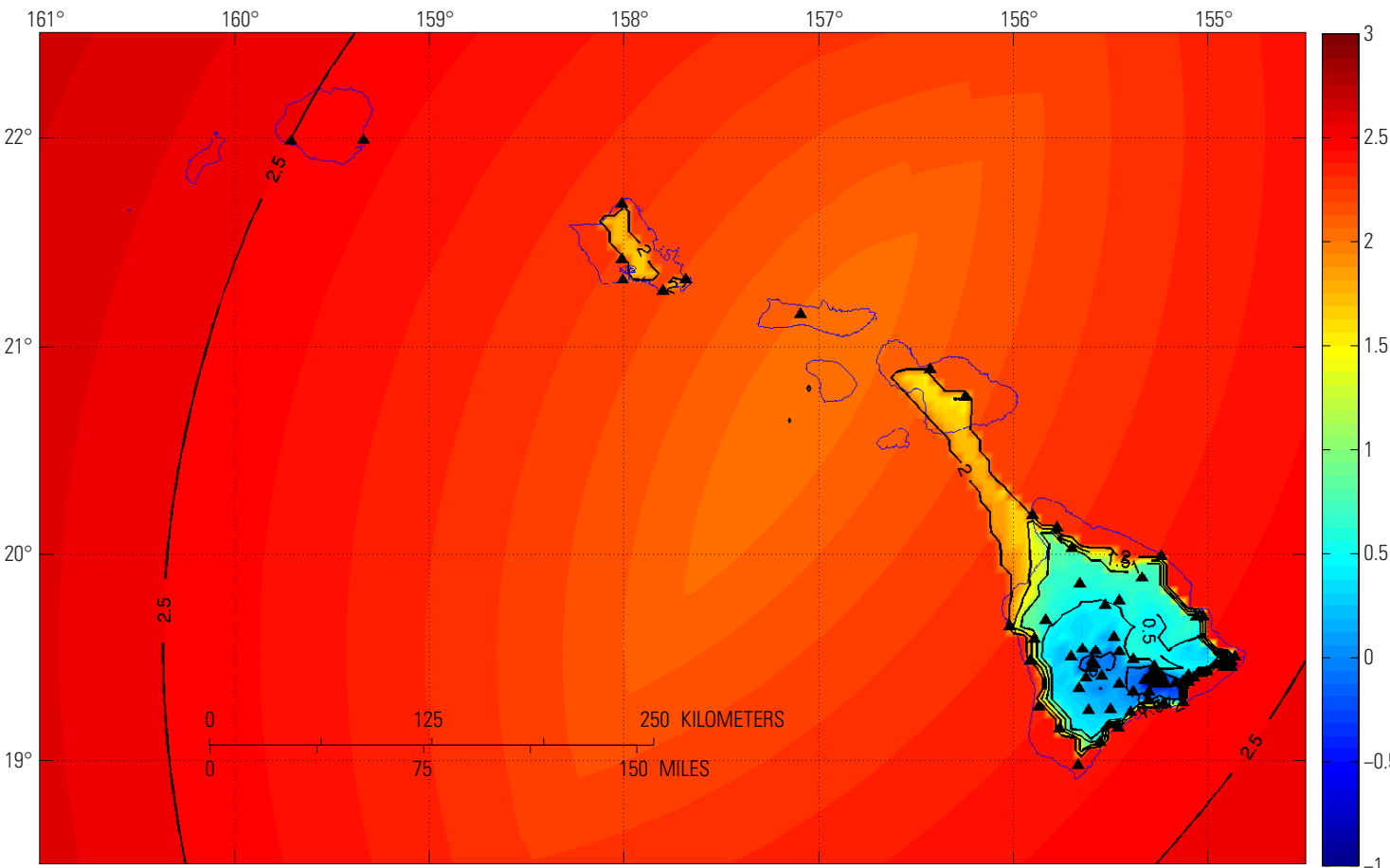

Figure 12. Map showing theoretical magnitude of quality location (TML) threshold for earthquakes in the State of Hawaii. Scale at right indicates magnitude.

Figure 13. Map showing theoretical magnitude of detection (TMD) threshold for earthquakes at the Island of Hawai'i. Scale at right indicates magnitude. 


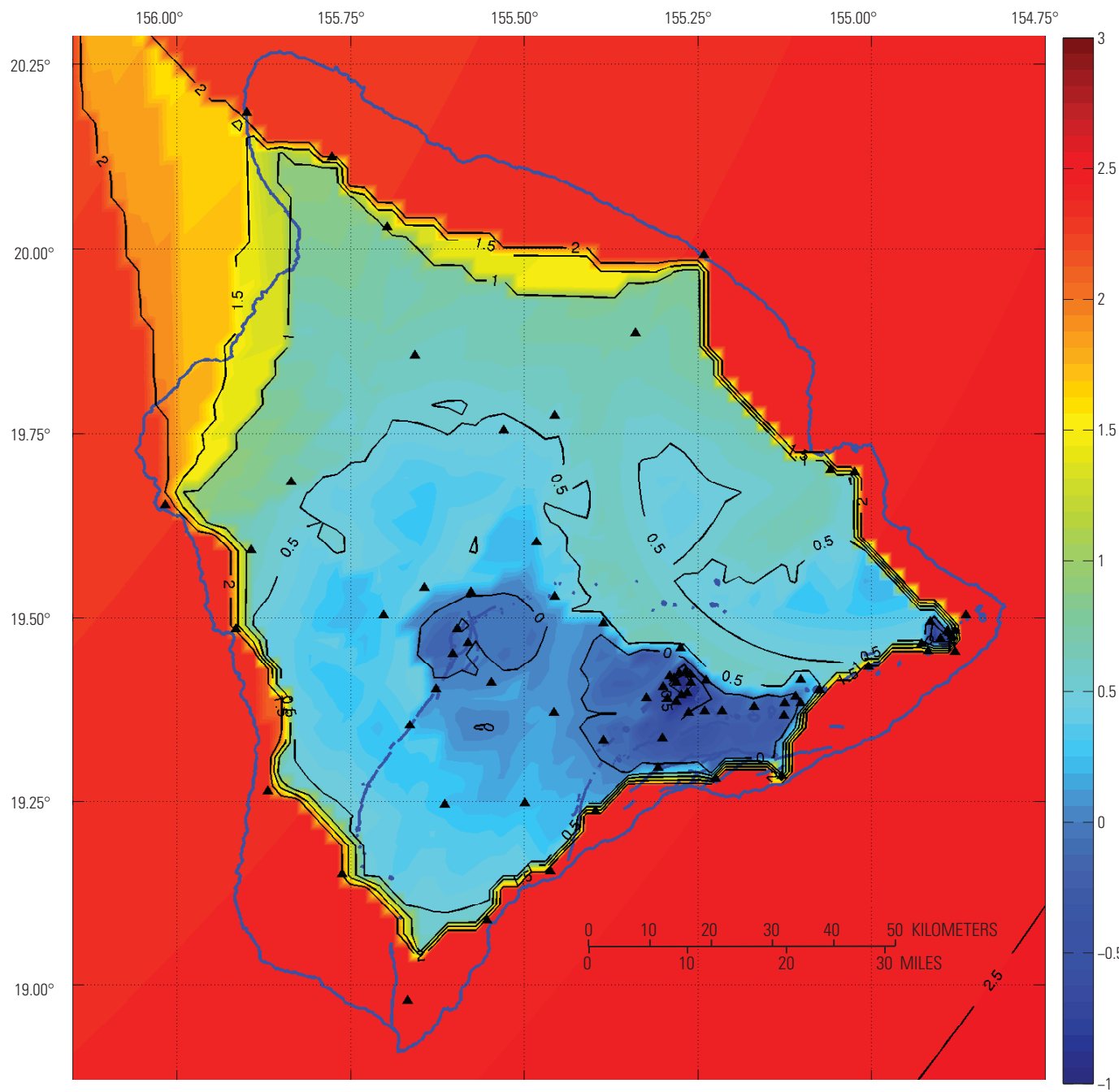

Figure 14. Map showing theoretical magnitude of quality location (TML) threshold for earthquakes at the Island of Hawai i. Scale at right indicates magnitude.

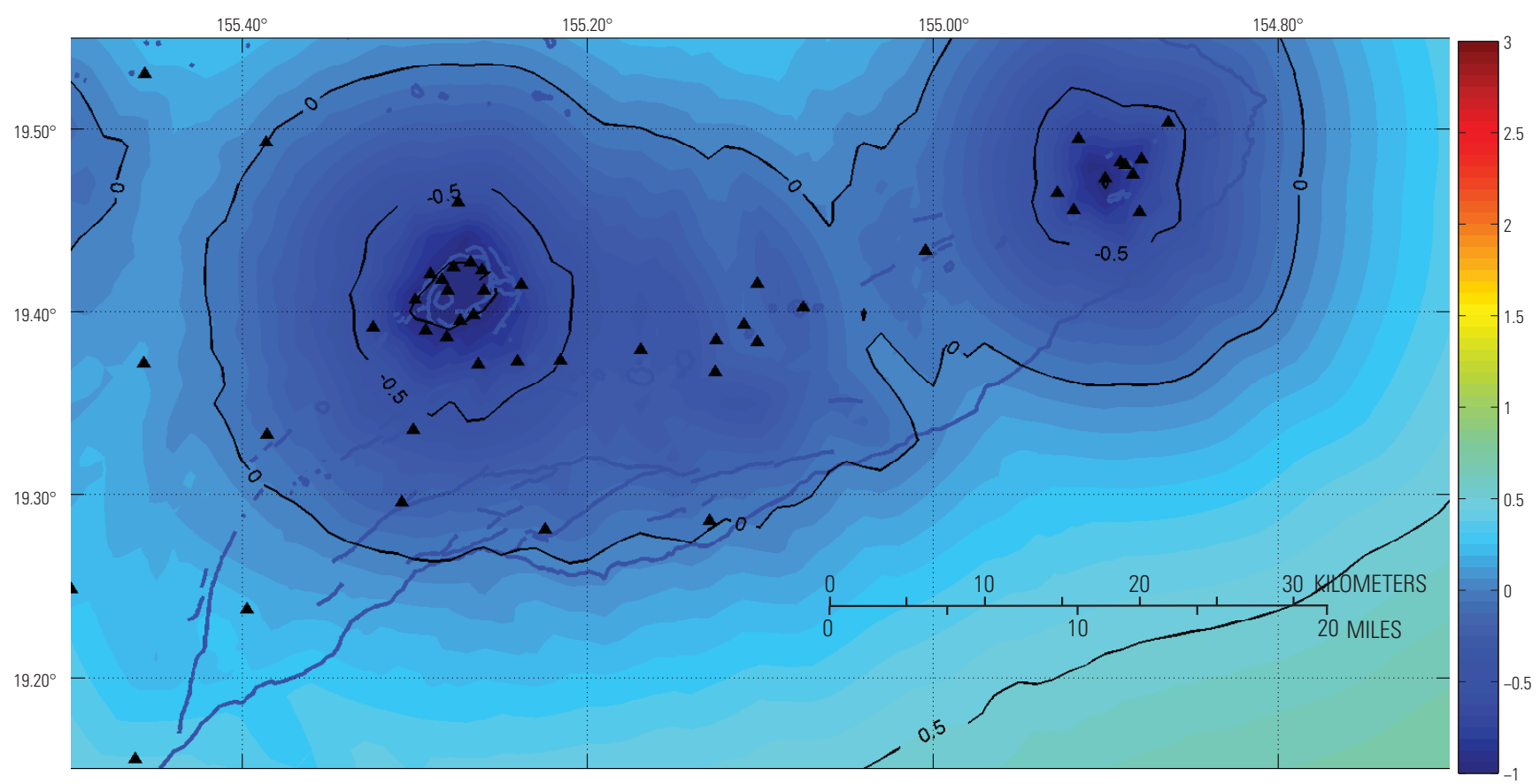

Figure 15. Map showing theoretical magnitude of detection (TMD) threshold for Killauea's south flank on the Island of Hawai'i. Scale at right indicates magnitude. 


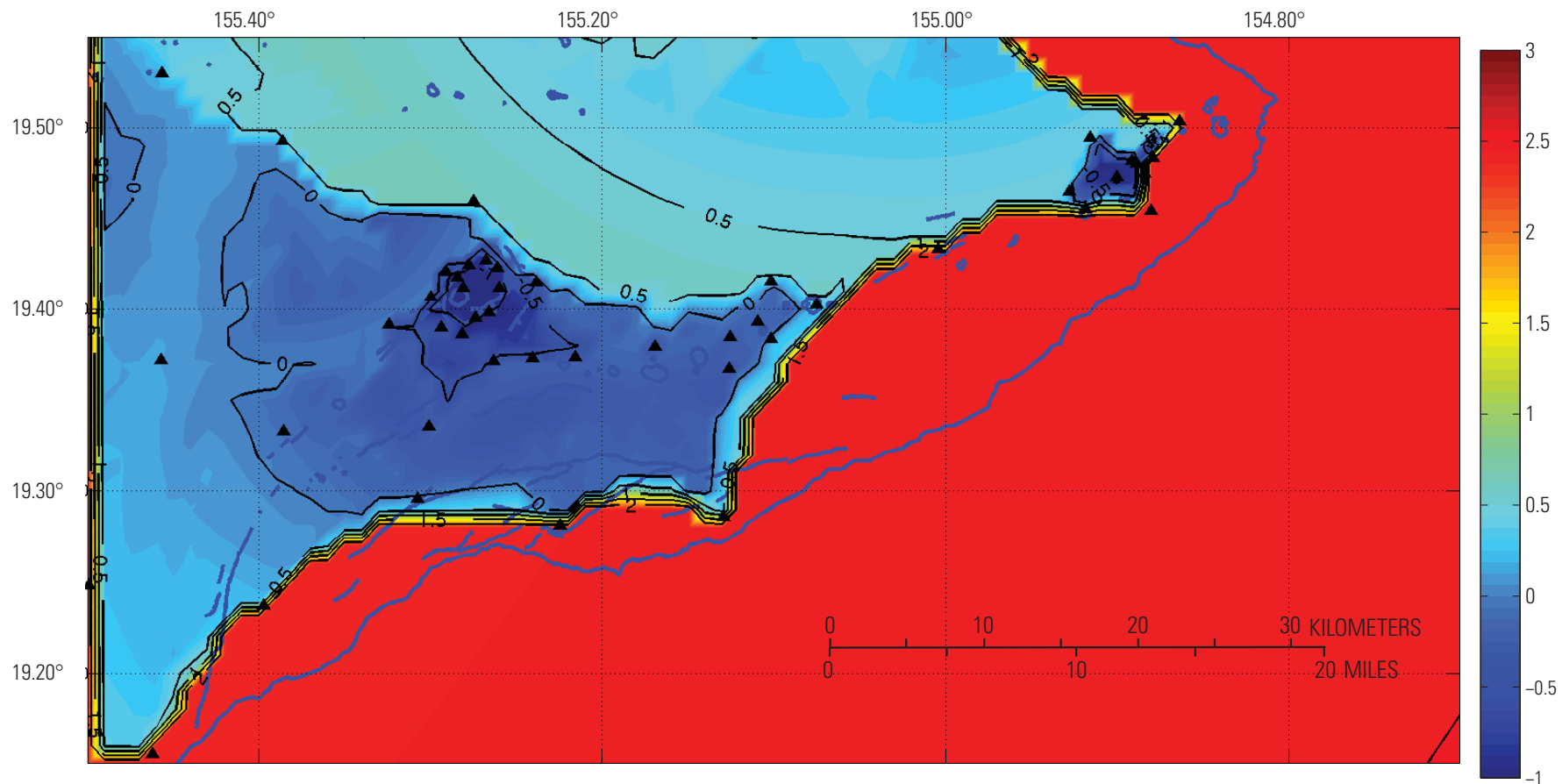

Figure 16. Map showing theoretical magnitude of quality location (TML) threshold for earthquakes at Kilauea's south flank on the Island of Hawai'i. Scale at right indicates magnitude.

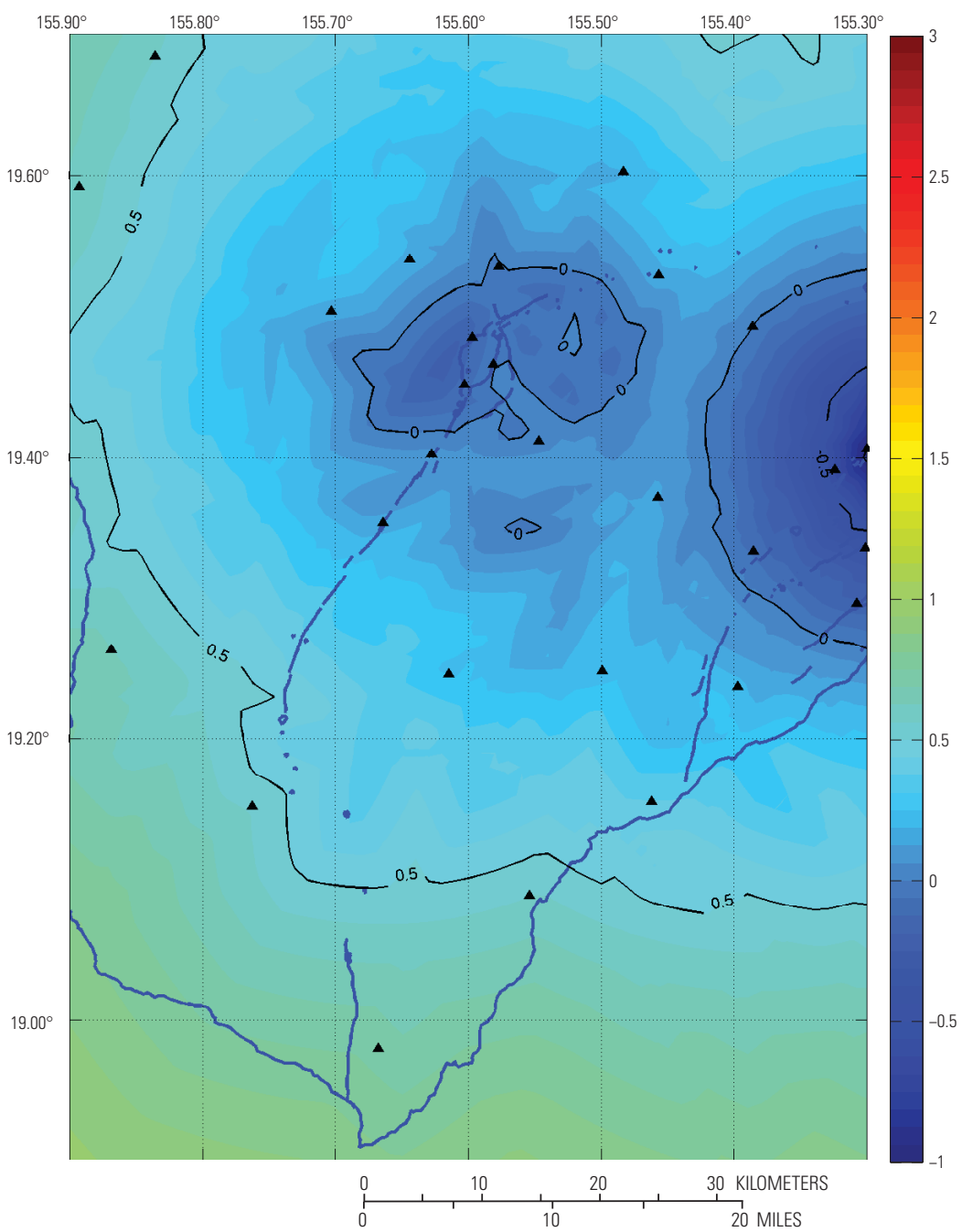

Figure 17. Map showing theoretical magnitude of detection (TMD) threshold for earthquakes at Mauna Loa on the Island of Hawai'i. Scale at right indicates magnitude. 


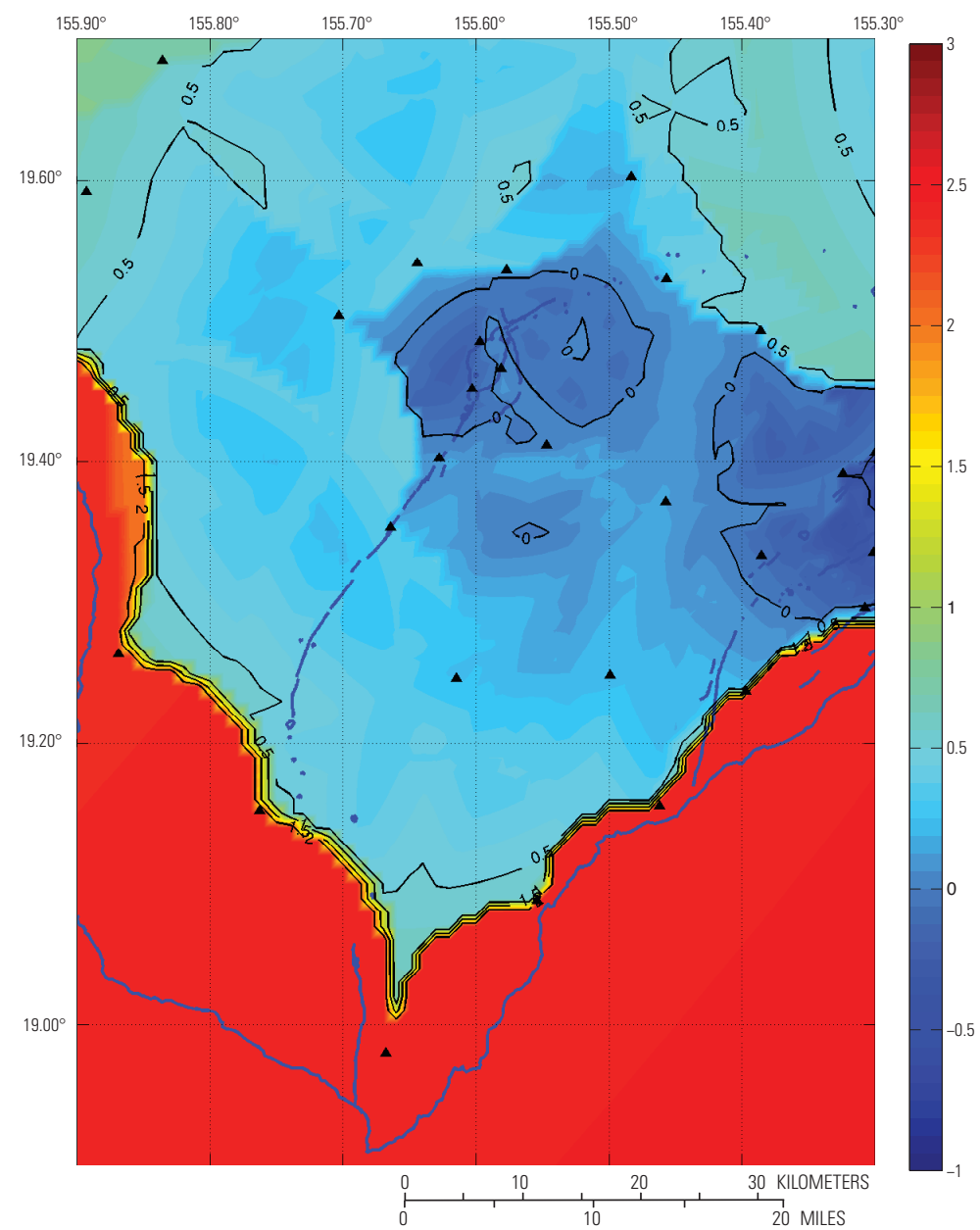

Figure 18. Map showing theoretical magnitude of quality location (TML) threshold for earthquakes at Mauna Loa on the Island of Hawai'i. Scale at right indicates magnitude.

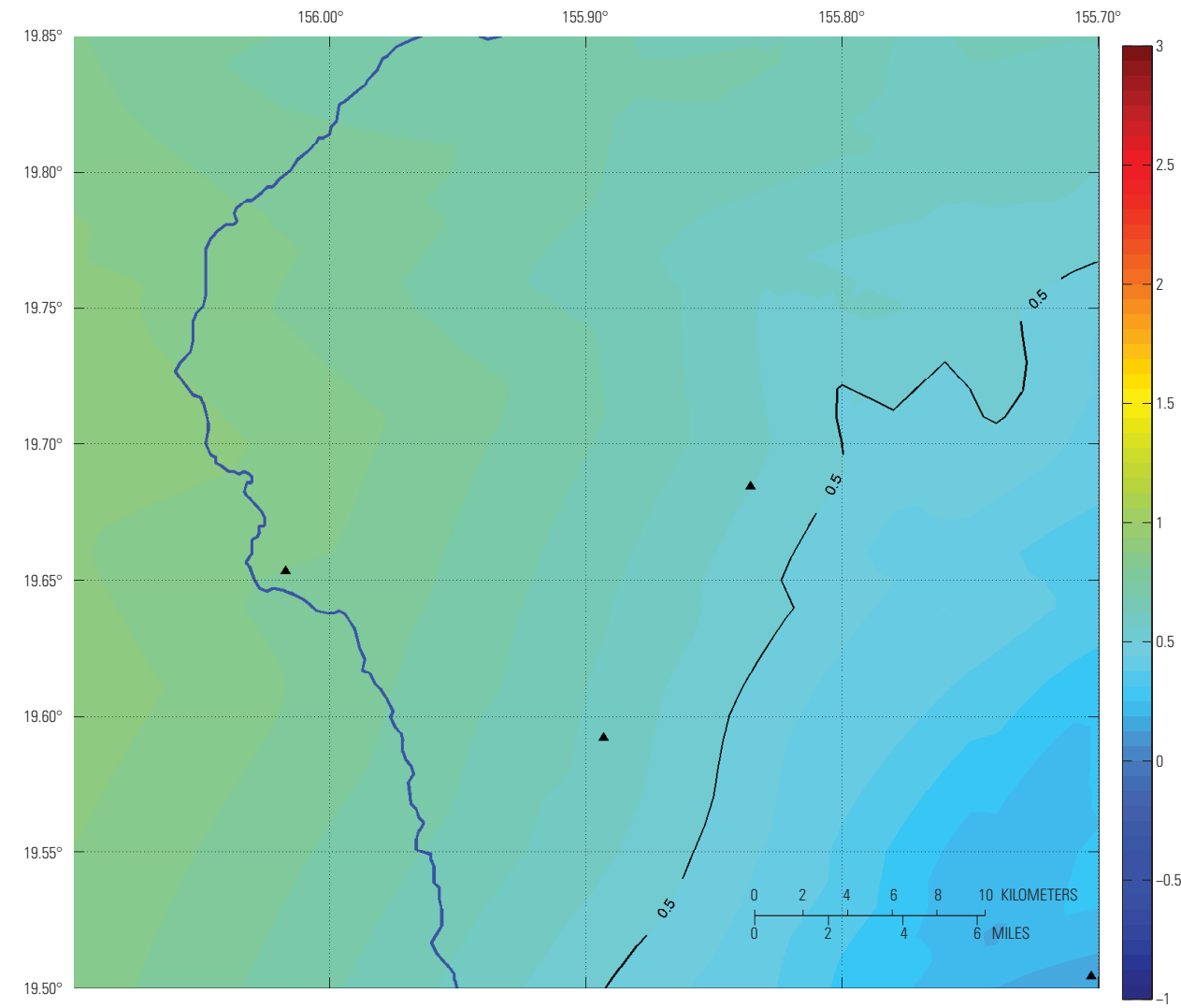

Figure 19. Map showing theoretical magnitude of detection (TMD) threshold for earthquakes at Hualālai on the Island of Hawai'i. Scale at right indicates magnitude. 

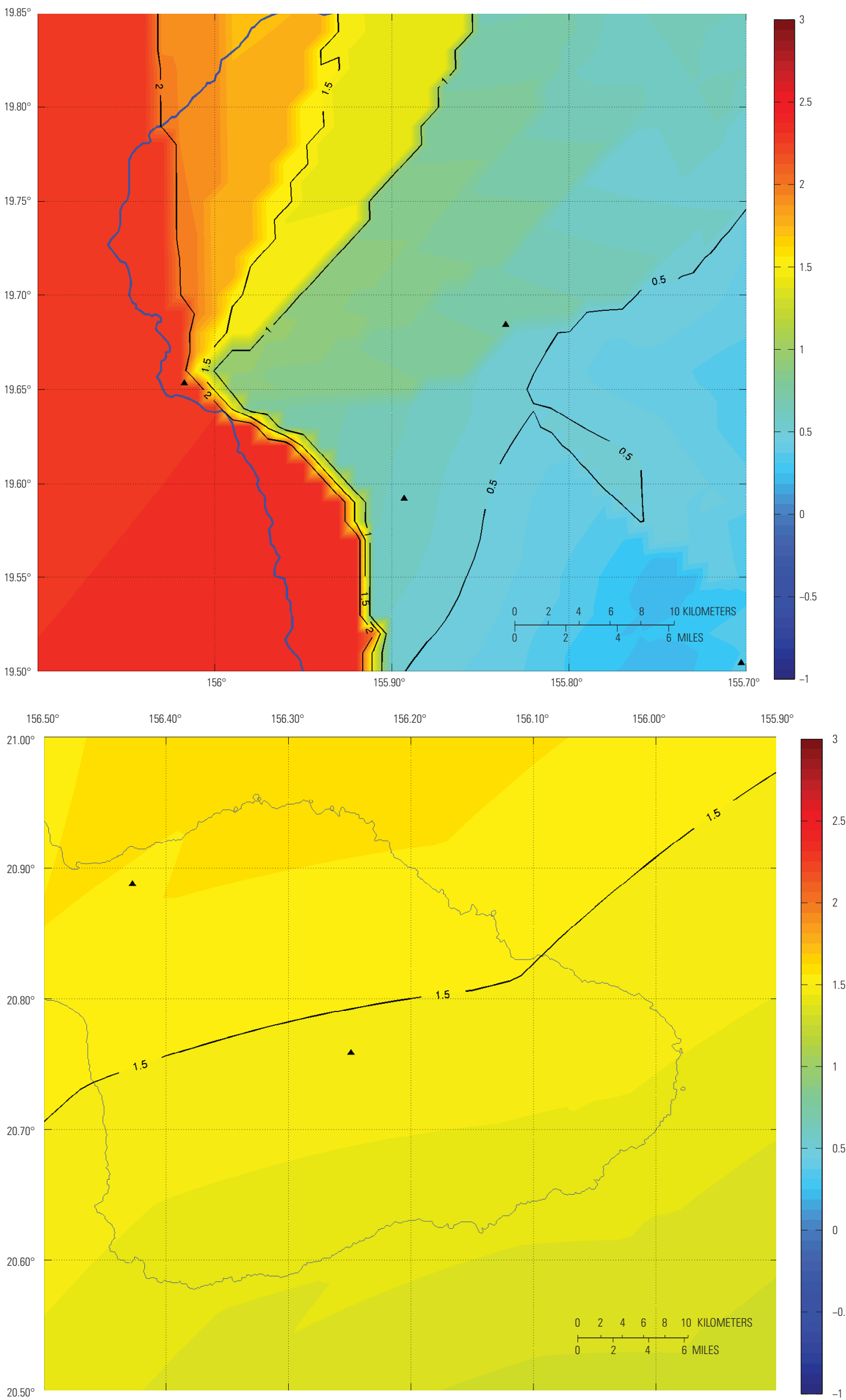

Figure 20. Map showing theoretical magnitude of quality location (TML) threshold for earthquakes at Hualālai on the Island of Hawai'i. Scale at right indicates magnitude.

Figure 21. Map showing theoretical magnitude of detection (TMD) threshold for earthquakes at Haleakalā on the Island of Maui. Scale at right indicates magnitude. 


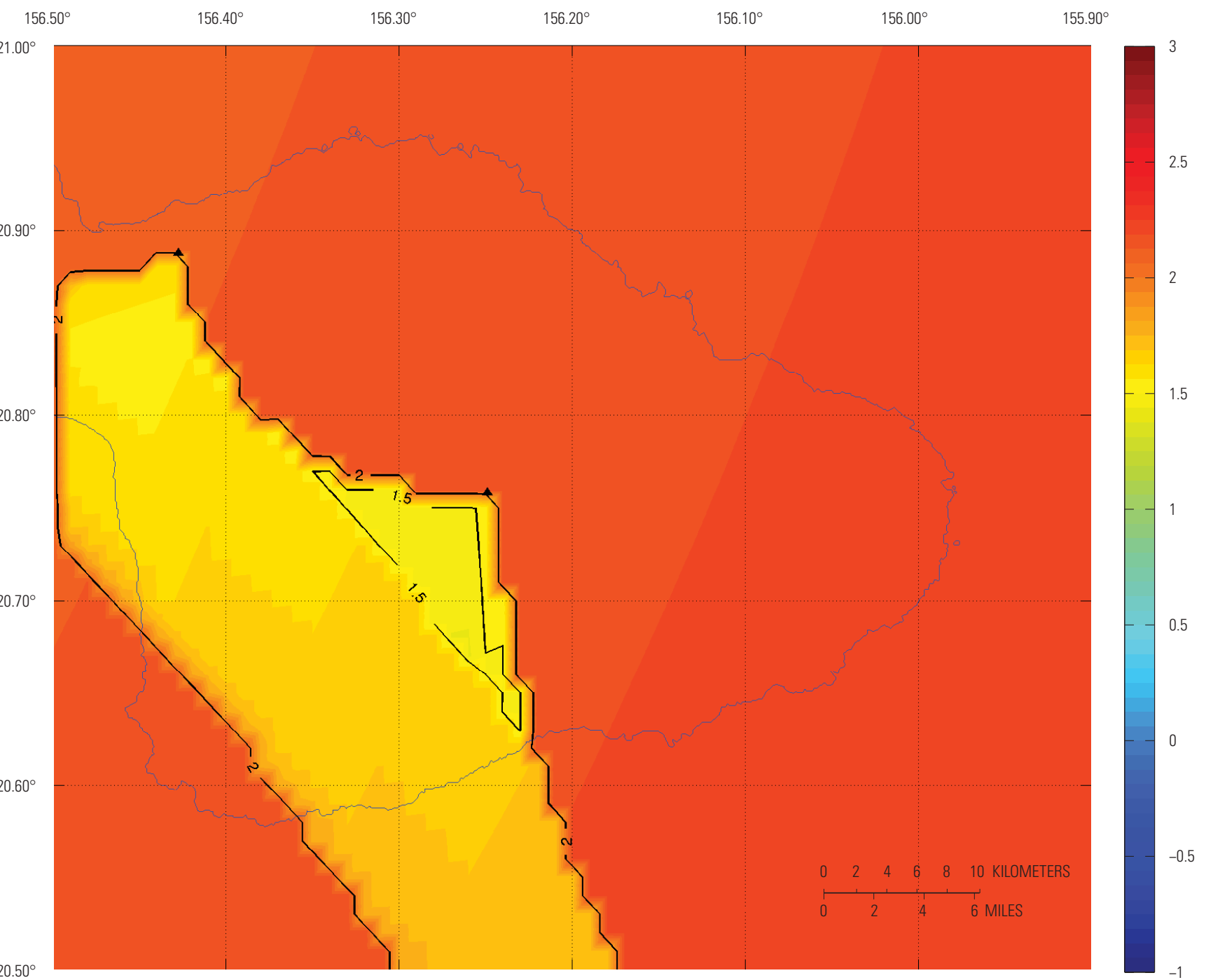

Figure 22. Map showing theoretical magnitude of quality location (TML) threshold for earthquakes at Haleakalā on the Island of Maui. Scale at right indicates magnitude. 


\section{Seismic Monitoring Gap of the Hawailan Volcano Observatory}

There is clearly a discrepancy between how the volcanoes of the State of Hawaii are currently monitored, and how they must be monitored to establish a comprehensive volcanic early warning system. In the Moran report, seismic network recommendations were cast with a radial geometry because the NVEWS report focused on stratovolcanoes, which typically erupt near the summit of the volcano. This geometry ignored the high and very high threat volcanoes in Hawai' $i$, which have long rift zones (as long as $100 \mathrm{~km}$ ) capable of erupting magma anywhere along their length. To achieve the goals of the NVEWS report and gain the capabilities laid out in the Moran report, these rift zones also need to be monitored in addition to the summit of each volcano. Thus, applying the radial geometry of the Moran report to the most threatening volcanoes of the State of Hawaii severely underestimates the number of seismic stations required to gain the expected capabilities. Mauna Kea has poorly defined rift zones and an eruptive history in which a point source is appropriate, and thus Mauna Kea is considered as suggested in the Moran report (that is, station configurations around a single point).

\section{Methodology for Determining the Seismic Monitoring Gap}

To adapt the standards in the Moran report to the volcanoes of Hawai ${ }^{i} i$, the point source geometry of a stratovolcano must be extended into the line sources of rift zones found on Hawaiian shield volcanoes. To do so, I first approximate each rift zone as a series of nodes approximately $5 \mathrm{~km}$ apart (fig. 23). For a single node, each quality level can be parameterized by stations within an inner radius and stations within an outer radius (table 3; Moran and others, 2008). For quality level 3 and 4 networks, the inner and outer radii are $5 \mathrm{~km}$ and $20 \mathrm{~km}$, respectively (table 3 ). For quality level 2 networks, the inner and outer radii are $10 \mathrm{~km}$ and $50 \mathrm{~km}$, respectively. Quality level 1 networks have inner and outer radii of $50 \mathrm{~km}$ and 200 $\mathrm{km}$, respectively. For each node, I first calculate the number and type of preexisting continuous network stations within a circle around the node with a radius length of the inner radius. I then randomly add stations within that circle until the desired number of stations to meet the desired quality level is reached. If broadband instruments or strong-motion instruments are required, those are added before adding short-period instruments. Stations are then randomly added to the annulus between the inner and outer radius, taking into account both the preexisting network stations and stations already added within the inner circle. Random stations are required to be on land and (1) located at least $500 \mathrm{~m}$ from an existing station if less than $5 \mathrm{~km}$ from the node and (2) $2 \mathrm{~km}$ away from an existing station if greater than $5 \mathrm{~km}$ from the node (preexisting stations or stations added as part of the analysis).
With the station thresholds satisfied for a given monitoring network level for a particular node, I then move to the next node down the rift zone (figs. 23 and 24). The process above is repeated, with the stations added to the previous nodes also included. A "run" is complete when a target quality level is satisfied at every node along each summit and rift zone. Because the stations are randomly placed within each radius without consideration of directionality, some randomly determined configurations may be more efficient at contributing to neighboring volcano networks. These differences are not trivial, as shown in figure 25. I also do not consider logistical problems (for example, telemetry, land ownership, visibility) that may arise when stations are permitted, or have differing site conditions, which may favor a particular location. Thus, there are multiple configurations that will satisfy a given quality level, and attempting to site each and every station is beyond the scope of this report given all of the considerations that go into selecting a station location. To investigate the range of station configurations that might be required to meet a given quality level, I make 1,000 runs for each quality level. The resulting distribution of the number of short-period, broadband, and strong-motion stations needed to meet each NVEWS quality level gives a statistical foundation to provide a range of stations that meet the requirements (see appendix). For the most part, the distributions of the histograms in the appendix are normal, suggesting that 1,000 runs are enough to capture most of the possible configurations. Given the normal distributions of the station configurations, the range of required stations is reported as plus or minus 1 standard deviation from the mean of the distribution.

\section{Characterizing the Seismic Monitoring Gap}

Thus far I have characterized the current state of the HVO seismic monitoring network with respect to the NQL. Now by simulating and assessing different network configurations, I can estimate the additional number of stations of each type (short-period, strong-motion, and broadband) that are required to meet a given NQL. The number of stations needed in addition to the current seismic network to meet a given NQL are summarized in table 4. These totals are further broken out by station type in tables 5,6 , and 7 . The volcanoes with prominent rift zones (Kīlauea, Mauna Loa, and Hualālai) are broken out individually between summit and rift zones. Mauna Kea and Haleakalā do not have prominent rift zones and thus are treated as single nodes. The histograms of the simulations for each region and instrument type are included in the appendix. Only existing stations in the network that record continuously are considered (that is, no triggered strong-motion stations).

Kilauea clearly has the densest seismic network of any Hawaiian volcano, and thus fewer stations are required to meet a given NQL than at the other volcanoes (figs. 2, 3, and 4). The summit region is already a quality level 4 network (fig. 8), 


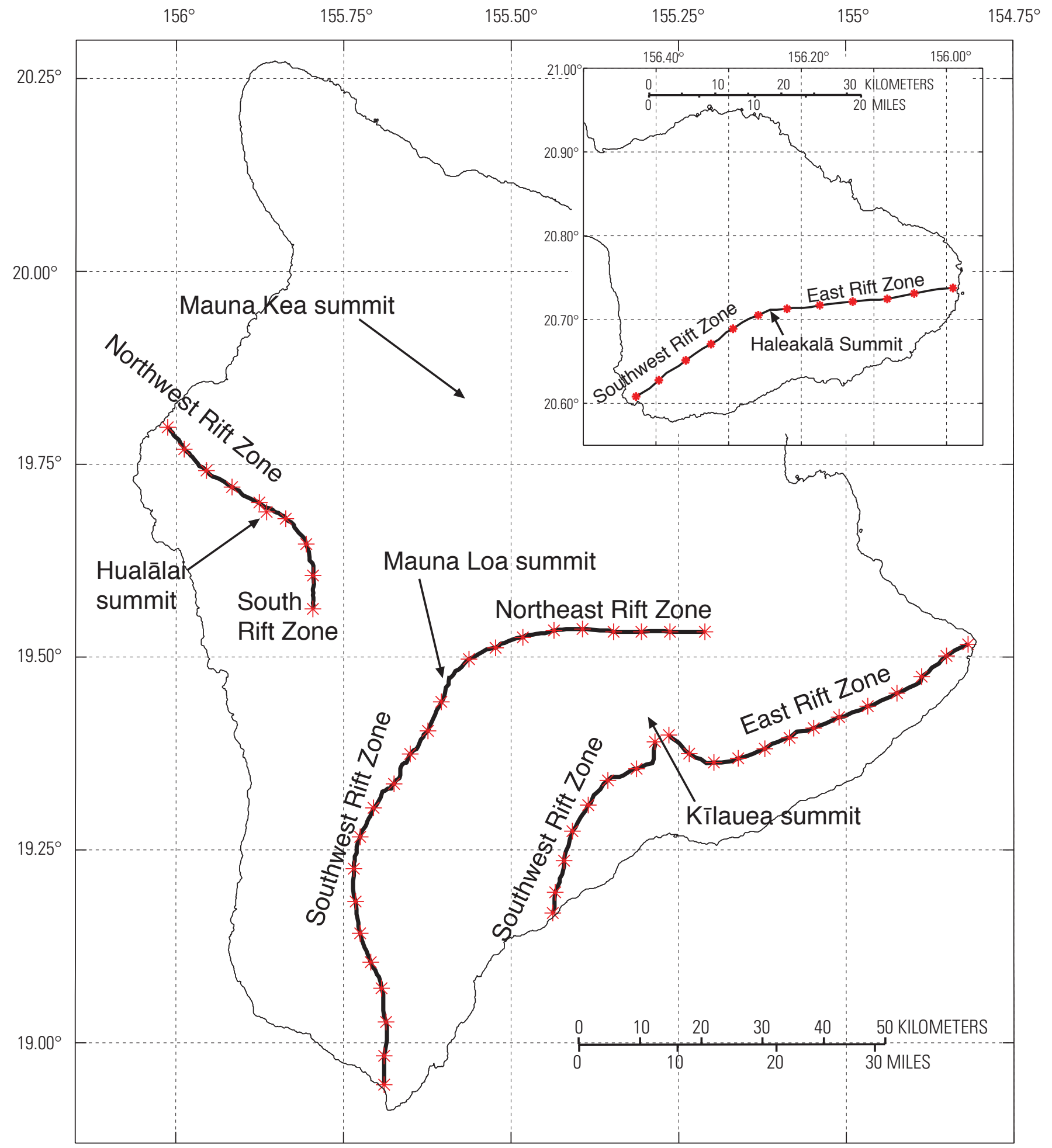

Figure 23. Map of the Island of Hawai'i showing the rift zones of Killauea, Mauna Loa, and Hualālai Volcanoes (black bold lines). Also shown are the individual nodes used to calculate the number of stations needed for a given network quality level (red asterisks). 

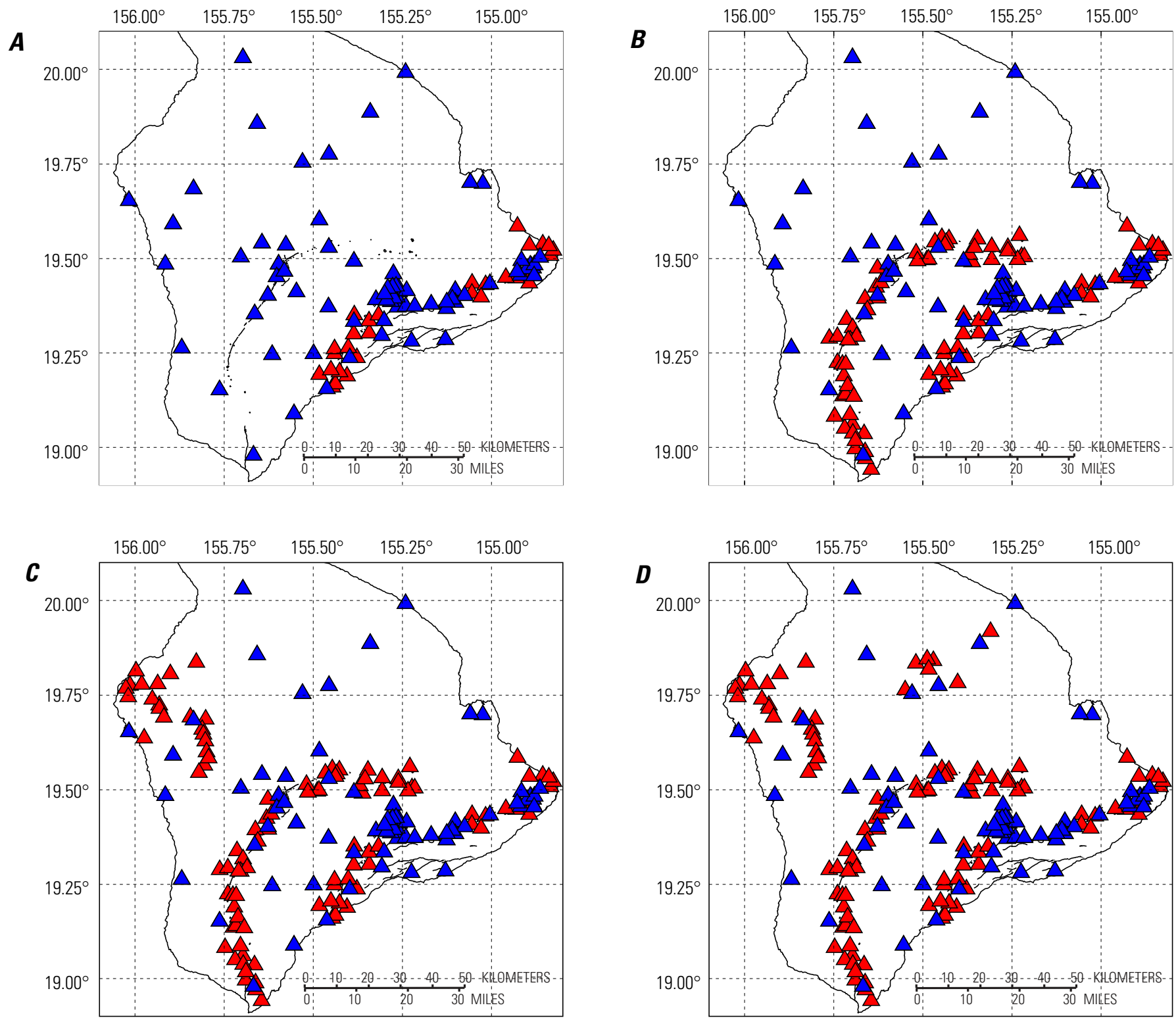

Figure 24. Maps showing different stages in determining the number of seismic stations necessary to meet the requirements of National Volcanic Early Warning System (NVEWS; Ewert and others, 2005) quality level 4 at Kilauea, Mauna Loa, Mauna Kea, and Hualālai Volcanoes. A, Results of one computer-model run after completion of the East Rift Zone and Southwest Rift Zone of Kilauea. Stations added as part of this run are shown with red triangles. Existing network stations are shown in blue triangles. $B$, Results after completion of Kilauea and the Northeast and Southwest Rift Zones of Mauna Loa. $C$, Results after completion of the two rift zones of Hualālai, in addition to the rift zones of Kilauea and Mauna Loa. $D$, Final results after inclusion of Mauna Kea in addition to the other active volcanoes of the Island of Hawai'i. 
$\boldsymbol{A}$

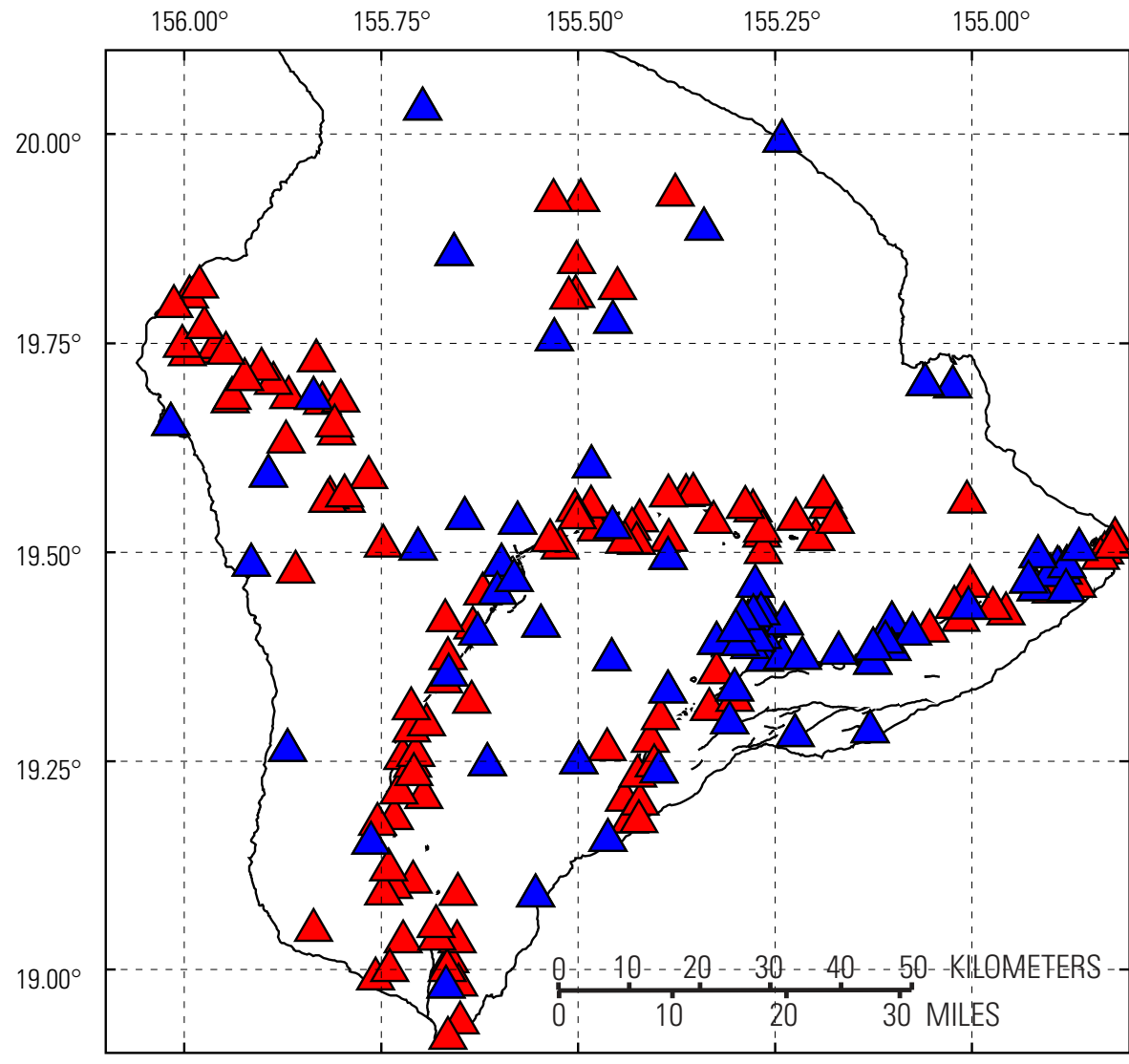

Figure 25. Maps showing final results of two different estimates of the number of stations necessary to satisfy the requirements of a National Volcanic Early Warning System (NVEWS; Ewert and others, 2005) quality level 4 seismic network on Kilauea, Mauna Loa, Mauna Kea, and Hualālai. $A$, Results computer-model run 1 of 1,000 . B, Results computermodel run 338 of 1,000 . Besides subtle differences in the station constellations during the two runs, the total number of stations needed to achieve a quality level 4 network varies as well.

B

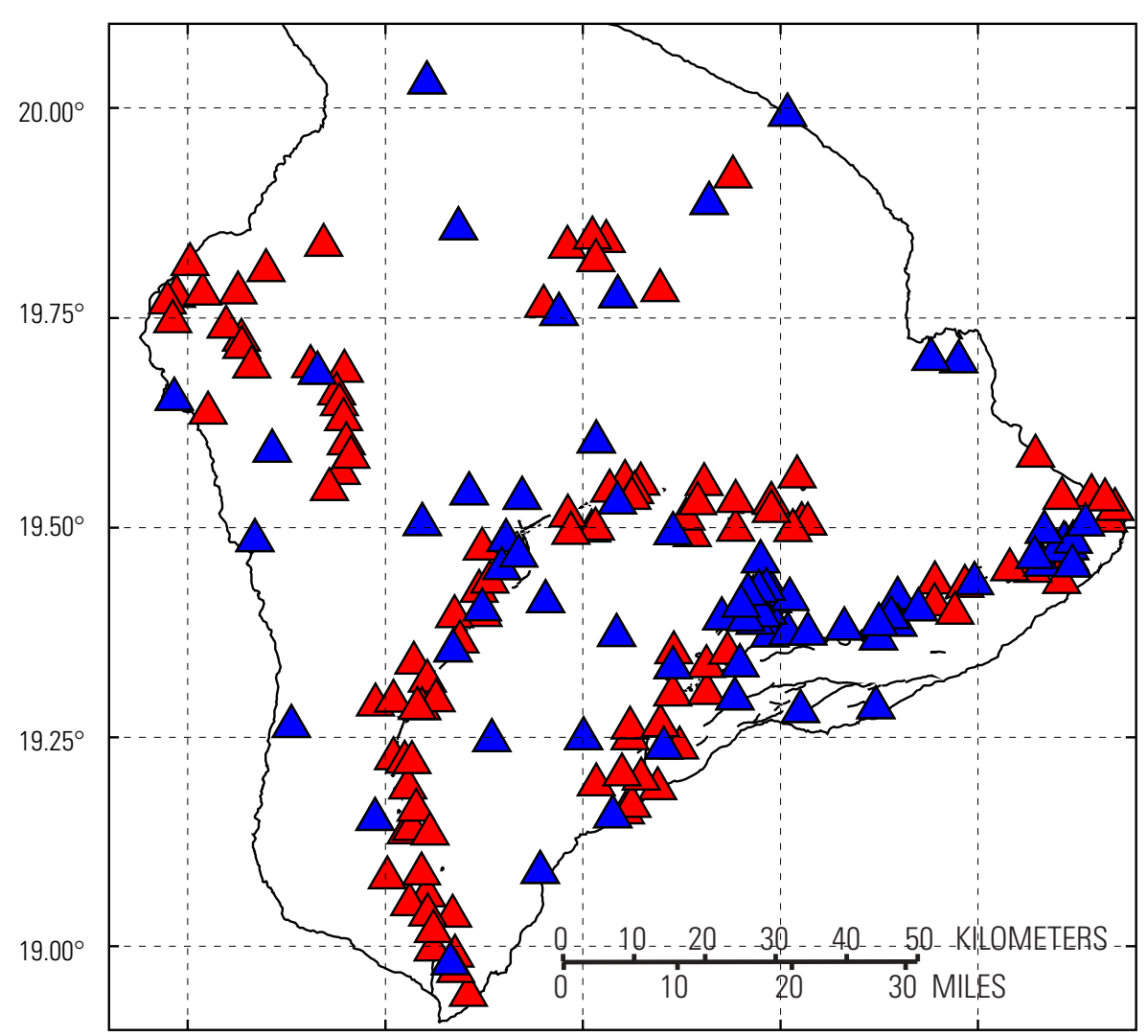


Table 4. Summary of the total number of additional stations needed to reach each National Volcanic Early Warning System (NVEWS) quality level (table 3) for Hawaiian volcanoes.

[Ranges represent one standard deviation above and below the mean of 1,000 computer-model runs]

\begin{tabular}{lccc}
\hline \multirow{2}{*}{ Volcano/region } & \multicolumn{3}{c}{ Quality level } \\
\cline { 2 - 4 } & Level 2 & Level 3 & Level 4 \\
\hline Kīlauea & 1 & $5-7$ & $12-15$ \\
$\quad$ East Rift Zone & 0 & $4-6$ & $11-15$ \\
$\quad$ Southwest Rift Zone & & & \\
Mauna Loa & 0 & 0 & 1 \\
$\quad$ Summit & $4-7$ & $9-11$ & $19-23$ \\
Northeast Rift Zone & $3-6$ & $12-16$ & $29-34$ \\
Southwest Rift Zone & & & \\
Hualālai & 2 & 4 & 6 \\
$\quad$ Summit & $1-4$ & $4-8$ & $10-14$ \\
Northwest Rift Zone & $1-4$ & $3-5$ & $7-10$ \\
South Rift Zone & 1 & 3 & 7 \\
Mauna Kea & & & \\
Haleakalā & 3 & 5 & $9-20$ \\
Summit & $2-6$ & $7-11$ & $10-15$ \\
East Rift Zone & $1-4$ & $4-8$ & \\
Southwest Rift Zone & & & \\
\hline
\end{tabular}

Table 6. Summary of the total number of additional broadband stations needed to reach each National Volcanic Early Warning System (NVEWS) quality level (table 3) for Hawaiian volcanoes.

[Ranges represent one standard deviation above and below the mean of 1,000 computer-model runs]

\begin{tabular}{lcc}
\hline \multicolumn{1}{c}{ Volcano/region } & \multicolumn{2}{c}{ Quality level } \\
\cline { 2 - 3 } & Level 3 & Level 4 \\
\hline Kīlauea & $3-5$ & $7-10$ \\
$\quad$ East Rift Zone & $3-5$ & $7-10$ \\
$\quad$ Southwest Rift Zone & & \\
Mauna Loa & 0 & 1 \\
$\quad$ Summit & $4-7$ & $9-12$ \\
Northeast Rift Zone & $7-10$ & $15-19$ \\
$\quad$ Southwest Rift Zone & & 6 \\
Hualālai & 4 & $4-7$ \\
$\quad$ Summit & $2-4$ & $3-6$ \\
Northwest Rift Zone & $1-3$ & 3 \\
$\quad$ South Rift Zone & 1 & 3 \\
Mauna Kea & & $6-10$ \\
Haleakalā & 1 & $4-7$ \\
Summit & $3-5$ & \\
East Rift Zone & $2-4$ & \\
Southwest Rift Zone & & \\
\hline
\end{tabular}

Table 5. Summary of the total number of additional short-period stations needed to reach each National Volcanic Early Warning System (NVEWS) quality level (table 3) for Hawaiian volcanoes.

[Ranges represent one standard deviation above and below the mean of 1,000 computer-model runs]

\begin{tabular}{lccc}
\hline \multicolumn{1}{c}{ Volcano/region } & \multicolumn{3}{c}{ Quality level } \\
\cline { 2 - 4 } & Level 2 & Level 3 & Level 4 \\
\hline Kīlauea & 1 & $2-4$ & $2-4$ \\
$\quad$ East Rift Zone & 0 & 1 & $0-2$ \\
$\quad$ Southwest Rift Zone & & & \\
Mauna Loa & 0 & 0 & 1 \\
$\quad$ Summit & $4-7$ & $4-6$ & $4-6$ \\
Northeast Rift Zone & $3-6$ & $4-7$ & $6-8$ \\
$\quad$ Southwest Rift Zone & & & \\
Hualālai & 2 & 4 & 5 \\
$\quad$ Summit & $1-4$ & $2-5$ & $2-5$ \\
Northwest Rift Zone & $1-4$ & $1-3$ & $0-3$ \\
$\quad$ South Rift Zone & 1 & 2 & 3 \\
Mauna Kea & & & \\
Haleakalā & 3 & 4 & $5-7$ \\
$\quad$ Summit & $2-6$ & $3-6$ & $2-6$ \\
East Rift Zone & $1-4$ & $2-5$ & \\
Southwest Rift Zone & & & \\
\hline
\end{tabular}

Table 7. Summary of the total number of additional strongmotion stations needed to reach National Volcanic Early Warning System (NVEWS) quality level 4 (table 3) for Hawaiian volcanoes.

[Ranges represent one standard deviation above and below the mean of 1,000 computer-model runs. In practice, these stations would be most useful when collocated with a short-period or broadband station]

\begin{tabular}{lc}
\hline \multicolumn{1}{c}{ Volcano/region } & Quality level \\
\cline { 2 - 2 } & Level 4 \\
\hline Kīlauea & 2 \\
$\quad$ East Rift Zone & $2-5$ \\
$\quad$ Southwest Rift Zone & \\
Mauna Loa & 0 \\
Summit & $4-7$ \\
Northeast Rift Zone & $6-9$ \\
Southwest Rift Zone & \\
Hualālai & 0 \\
Summit & $2-4$ \\
Northwest Rift Zone & $1-3$ \\
South Rift Zone & 1 \\
Mauna Kea & \\
Haleakalā & 1 \\
Summit & $3-5$ \\
East Rift Zone & $2-4$ \\
Southwest Rift Zone & \\
\hline
\end{tabular}


and thus no additional stations are needed. The total number of new stations required to meet quality level 2, 3, and 4 on Kîlauea's East Rift Zone is 1 station, 5-7 stations, and 12-15 stations, respectfully (table 4). To achieve a quality level 2 network, Kīlauea's East Rift Zone only requires one additional short-period seismometer (table 5 ). To achieve a quality level 3 network on the East Rift Zone, 2-4 additional short-period stations and 3-5 additional broadband stations are required (tables 5 and 6). To upgrade the network on Kīlauea's East Rift Zone to a quality level 4 network, 2-4 additional shortperiod stations, $7-10$ additional broadband stations, and 2 additional strong-motion stations are required (tables 5, 6, and 7). Kîlauea's Southwest Rift Zone is already a quality level 2 network along its entire length, and thus no additional stations are required. In total, 4-6 additional stations and 11-15 additional stations are required to meet a quality level 3 and quality level 4 network on the Southwest Rift Zone of Kīlauea, respectfully. For a quality level 3 network, this is partitioned among 1 short-period station and 3-5 broadband stations (tables 5 and 6). To upgrade the current network on the Southwest Rift Zone of Kỉlauea to a quality level 4 network, $0-2$ short-period stations, $7-10$ broadband stations, and $2-5$ strong-motion stations are required (tables 5, 6, and 7). The spread in the number of seismometers on the Southwest Rift Zone depends heavily on the exact placement of seismometers on the southeast flank of Mauna Loa.

Mauna Loa is the largest active volcano in the world, and thus the number of stations required to monitor the length of the rift zones is high. The summit of Mauna Loa has a quality level 3 network (fig. 8), and thus the number of additional stations to meet the different quality levels is low. Only one additional broadband station is required in the summit area to make it a quality level 4 network. To upgrade the Northeast Rift Zone of Mauna Loa at quality levels 2, 3, and 4 will require 4-7, 9-11, and 19-23 total stations, respectfully (table 4). To upgrade the region around the Northeast Rift Zone to quality level 2, 4-7 additional short-period stations are required (table 5). To achieve a quality level 3 network along the Northeast Rift Zone, 4-6 additional short-period stations and 4-7 additional broadband stations are needed (tables 5 and 6). A quality level 4 network on the Northeast Rift Zone requires 4-6 additional short-period stations, 9-12 broadband stations, and 4-7 additional strong-motion stations (tables 5, 6, and 7). In the Southwest Rift Zone of Mauna Loa the total number of additional stations required to meet quality level 2, 3, and 4 standards are 3-6, 12-16 and 20-34, respectfully (table 4 ). To achieve a quality level 2 network on the Southwest Rift Zone, 3-6 additional short-period stations are required (table 5). To upgrade the current network on the Southwest Rift Zone to a quality level 3 network, 4-6 additional short-period stations and 7-10 additional broadband stations are needed (tables 5 and 6). A quality level 4 network on the Southwest Rift Zone of Mauna Loa requires 6-8 additional short-period stations, 15-19 additional broadband stations, and 6-9 additional strong-motion stations (tables 5, 6, and 7).
Hualālai is more sparsely monitored than either Kîlauea or Mauna Loa, mostly because of its relative volcanic activity rate. Even so, Hualālai is smaller than Mauna Loa and has a smaller subaerial footprint than Kîlauea, and thus the number of stations to meet a given quality level is relatively modest. The total number of stations required to meet quality level 2 , 3 , and 4 standards are 2, 4, and 6 stations, respectively, for Hualālai's summit area, 1-4, 4-8, and 10-14, respectively, for the Northeast Rift Zone and 1-4, 3-5, and 7-10, respectively, for the South Rift Zone (table 4). In the region around the summit, two short-period stations are required to meet the quality level 2 standard (table 5). To meet quality level 3 standards, four additional short period stations are required (table 5). To upgrade the current network around the summit to a level 4 network, 5 additional short-period stations and 1 additional broadband station is needed (tables 5 and 6 ). On the Northwest Rift Zone of Hualālai, 1-4 additional short-period stations are required to meet a quality level 2 standard (table 5 ). To upgrade the current network to a quality level 3 standard, 2-5 additional short-period stations and 2-4 additional broadband stations are required (tables 5 and 6 ). To meet the requirements of a quality level 4 network on the Northwest Rift Zone, 2-5 additional short-period stations, 4-7 additional broadband stations, and 2-4 additional strong-motion stations are needed (tables 5, 6, and 7). The South Rift Zone of Hualālai requires 1-4 additional short-period stations to meet a quality level 2 standard (table 5). To meet the requirements of a quality level 3 network, upgrades of 1-3 short period stations and 3-6 broadband stations are needed (tables 5 and 6 ). To achieve a quality level 4 network on the South Rift Zone of Hualālai, 0-3 additional short period stations, 3-6 additional broadband stations and 1-3 additional strong-motion stations are required (tables 5, 6, and 7).

Mauna Kea has relatively low requirements to meet the different NQLs because it does not possess prominent rift zones and thus is treated as a single eruptive site. The total number of stations required to meet quality level 2, 3, and 4 standards are 1, 3, and 7 additional stations, respectively. To meet a quality level 2 standard, 1 additional short-period station is required (table 5). An additional 2 short-period stations and 1 broadband station are required to meet a quality level 3 standard (tables 5 and 6). To satisfy the requirements of a quality level 4 network, 3 additional short-period stations, 3 additional broadband stations, and 1 additional strong-motion station are required (tables 5, 6, and 7).

Haleakalā does not have the benefit of neighboring volcano networks and is in a sparse part of the existing seismic network, and thus the number of stations required to meet a given quality level is relatively high, despite a small subaerial footprint. The total number of stations to meet the requirements of a quality level 2,3, and 4 network are 3, 5, and 9 additional stations, respectively, for Haleakalā's summit area; 2-6, 7-11, and 15-20, respectively, for the East Rift Zone; and $1-4,4-8$, and 10-15, respectively, for the Southwest Rift Zone (table 4). At the summit of Haleakalā, to meet the requirements of a quality level 2 network, 3 short-period stations are 
needed. To meet quality level 3 standards, 4 additional shortperiod stations and 1 additional broadband station are required. To achieve the quality level 4 network standards, 5 additional short-period stations, 3 additional broadband stations, and 1 additional strong-motion station are needed. On the East Rift Zone, 2-6 short-period stations are required to meet quality level 2 standards (table 5). To achieve the requirements of a quality level 3 network, 3-6 short period stations and 3-5 broadband seismometers are needed (tables 5 and 6 ). An additional 4-7 short-period stations, $6-10$ broadband stations, and 3-5 strong-motion stations need to be installed to achieve the requirements of the quality level 4 seismic network (tables 5, 6, and 7). On the Southwest Rift Zone, 1-4 new short-period stations need to be installed to achieve the quality level 2 requirements (table 5). An additional $2-5$ short period stations and $2-4$ broadband stations are required to meet quality level 3 standards (tables 5 and 6). Finally, to achieve the requirements of a quality level 4 network, an additional 2-6 short-period stations, 4-7 broadband stations, and 2-4 strong motion stations must be installed (tables 5, 6, and 7).

\section{Potential Priorities for Network Upgrades}

Thus far, I have summarized the current state of the network in a NVEWS quality level framework, which focused on the number and types of stations in a given area, and an earthquake detection and location framework, which considers the number of stations and orientation of those sources around a given earthquake source. I also considered the number of stations needed to upgrade the current network to certain NQLs as defined by Moran and others (2008). Here I combine all of the results discussed thus far with characteristics of each volcano to form potential priorities for network upgrades.

Ewert and others (2005) state that very high threat and high threat volcanoes should have quality level 4 monitoring networks and that moderate threat volcanoes should have quality level 3 monitoring networks (table 2). Given the long rift zones present on three Hawaiian volcanoes, the resulting numbers to reach the NVEWS suggested quality levels is high compared to a single stratovolcano or group of stratovolcanoes. Table 8 and figure 26 show the total number of stations required for each volcano to meet the quality level prescribed in the NVEWS report (table 2). In total, upgrading all of the volcanoes to the optimal quality levels will take between 104 and 125 additional stations. These numbers represent good goals for the final configuration; however, it is likely that any network improvements will be done incrementally with monies that will have a specific volcano as a target. Therefore, in this section I attempt to present possible priorities for new station installations by taking into account TMD, TML, magmaplumbing geometry, volcanic growth stages, and population exposure.

Hawaiian volcanoes in a shield stage, such as Kīlauea and Mauna Loa, receive magma initially into a shallow magma system that lies near the summit of the volcano (Lockwood

Table 8. Summary of the total number of seismic stations needed to achieve an optimal configuration for Hawaiian volcanoes as defined by the National Volcanic Early Warning System (NVEWS) report (Ewert and others, 2005; table 2)

[Kīlauea, Mauna Loa and Hualālai all have quality level 4 networks, whereas Mauna Kea and Haleakalā have quality level 3 networks]

\begin{tabular}{|c|c|c|c|c|}
\hline \multirow[t]{2}{*}{ Volcano/region } & \multicolumn{4}{|c|}{ Instrument Type } \\
\hline & Short-period & Broadband & Strong-motion & Total \\
\hline \multicolumn{5}{|l|}{ Kîlauea } \\
\hline East Rift Zone & $2-4$ & $7-10$ & 2 & $12-15$ \\
\hline Southwest Rift Zone & $0-2$ & $7-10$ & $2-5$ & $12-15$ \\
\hline \multicolumn{5}{|l|}{ Mauna Loa } \\
\hline Summit & 0 & 1 & 0 & 1 \\
\hline Northeast Rift Zone & $4-6$ & $9-12$ & $4-7$ & $19-23$ \\
\hline Southwest Rift Zone & $6-8$ & $15-20$ & $6-9$ & $29-34$ \\
\hline \multicolumn{5}{|l|}{ Hualālai } \\
\hline Summit & 5 & 1 & 0 & 0 \\
\hline Northwest Rift Zone & $2-5$ & $4-7$ & $2-4$ & $10-14$ \\
\hline South Rift Zone & $0-3$ & $3-6$ & $1-3$ & $7-10$ \\
\hline Mauna Kea & 2 & 1 & 0 & 3 \\
\hline \multicolumn{5}{|l|}{ Haleakalā } \\
\hline Summit & 4 & 1 & 0 & 5 \\
\hline East Rift Zone & $3-6$ & $3-5$ & 0 & $7-11$ \\
\hline Southwest Rift Zone & $2-5$ & $2-4$ & 0 & $4-8$ \\
\hline
\end{tabular}




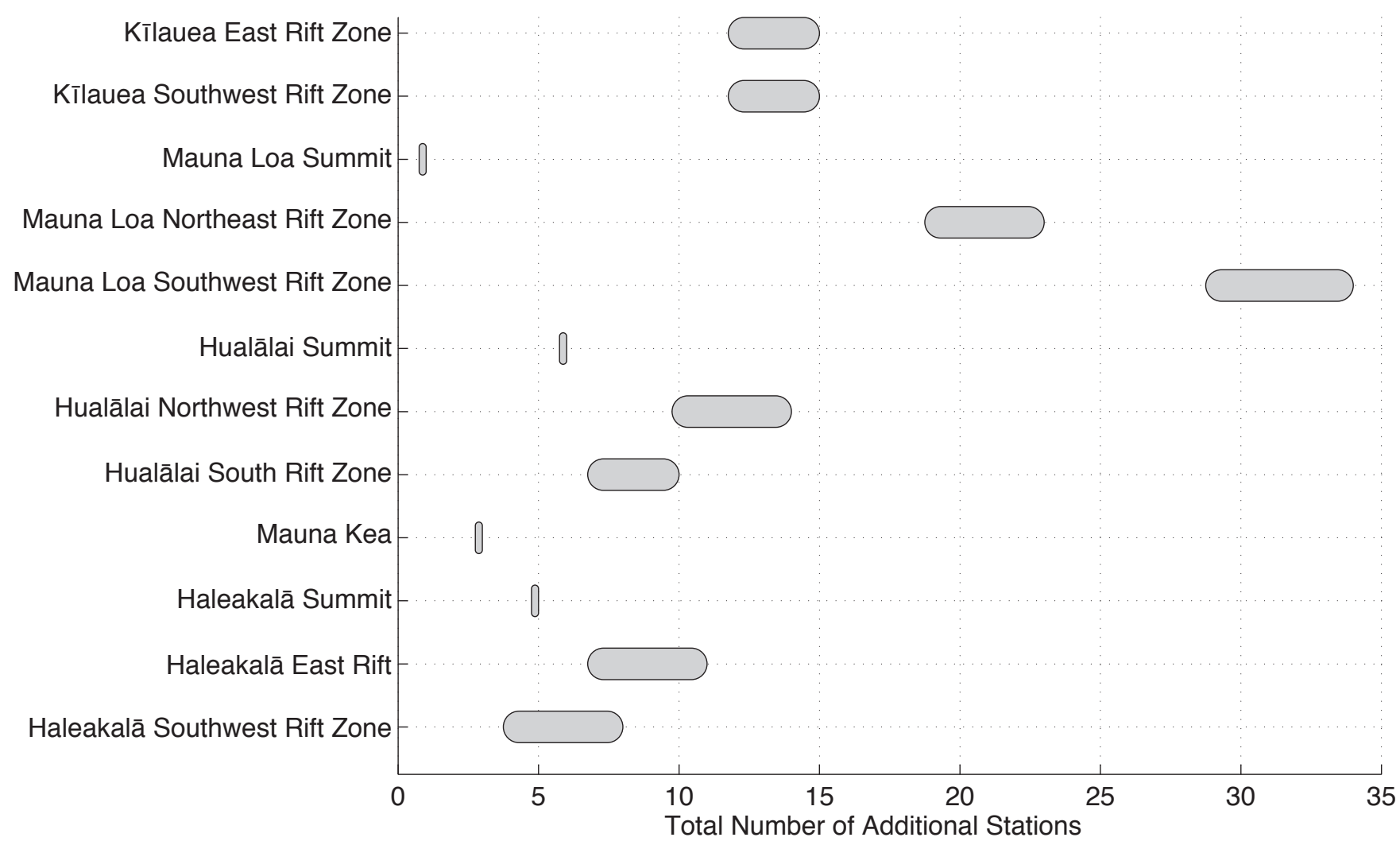

Figure 26. Bar graph showing total number of additional stations needed in each respective region of the State of Hawaii to meet the optimal level of seismic monitoring as recommended by the National Volcanic Early Warning System (NVEWS) report (Ewert and others, 2005). Once upgraded, Kỉlauea, Mauna Loa, and Hualālai will have quality level 4 networks, whereas Mauna Kea and Haleakalā will have quality level 3 networks.

and others, 1987; Poland and others, 2014). With or without a summit eruption, magma typically moves downrift to erupt effusively. The connection between the summit and rift plumbing systems is typically quite good as reflected by changes in summit lava lake levels or summit subsidence on initiation of a rift-zone eruption (for example, Kapoho eruption, 1960). Thus any preeruptive signal is expected to be present first at the summit and then subsequently at the rift-zone eruption site. This fact underscores the importance of prioritizing a good monitoring network surrounding the summit of any shieldstage volcano.

Volcanoes in a post-shield stage, such as Hualālai, Haleakalā, and Mauna Kea, typically have much less frequent eruptions, mostly because the volcano is no longer over the hotspot and has a lower supply of magma from the mantle, if any supply exists at all (Clague and Sherrod, 2014; Frey and others, 1991). The relation between summit and rift activity that is seen in shield-stage volcanoes does not necessarily apply to post-shield-stage volcanoes. Typically, eruptive products are sourced from much deeper zones than are active during the shield stage. Hualālai, although in the post-shield stage (Clague and Sherrod, 2014), has had historical eruptions in 1800 and 1801 that issued from the Northwest Rift Zone and thus should be more similar in network needs to the shield-stage volcanoes. Similarly, the East Rift Zone and
Southwest Rift Zone of Haleakalā have hosted all of the eruptions on that volcano in the past 13,000 years, requiring future monitoring of the rift zones (Sherrod and others, 2006). Eruption rates at Hualālai and Haleakalā have been similar during the past 13,000 years; however, the volume of the eruptions at Haleakalā has been lower (Sherrod and others, 2006).

The following sections discuss specific recommendations for the different active volcanoes on the Islands of Hawai' $i$ and Maui. Table 8 and figure 26 outline the total number of stations suggested for each region. Much of the discussion below lays out suggested priorities within each region to ensure the highest risk and hazard areas are well monitored.

\section{Kīlauea and Associated Rift Zones}

Kîlauea is among the most active volcanoes in the world and thus has a dense permanent monitoring network (quality level 4) near the summit of the volcano that includes 13 seismic stations within $5 \mathrm{~km}$ of the active vent (fig. 8). Historically, the summit and East Rift Zone of Kîlauea have significantly more eruptions than the Southwest Rift Zone (Holcomb, 1987). This suggests that the East Rift Zone be prioritized over the Southwest Rift Zone. Further, population density increases in the lower East Rift Zone, where the 
communities of Lelani Estates, Nānāwale Estates, and Kapoho exist. Historical eruptions emanated from the lower East Rift Zone in 1955 and 1960 (Helz and Wright, 1992; Wright and Helz, 1996). For all of these reasons, the East Rift Zone of Kîlauea is a priority for station upgrades. Currently a quality level 4 network exists down most of the East Rift Zone to $\mathrm{Pu}^{\prime} \mathrm{u}$ ' $\overline{\mathrm{O}}^{‘} \mathrm{o}$ (fig. 8). However, downrift of $\mathrm{Pu}^{‘} \mathrm{u}^{\prime}{ }^{\mathrm{O}}{ }^{‘} \bar{o}$ to near the Pāhoa-Kalapana Road and downrift of Kapoho Cone, the current seismic network configuration results in a large TML (greater than $M 2$; fig. 16). These areas are priorities for upgrading to a quality level 4 network because of the population exposure in the communities that live on and around the East Rift Zone in that area. This upgrade will require between 12 and 15 total stations, 2-4 short-period stations, 7-10 broadband stations, and 2 strong-motion stations (fig. 26, table 8). Future network upgrades on the East Rift Zone likely should initially be between stations KUPD and KLUD (fig. 4), taking care to install stations as much as $10 \mathrm{~km}$ off the rift to ensure that locations are not biased to one side of the rift and the depths are well constrained above the décollement, where seismicity is concentrated.

Because the Southwest Rift Zone of Kîlauea has been less active historically and is more sparsely populated, the potential priority for upgrading this part of the network is lower than the East Rift Zone. Still, its historical eruptive history warrants a quality level 4 network, which will require between 11 and 15 additional stations, including as many as 2 short-period stations, $7-10$ broadband stations, and 2-5 strong-motion stations (fig. 26, table 8). Future expansion of the network on Kīlauea's Southwest Rift Zone should likely be prioritized downrift of station DESD, where both TMD and TML increase progressively downrift (figs. 2, 15, and 16). Preeruptive earthquake swarms from eruptions in 1971 and 1974 on the Southwest Rift Zone began in the summit and propagated downrift to Mauna Iki (Klein and others, 1987), and thus having a dense network around and downrift of Mauna Iki will allow scientists to track the advancement of a propagating dike with more accuracy then previously possible.

\section{Mauna Loa and Associated Rift Zones}

Mauna Loa has an extremely active historical eruption record. Between 1832 and 1950, Mauna Loa averaged an eruption every 4 years (Lockwood and others, 1987). Since 1950, eruptions have occurred twice, in 1975 and 1984. Each historical eruption has begun with a summit eruption, underscoring the importance of a permanent quality level 4 network around the summit of Mauna Loa for early warning. Subsequent rift eruptions, if they occur, do not prefer one rift zone over another (Lockwood and Lipman, 1987). Eruptions from the Northwest Rift Zone have come within $10 \mathrm{~km}$ of Hilo or closer in 1852, 1855, 1881, 1942, and 1984 (Trusdell and others, 2002). Eruptions from the Southwest Rift Zone have affected the modern-day towns of Ocean View $(1887,1907)$ and Milolii $(1919,1926)$ (Trusdell and others, 2002). Less often, there are flank eruptions on Mauna Loa, particularly on the Northwest Flank. One such eruption in 1859 inundated an area of Waikoloa that is currently occupied by several hotels and vacation rentals.

Because the summit of Mauna Loa typically erupts before its rift zones (Lockwood and others, 1987), the summit is likely the first priority when upgrading the seismic network on Mauna Loa. Upgrading the summit to quality level 4, which is suggested given the historical eruptive history, will require only one additional broadband station (table 8, fig. 26). On the basis of the highest values of TMD and TML, the site for this broadband station should be to the northeast of the summit caldera (figs. 17 and 18).

The combined high hazard and high risk of both Mauna Loa rift zones necessitates their eventual upgrade to quality level 4 . This is would be a major undertaking, requiring as many as 24 stations for the Northeast Rift Zone and 34 stations for the Southwest Rift Zone (fig. 26, table 8). The priority within the rift zones should be to set up an initial relatively sparse network that covers the geographic boundaries of the rift zones for seismologists to track the position of a propagating dike. The next priority should be to fill in areas of high TMD and TML above Ocean View and Hilo (figs. 17 and 18). Specifically those areas between stations DAND and OVED on the Southwest Rift Zone to provide better warnings for Ocean View and the area downrift of station PLAD on the Northeast Rift Zone to provide better warnings for the communities of Hilo, Volcano, and Mountain View (fig. 2).

\section{Hualālai and Associated Rift Zones}

Hualālai last erupted in 1800 and 1801 from two localities on the Northwest Rift Zone (Moore and others, 1987). One of the resulting lava flows inundated the region around the Kona International Airport. Hualālai is in a post-shield stage of growth and therefore not likely to produce as frequent eruptions as its shield-stage neighbors Mauna Loa and Kīlauea (Moore and others, 1987; Clague and Sherrod, 2014). Since the last eruption in 1801, there has been one vigorous swarm of earthquakes in 1929, which was thought to be caused by an intrusion. The swarm was incredibly strong and included two magnitude 6+ earthquakes (Wyss and Koyanagi, 1992; Klein and Wright, 2000). In addition, the town of Kalaoa lies on the Northwest Rift Zone of Hualālai. The diffuse South Rift Zone of Hualālai does not have any towns built on it and has no historical record of activity. Generally, a post-shield Hawaiian volcano is removed from the hotspot, and thus all magma is remnant from when the hotspot was under the volcano (Clague and Sherrod, 2014). Generally, magma chambers also have deeper source depths in this phase, and the typical summit and rift zone connection seen in shield-stage volcanoes is broken (Clague and Sherrod, 2014, Frey and others, 1991). Instead, rift zone eruptions in post-shield stage are postulated to be fed directly from deep, relic magma chambers. Indeed, the 1800-1801 lavas did have significant zenoliths, suggesting a 
deeper source depth (Moore and others, 1987). To constrain these deeper depths, the seismic network around Hualālai will need to have an aperture that is approximately the same as the source depth for the eruptions. The additional aperture can likely be accommodated with a combination of the existing network and upgrades to networks on neighboring volcanoes.

The combination of historical activity and an exposed nearby population make it important to upgrade the seismic network of Hualālai to a quality level 4 network. Both the summit and Northwest Rift Zone of Hualālai are priorities in future seismic upgrades, as the geophysical signature of an eruption is unknown on this volcano. This will take as many as 20 total stations with 7-10 short-period stations, 5-8 broadband stations, and 2-4 strong-motion stations (fig. 26, table 8). Future expansion of the existing network in the area should be focused in the areas of highest TMD and TML (figs. 19 and 20), specifically areas of the Northwest Rift Zone around Kalaoa. If the source of the magmas that feed the eruptions is indeed deep, then the network on the Northwest Rift Zone will need to have a broad extent to have the aperture required to constrain a deep source. The South Rift Zone is a lower priority with respect to the regions of Hualālai because of the low population exposure, low historical activity rates, and the collateral benefit of having a good network on Mauna Loa, which will incidentally improve the TMD and TML.

\section{Mauna Kea}

Mauna Kea is in a post-shield stage and thus has infrequent low-volume eruptions from relatively deep magma chambers (Frey and others, 1991; Clague and Sherrod, 2014). In addition, the at-risk population on Mauna Kea is very low. Because of the infrequent eruptions and low at-risk populations, the NVEWS recommendation of a quality level 3 network seems appropriate (table 2). Because of existing HVO stations in the vicinity, a quality level 3 network can be easily achieved by adding just three additional stations - 1 broadband seismometer at the summit and 2 short-period stations to the north and north-northeast of the summit, where the TMD and TML are highest (figs. 13 and 14).

\section{Haleakalā}

Like Hualālai of the Island of Hawai'i, Maui's Haleakalā is in a post-shield stage with infrequent low-volume eruptions compared to shield-stage volcanoes (Sherrod and others, 2006; Clague and Sherrod, 2014). Even so, eruptions in the past 1,500 years have occurred on both rift zones and the summit area. Significant numbers of people and infrastructure are exposed to Haleakalā hazards in the event of an eruption, especially at the summit of Haleakalā and in the town of Hāna. For these reasons, a level 3 network should be installed around the summit area, East Rift Zone, and Southwest Rift Zone.

Meeting the standards of a quality level 3 network will require as many as 15 additional short-period stations and as many as
10 additional broadband stations (fig. 26, table 8 ). The TML and TMD on Maui are generally high, and any improvements to the network will significantly improve those metrics. Future expansion is recommended first near the summit of Haleakalā and on the East Rift Zone, where the risk to population is highest (figs. 21 and 22). The generally deeper magma systems that are the sources for post-shield eruptions require a seismic network with a wide aperture to properly constrain depths. To widen the aperture of the seismic network on Haleakalā, the Southwest Rift Zone is recommended to be sparsely populated with new seismic installations during the full build out of the seismic network at the summit and East Rift Zone. The network that is proposed has the added benefit of aiding in the detection of tectonic seismicity - a significant shaking hazard to the population of Maui County - both on Maui and the neighboring islands.

\section{Island of Hawai'i}

For parts of the Island of Hawai' $i$ removed from volcanic systems, the purposes of improving the network are largely to improve locations, magnitude determinations, focal mechanisms, "shakemaps," and moment tensors of tectonic seismicity (for example, tectonic seismicity on crustal faults and earthquakes on the décollemont and in the mantle). Recently, there has been an increased interest for earthquake early warning (EEW), in which critical buildings and structures use rapid magnitude estimates of large magnitude earthquakes to mitigate damage in the few seconds before the S-wave impacts the structure. Most of the techniques mentioned above require a dense coverage of seismometers that surround any earthquake source as much as possible. The best measure to improve the network geometry on the Island of Hawai' $i$ is TML (figs. 14, 16,18 , and 20). In general, TML is highest on the perimeter of the island, and thus future network upgrades to better track tectonic seismicity would be best focused on the perimeter of the island, particularly to the west of South Point and between Hawi and Honoka'a (fig. 2). Enhancing the coverage on the perimeter of the Island of Hawai' $i$ will also improve the earthquake early warning capability for events offshore. In the interior of the island, the area between Glenwood and Kea'au needs future network expansion to enhance the density of stations in that area (fig. 2). Future installations need to be combination broadband and strong-motion stations to better constrain large ground motions for shakemaps and to provide broadband signals for moment tensor calculations.

\section{Maui, Kaho‘olawe, Lāna‘i, Moloka‘i, O‘ahu, Kaua'i and Ni'ihau}

The seismic hazard declines moving from the Island of Hawai' $i$ northwest up the Hawaiian Islands (Klein and others, 2001). In 1871, a M6.8 earthquake struck southwest of the Island of Lāna' $i$, causing strong ground shaking from north of the Island of Hawai'i to O'ahu (Wyss and Koyanagi, 1992). 
In addition, a M6.9 earthquake struck north of Maui in 1938, also causing strong ground shaking from the northern part of the Island of Hawai' $i$ to $\mathrm{O}^{\prime}$ ahu. Based on the seismic hazard, its clear that network upgrades in this area are important; however, the geography of the island chain prevents a stable geometry for locating such events. Even so, to do the best job possible, new stations are likely best prioritized in places of high TMD and TML within Maui County, such as southeast Maui, northwest Maui, Lāna'i, east Moloka'i, and Kaho'olawe (figs. 11 and 12).

The discussion of priorities for seismic network monitoring levels also assume that there is a portable cache of instruments that is ready to be deployed with real-time telemetry. This assumption is based on the premise that any existing level 2 or level 3 network at a Hawaiian volcano could be rapidly upgraded to a level 4 network near the site of a rift zone breakout, flank eruption, post-shield eruption, or aftershock sequence. Providing the most complete dataset possible through the deployment of temporary instruments will help early warning capabilities, but it will also help understanding of the processes behind the phenomenon that are behind the swarms, eruptions, or large earthquakes.

The makeup of the portable cache of instruments would best be dominantly broadbands (as many as six) with two three-component short-period seismometers and a single sixchannel strong-motion station. Radio equipment also needs to be available to communicate with existing telemetry hubs. At least two cell-phone modems are needed so that instruments can be placed in areas out of direct line-of-sight to a telemetry node (that is, areas of rainforest). Power systems and vault materials also need to be readily available to facilitate a temporary deployment within 24 hours of the start of a crisis.

\section{Conclusions}

To this point, the current seismic network has been discussed with respect to a defined quality level, minimum magnitude of detection, or a minimum magnitude of quality location. Adding more stations, as is prescribed in principle by the NVEWS Instrumentation report (Moran and others, 2008), will certainly serve to lower the detection and quality location thresholds; however, this is not the only benefit. Other capabilities, such as detecting temporal changes in seismic velocity, moment tensor modeling of volcanic seismic sources, amplitude-based locations of tremor and low-frequency earthquakes, and four-dimensional seismic tomography would also be enhanced by adding stations (table 3 ).

Significant improvements are needed to the existing seismic networks installed on the rift zones of Killauea to achieve the NVEWS prescribed quality level that is commensurate with Kīlauea's historical eruptive history and population risk (table 9). This level includes 12 to 15 additional stations each for the East and Southwest Rift Zones (table 8). Areas to be prioritized include the area downrift of $\mathrm{Pu}^{\prime} \mathrm{u}$ ' ${ }^{\prime}{ }^{`} \overline{\mathrm{o}}$ on the East Rift Zone and downrift of Mauna Iki on the Southwest Rift Zone (figs. 15 and 16).

On Mauna Loa, the large size of the volcano and the long rift zones mean that the number of stations needed to upgrade the current network to the NVEWS-prescribed level is high (19 to 23 additional stations on the Northwest Rift Zone and 29 to 34 additional stations on the Southwest Rift Zone; table 8). Station upgrades are best focused on establishing a sparse network along the length of each rift zone and then densifying the network in the rift zones above Ocean View on the Southwest Rift Zone and in the middle region of the Northeast Rift Zone (figs. 17 and 18).

On Hualālai, the prescribed upgrades are relatively modest, in part due to its small subaerial size and in part due to the neighboring seismic network on Mauna Loa. To upgrade the current seismic network to the prescribed level (quality level 4), 6, 10 to 14 , and 7 to 10 additional stations are required on the summit, Northwest Rift Zone, and South Rift Zone, respectively. Station upgrades would be best focused initially on the Northwest Rift Zone and summit (figs. 19 and 20).

The suggested network upgrades on Mauna Kea are minor, mostly due to its low activity rate and neighboring Mauna Loa seismic network. On Mauna Kea, 3 additional stations are estimated to upgrade the current seismic network to a level 3 network. The additional stations would be best focused to the north and northeast of the summit.

Haleakala is believed to have an activity level similar to Hualālai. However, Haleakalā generally has much lower volume eruptions. The suggested quality level is thus lower than for Kīlauea, Mauna Loa, and Hualālai. To upgrade the current network to a quality level 3 network will require between 12 and 24 stations to fully cover the summit and both rift zones. In addition to installing stations, there is a lack of HVO infrastructure on Maui to collect data, which should be considered when planning new installations. HVO currently does not have communications equipment occupying any towers or telemetry nodes on Maui, and thus a significant amount of effort would likely be needed to bring the data back from these five stations in real time.

Adding as many as 145 additional stations, as prescribed here, will nearly triple the number of stations in the current network. Such a network will enable a shift from pattern-based forecasting model, where current activity is compared against previous preeruptive episodes, to a process-based forecasting model in which forecasts are based on an understanding of the underlying process. This will inevitably improve HVO's forecasting ability; however, it comes at a cost. The personnel required to maintain the network, develop an understanding of the current processes, and build new tools for understanding those processes are many. With a combination of an enhanced seismic network and additional personnel to maintain and use the new data from the network, it would be possible for HVO to realize the capabilities afforded by an upgraded network within 5 years after its full installation. 


\section{References Cited}

Badger, N.B., Garces, M.A., Perttu, A.B., Poland, M., and Thelen, W.A., 2013, Infrasonic jetting from the Kamoamoa fissure eruption, Kilauea Hawaii, 5-9 March 2011 [abs.]: Proceedings of Hawaiian Volcanoes_-From Surface to Source, American Geophysical Union Chapman Conference, Waikoloa, Hawaii, August 20-24, 2012, accessed May 12, 2014, at http://hilo.hawaii.edu/ kenhon/ HawaiiChapman/documents/1HawaiiChapmanAbstracts. pdf.

Bakun, W.H., and Joyner, W., 1984, The ML scale in Central California: Bulletin of the Seismological Society of America, v. 74, no. 5, p. 1827-1843.

Clague, D.A., and Sherrod, D.R., in press, Growth and degradation of Hawaiian Volcanoes, chap. 1 of Poland, M.D., ed., Characteristics of Hawaiian volcanoes: U.S. Geological Survey Professional Paper 1801.

De Angelis, S., Fee, D., Haney, M., Schneider, D., 2012, Detecting hidden volcanic explosions from Mt. Cleveland Volcano, Alaska with infrasound and ground-coupled airwaves: Geophysical Research Letters, v. 39, L21312.

Ewert, J.W., Guffanti, M., and Murray, T.L., 2005, An assessment of volcanic threat and monitoring capabilities in the United States - Framework for a National Volcanic Early Warning System [NVEWS]: U.S. Geological Survey Open-File Report 2005-1164, 62 p., http://pubs.usgs.gov/ of/2005/1164/.

Fee, D., Garcés, M.A., Patrick, M., Chouet, B., Dawson, P., and Swanson, D., 2010, Infrasonic harmonic tremor and degassing bursts from Halema'uma'u Crater, Kilauea Volcano, Hawaii: Journal of Geophysical Research, v. 115, B11316.

Fiske, R.S., Rose, T.R., Swanson, D.A., Champion, D.E., and McGeehin, J.P., 2009, Kulanaokuaiki Tephra (ca. AD 400 1000) - Newly recognized evidence for highly explosive eruptions at Kīlauea Volcano, Hawai'i: Geological Society of America Bulletin, v. 121, no. 5-6, p. 712-728.

Frey, F.A., Garcia, M.O., Wise, W.S., Kennedy, A., Gurriet, P., and Albarede, F., 1991, The evolution of Mauna Kea volcano, Hawaii-Petrogenesis of tholeiitic and alkalic basalts: Journal of Geophysical Research, v. 96, no. B9, p. 14347-14375.

Helz, R., and T., Wright, 1992, Differentiation and magma mixing on Kilauea's east rift zone: Bulletin of Volcanology, v. 54, p. 361-384.
Holcomb, R.T., 1987, Eruptive history and long-term behavior of Kilauea Volcano, Hawaii, chap. 12 of Decker, R.W., Wright, T.L., Stauffer, P.H., eds., Volcanism in Hawaii, volume 1: U.S. Geological Survey Professional Paper 1350, p. 261-350, http://pubs.usgs.gov/pp/1987/1350/.

Klein, F.W., Frankel, A.D., Mueller, C.S., Wesson, R.L., and Okubo, P.G., 2001, Seismic hazard in Hawaii-High rate of large earthquakes and probabilistic ground-motion maps: Bulletin of the Seismological Society of America, v. 91, no. 3, p. 479.

Klein, F.W., Koyanagi, R.Y., Nakata, J.S., and Tanigawa, W.R., 1987, The seismicity of Kilauea's magma system, chap. 43 of Decker, R.W., Wright, T.L., and Stauffer, P.H., eds., Volcanism in Hawaii, volume 2: U.S. Geological Survey Professional Paper 1350, p. 1019-1185, http://pubs. usgs.gov/pp/1987/1350/.

Klein, F.W., and Wright, T.L., 2000, Catalog of Hawaiian earthquakes, 1823-1959: U.S. Geological Survey Professional Paper 1623, p. 1-103, http://pubs.usgs.gov/pp/ pp1623/.

Moore, R.B., Clague, D.A., Rubin, M., and Bohrson, W.A., 1987, Hualālai Volcano-A preliminary summary of Geologic, Petrologic, and Geophysical data, chap. 20 of Decker, R.W., Wright, T.L., and Stauffer, P.H., eds., Volcanism in Hawaii, volume 1: U.S. Geological Survey Professional Paper 1350, p. 571-585, http://pubs.usgs.gov/ pp/1987/1350/.

Moran, S.C., ed., 2004, Seismic monitoring at Cascade Volcanic Centers, 2004-Status and recommendations: U.S. Geological Survey Scientific Investigations Report 2004-5211, 28 p., http://pubs.usgs.gov/sir/2004/5211/.

Moran, S.C., Freymueller, J.T., LaHusen, R.G., Mcgee, K.A., Poland, M.P., Power, J.A., Schmidt, D.A., Schneider, D.J., Stephens, G., and Werner, C.A., 2008, Instrumentation recommendations for volcano monitoring at U.S. volcanoes under the National Volcano Early Warning System: U.S. Geological Survey Scientific Investigations Report 20085114, 47 p., http://pubs.usgs.gov/sir/2008/5114/.

Okubo, P., Nakata, J., and Koyanagi, R., in press, The evolution of seismic monitoring systems at the Hawaiian volcano observatory and highlighted findings afforded by network growth, densification, and modernization, chap. 2 of Poland, M.D., ed., Characteristics of Hawaiian volcanoes: U.S. Geological Survey Professional Paper 1801.

Langston, C.A., Brazier, R., Nyblade, A.A., and Owens, T.J., 1998, Local magnitude scale and seismicity rate for Tanzania, East Africa: Bulletin of the Seismological Society of America, v. 88, p. 712-721. 
Lockwood, J.P., Dvorak, J.J., English, T.T., Koyanagi, R.Y., Okamura, A.T., Summers, M.L., and Tanigawa, W.R., 1987, Mauna Loa 1974-1984-A decade of intrusive and extrusive activity, chap. 19 of Decker, R.W., Wright, T.L., and Stauffer, P.H., eds., Volcanism in Hawaii, volume 1: U.S. Geological Survey Professional Paper 1350, p. 537-570, http://pubs.usgs.gov/pp/1987/1350/.

Poland, M.P., Miklius, A., and Montgomery-Brown, E.K., in press, Magma supply, storage, and transport at shield-stage Hawaiian volcanoes, chap. 5 of Poland, M.D., ed., Characteristics of Hawaiian volcanoes: U.S. Geological Survey Professional Paper 1801.

Sherrod, D.R., Hagstrum, J.T., McGeehin, J.P., Champion, D.E., and Trusdell, F.A., 2006, Distribution, ${ }^{14} \mathrm{C}$ chronology, and paleomagnetism of latest Pleistocene and Holocene lava flows at Haleakalā volcano, Island of Maui, Hawai' $\mathrm{i}$ :- A revision of lava flow hazard zones: Journal of Geophysical Research, v. 111, no. B5, B05205, doi:10.1029/2005JB003876.
Trusdell, F.A., Graves, P., and Tincher, C.R., 2002, Maps showing lava inundation zones for Mauna Loa, Hawai ${ }^{i} \mathrm{i}$ : U.S. Geological Survey Miscellaneous Field Studies Map, MF-2401, 12 p., http://pubs.usgs.gov/mf/2002/2401/.

Wright, T.L., and Helz, R.T., 1996, Differentiation and magma mixing on Kilauea's east rift zone-A further look at the eruptions of 1955 and 1960, Part II-The 1960 lavas: Bulletin of Volcanology, v. 57, no. 8, p. 602-630, doi:10.1007/ s004450050115.

Wyss, M., Klein, F.W., Nagamine, K., and Wiemer, S., 2001, Anomalously high b-values in the south flank of Kilauea volcano, Hawaii-Evidence for the distribution of magma below Kilauea's East Rift Zone: Journal of Volcanology and Geothermal Research, v. 106, no. 1-2, p. 23-37.

Wyss, M., and Koyanagi, R.Y., 1992, Isoseismal maps, macroseismic epicenters and estimated magnitudes of historic earthquakes in the Hawaiian Islands: U.S. Geological Survey Bulletin 2006, 93 p. 


\section{Appendix-Histograms of NVEWS Station Requirements}

Included in this section are the histograms from the 1,000 computer simulations for each NVEWS level, along with a simulation for the prescribed NVEWS level at each volcano (figs. 27 through 38). The procedure by which these are calculated is detailed in the section titled Methodology for Determining the Seismic Monitoring Gap. Statistics for the total number of stations, the number of short-period stations, the number of broadband stations, and the number of strong-motion stations is calculated independently, based on the results of each model run. That is to say the average total number of stations may not be exactly the sum of the average number of short-period, broadband, and strong-motion stations for a particular volcanic region.

A

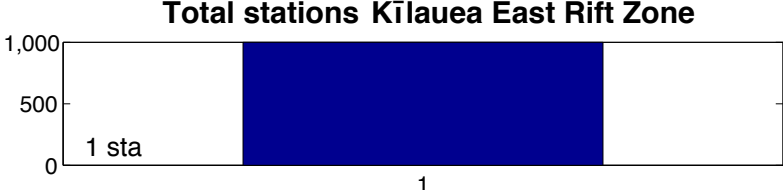

Total stations Mauna Loa summit

C

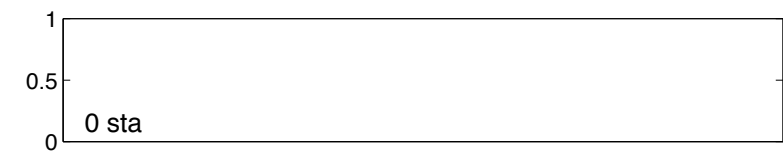

Total stations Mauna Loa SW Rift Zone

$\boldsymbol{E}$

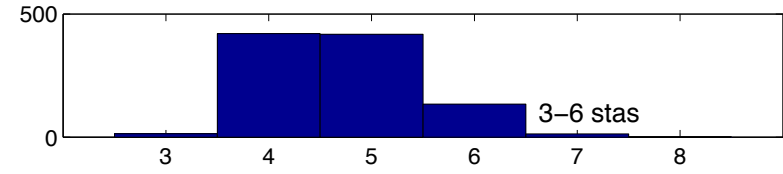

Total stations Hualālai NE Rift Zone

G

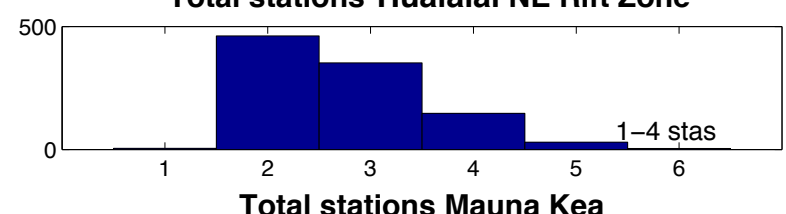

I

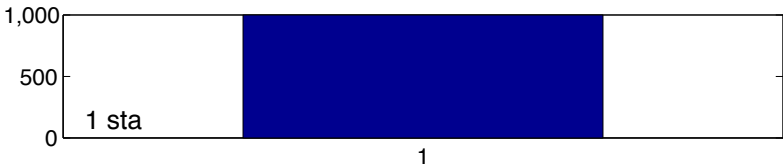

Total stations Haleakalā East Rift Zone

K

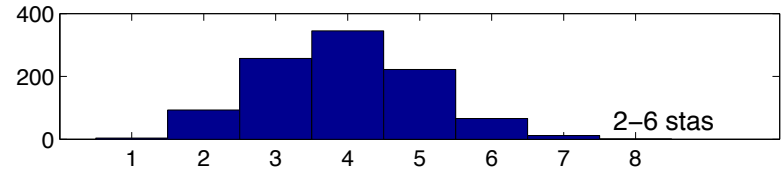

$\boldsymbol{B}$

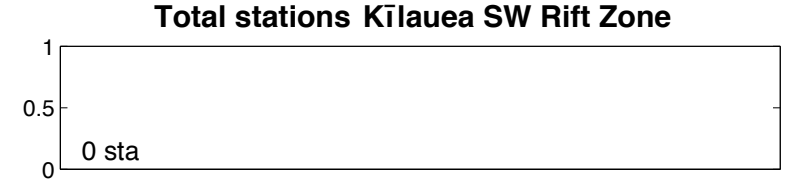

Total stations Mauna Loa NE Rift Zone

D

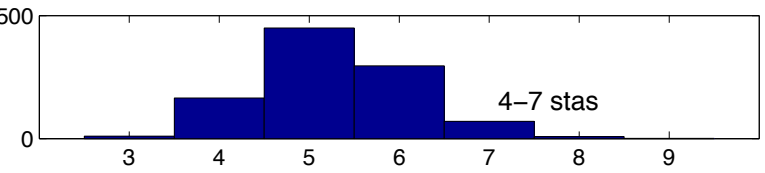

Total stations Hualālai summit

$\boldsymbol{F}$

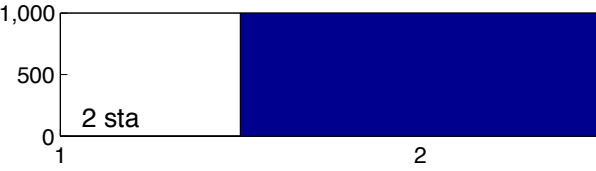

Total stations Hualālai S Rift Zone

H

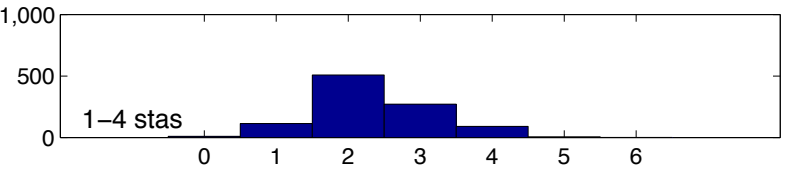

Total stations Haleakalā summit

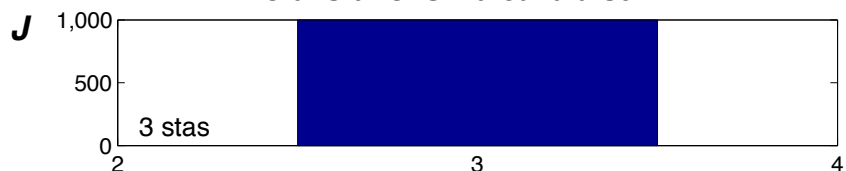

Total stations Haleakalā SW Rift Zone

$\boldsymbol{L}$

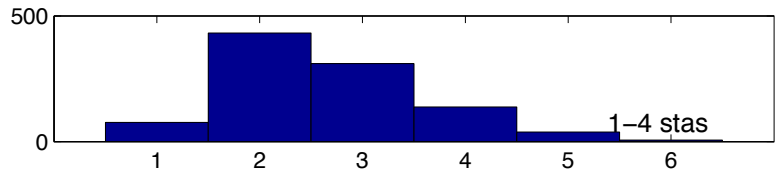

Figure 27. Graphs showing total number of seismic stations needed to meet National Volcanic Early Warning System (NVEWS; Ewert and others, 2005) quality level 2 status in study areas on the Islands of Hawai'i and Maui. Because a quality level 2 seismic network does not require broadband or strong-motion stations, all of these stations should be short period in character. The station range given is plus and minus one standard deviation from the mean of the computer simulations. $A$, Stations needed on the East Rift Zone of Kilauea. B, Stations needed on the Southwest (SW) Rift Zone of Kilauea. $C$, Stations needed on the summit of Mauna Loa. $D$, Stations needed on the Northeast (NE) Rift Zone of Mauna Loa. E, Stations needed on the Southwest (SW) Rift Zone of Mauna Loa. F, Stations needed on the summit of Hualālai. G, Stations needed on the Northeast (NE) Rift Zone of Hualālai. H, Stations needed on the South (S) Rift Zone of Hualālai. I, Stations needed on Mauna Kea. J, Stations needed on Haleakalā summit. K, stations needed on the East Rift Zone of Haleakalā. $L$, stations needed on the southwest (SW) Rift Zone of Haleakalā. Vertical axes indicate number of computer simulations; horizontal axes indicate number of stations (stas) needed. 
$\boldsymbol{A}$

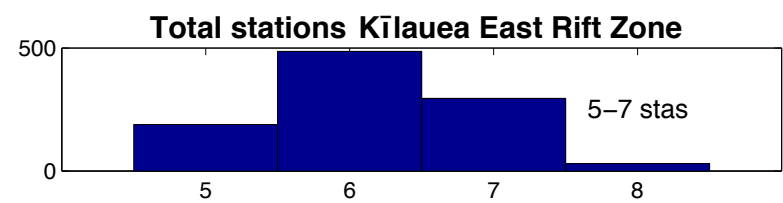

C

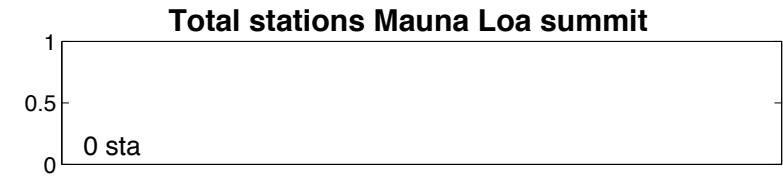

E

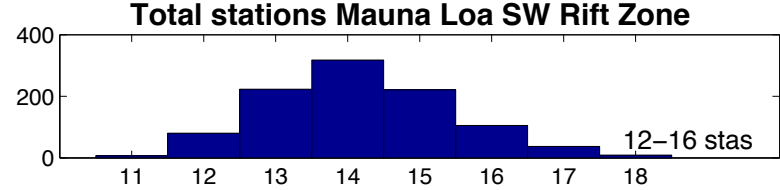

G

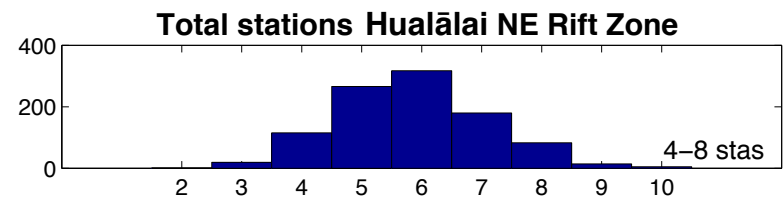

I

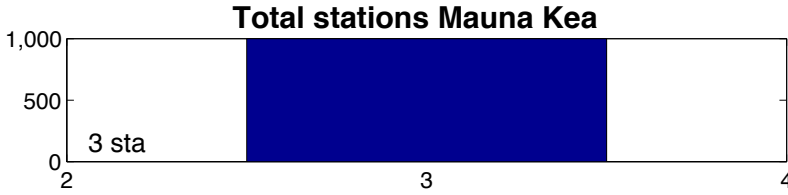

Total stations Haleakalā East Rift Zone

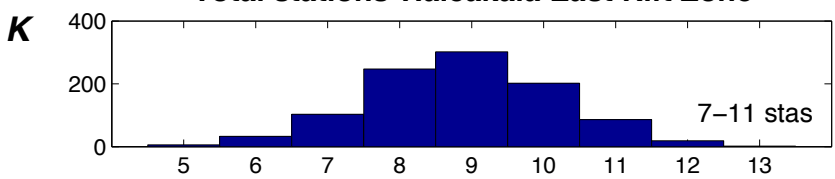

B

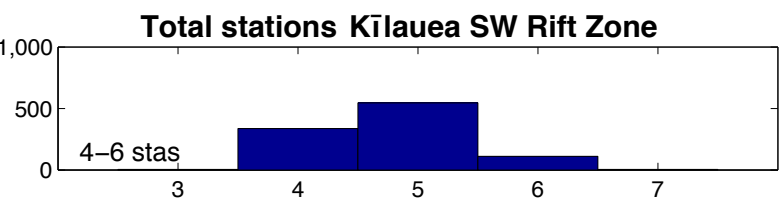

D

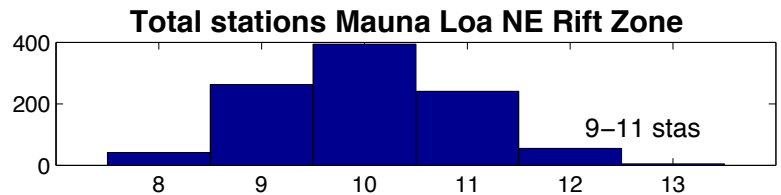

$\boldsymbol{F}$

Total stations Hualālai summit

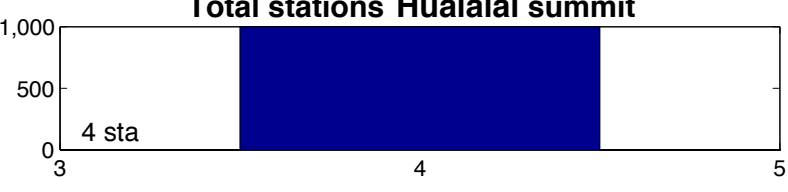

H $500 \quad$ Total stations Hualālai S Rift Zone

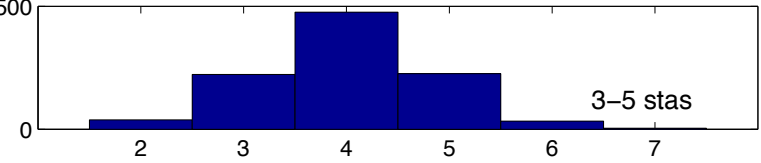

Total stations Haleakalā summit

$\boldsymbol{J}$

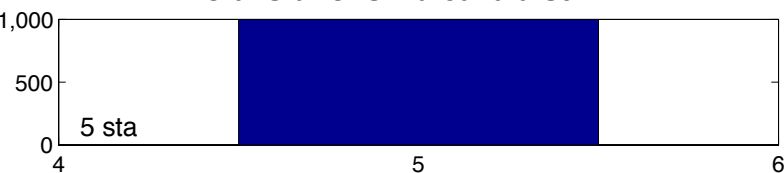

Total stations Haleakalā SW Rift Zone

$L$

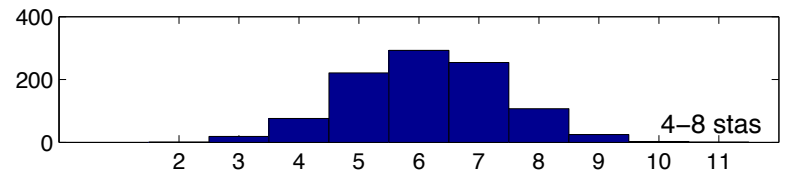

Figure 28. Graphs showing total number of seismic stations needed to meet National Volcanic Early Warning System (NVEWS; Ewert and others, 2005) quality level 3 status in study areas on the Islands of Hawai'i and Maui. The station range given is plus and minus one standard deviation from the mean of the computer simulations. See figure 27 for explanation of individual plots and abbreviations. 
$\boldsymbol{A}$

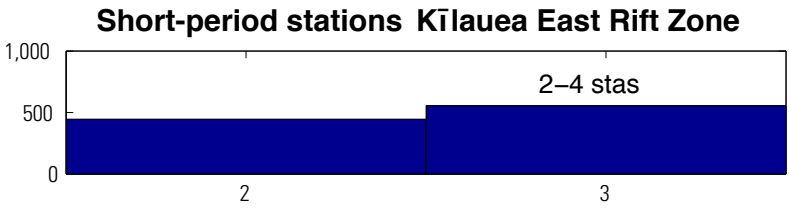

C

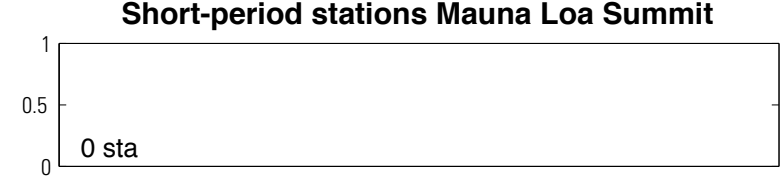

$E$

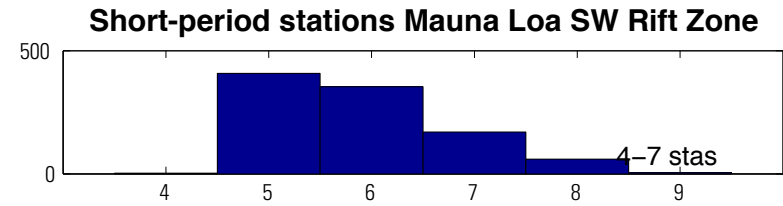

G

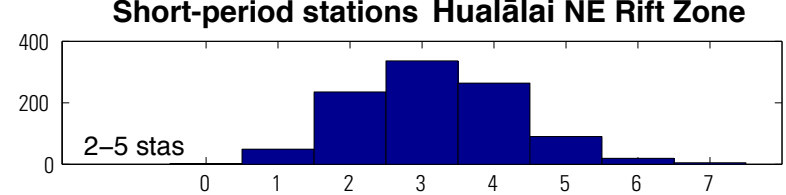

I

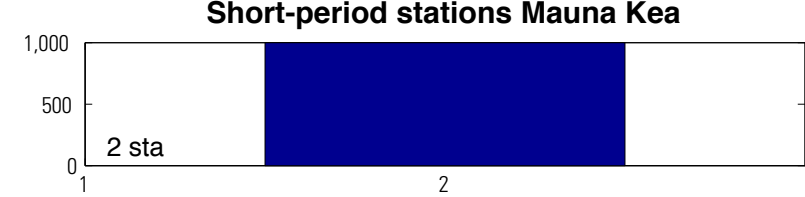

Short-period stations Haleakalā East Rift Zone

K

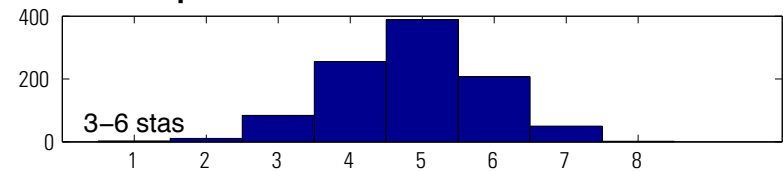

B

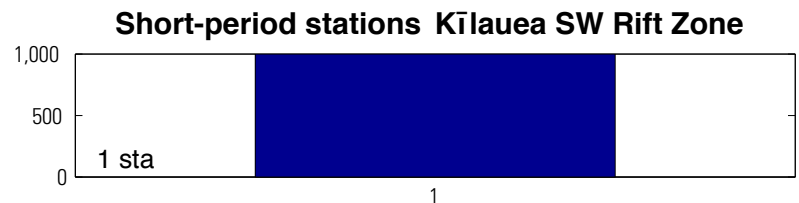

D

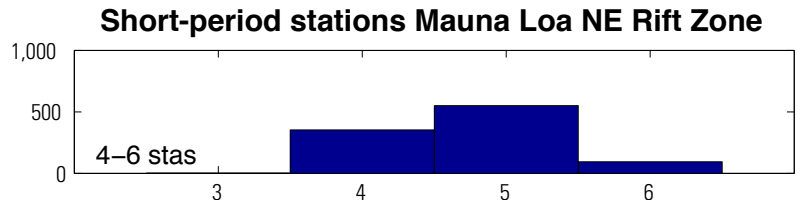

$\boldsymbol{F}$

Short-period stations Hualālai summit

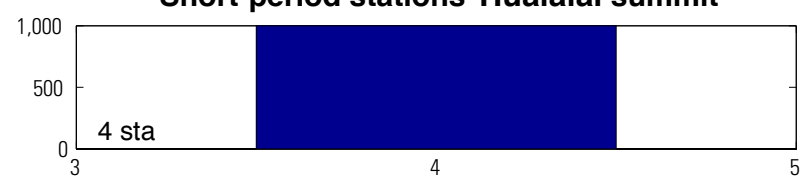

H

Short-period stations Hualālai S Rift Zone

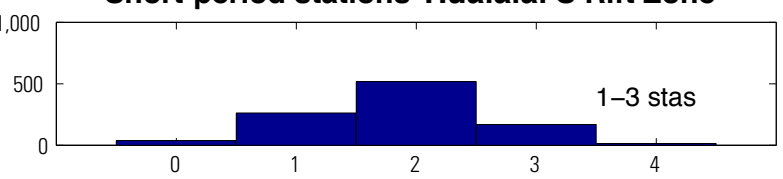

Short-period stations Haleakalā summit

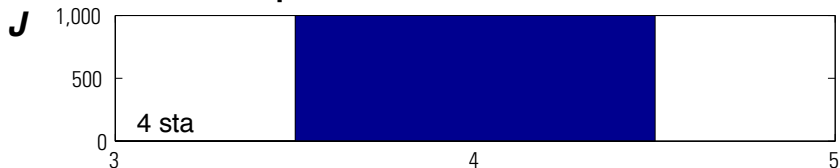

Short-period stations Haleakalā SW Rift Zone

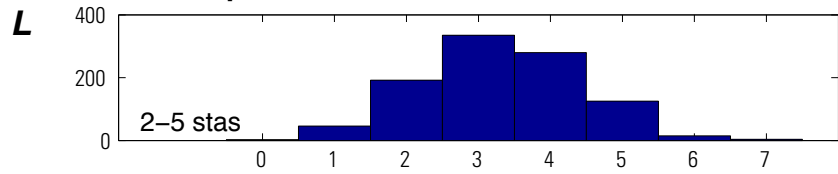

Figure 29. Graphs showing total number of short-period stations needed to meet National Volcanic Early Warning System (NVEWS; Ewert and others, 2005) quality level 3 status in study areas on the Islands of Hawai'i and Maui. The station range given is plus and minus one standard deviation from the mean of the computer simulations. See figure 27 for explanation of individual plots and abbreviations. 


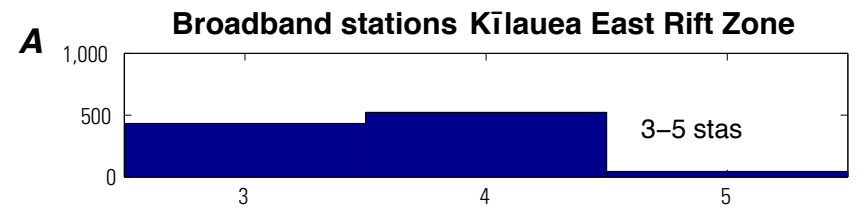

C

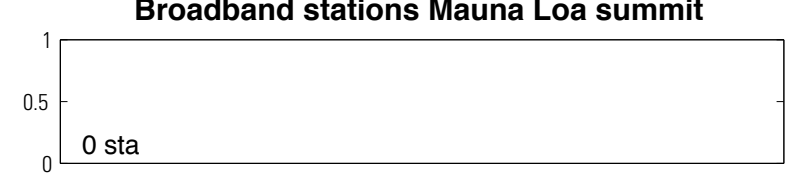

E

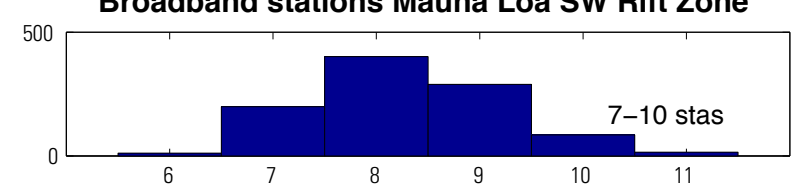

G

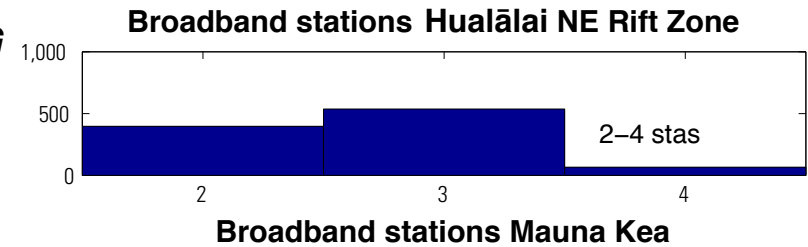

$$
\text { I }
$$
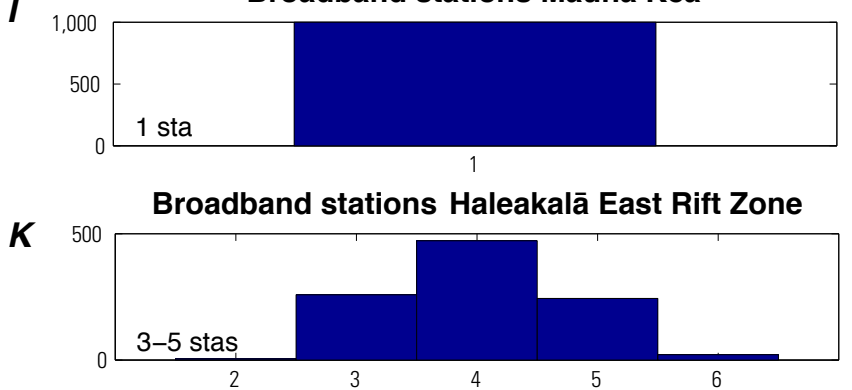

B

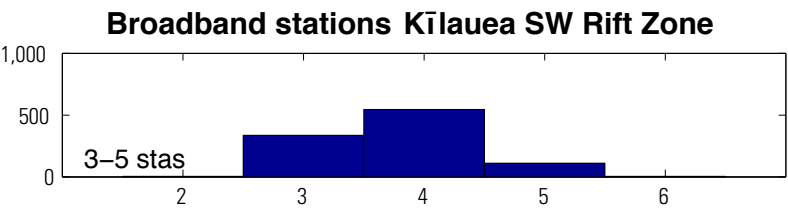

D

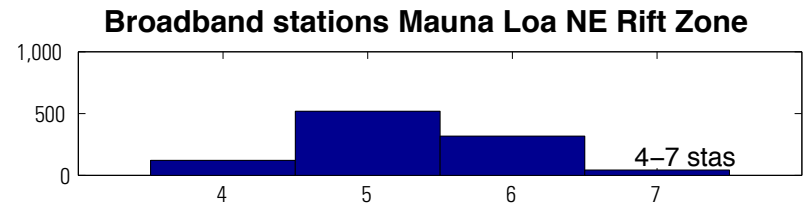

$\boldsymbol{F}$

Broadband stations Hualālai summit

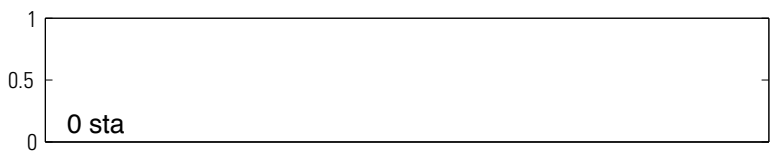

H

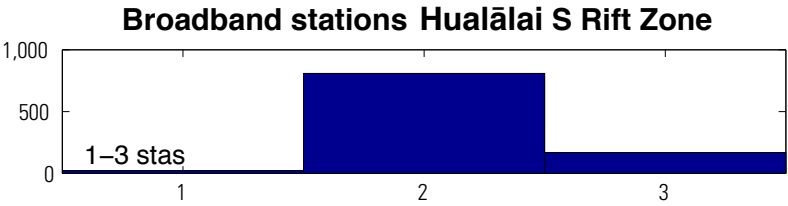

Broadband stations Haleakalā summit
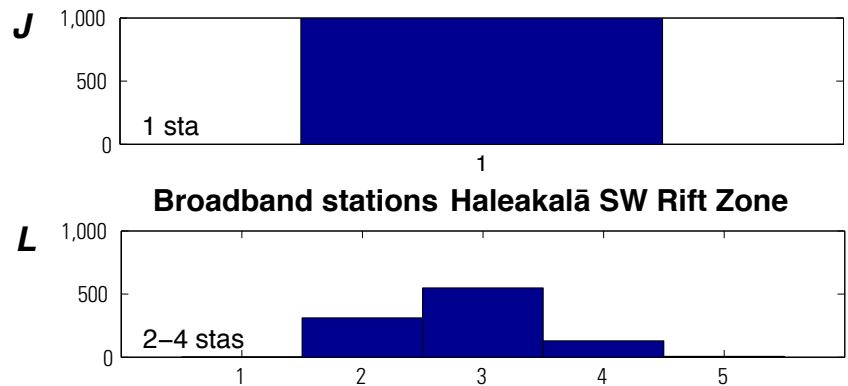

Figure 30. Graphs showing total number of broadband stations needed to meet National Volcanic Early Warning System (NVEWS; Ewert and others, 2005) quality level 3 status in study areas on the Islands of Hawai'i and Maui. The station range given is plus and minus one standard deviation from the mean of the computer simulations. See figure 27 for explanation of individual plots and abbreviations. 
A

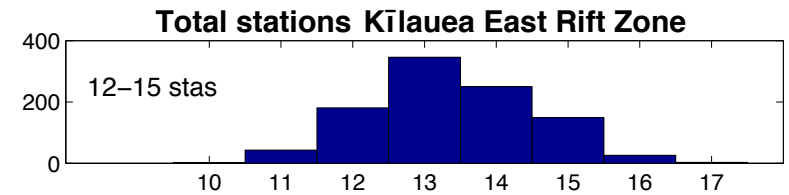

C

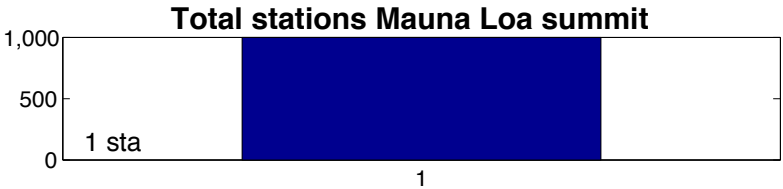

E

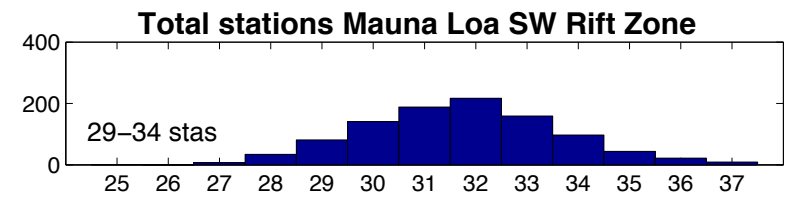

G

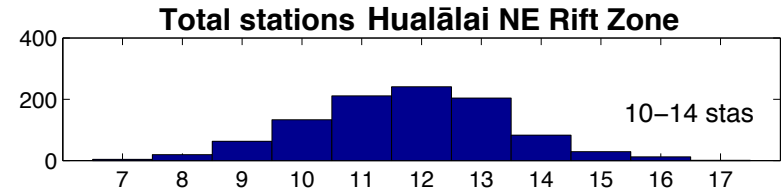

I

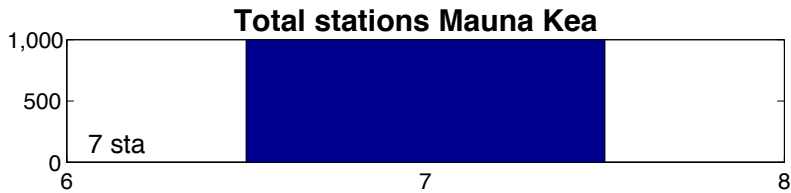

K

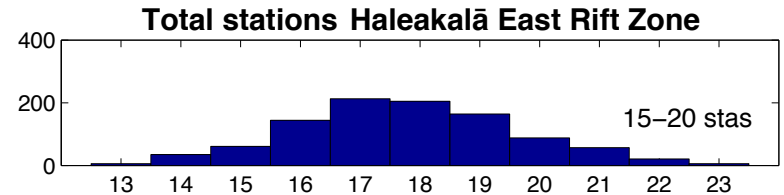

B

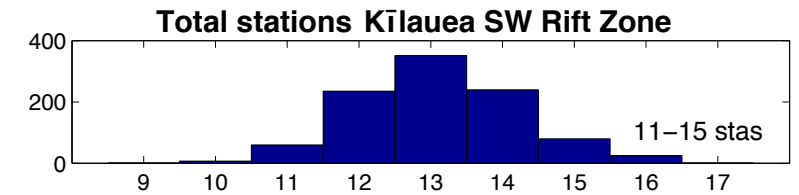

D

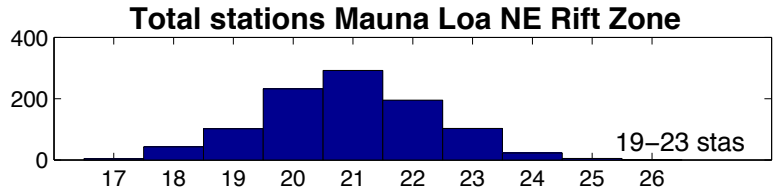

$\boldsymbol{F}$

Total stations Hualālai summit

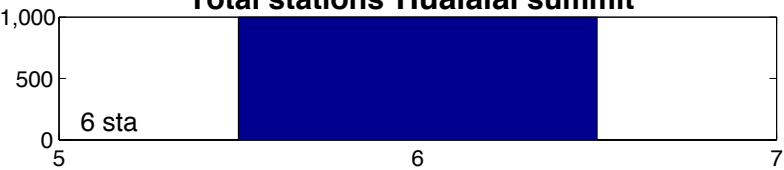

H

Total stations Hualālai S Rift Zone

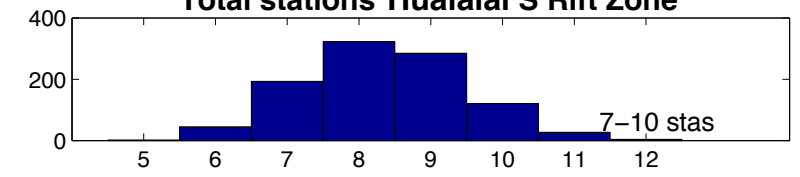

Total stations Haleakalā summit

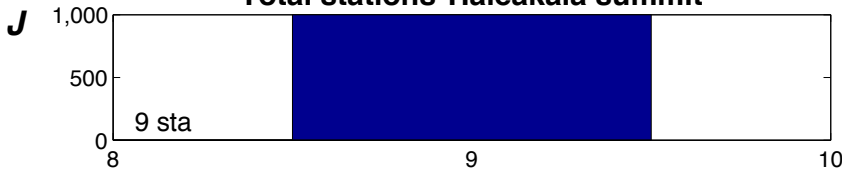

L $\quad 400 \quad$ Total stations Haleakalā SW Rift Zone

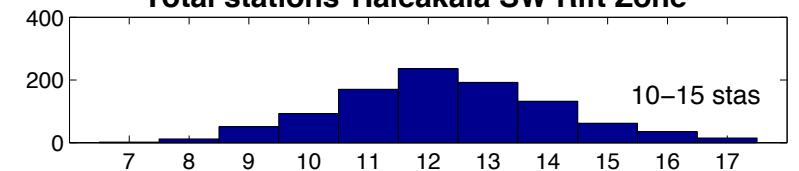

Figure 31. Graphs showing total number of seismic stations needed to meet National Volcanic Early Warning System (NVEWS; Ewert and others, 2005) quality level 4 status in study areas on the Islands of Hawai'i and Maui. The station range given is plus and minus one standard deviation from the mean of the computer simulations. See figure 27 for explanation of individual plots and abbreviations. 
A

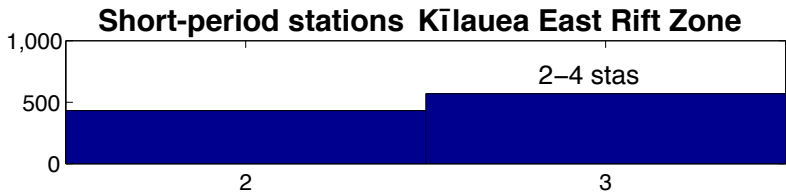

C

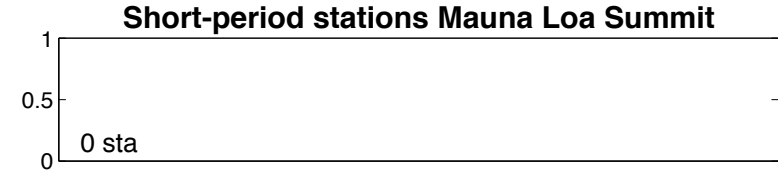

E

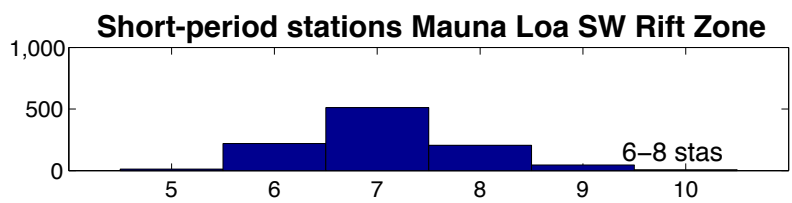

G

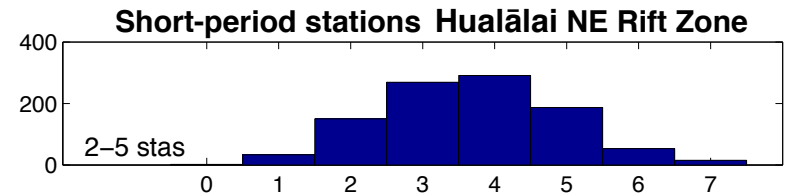

I

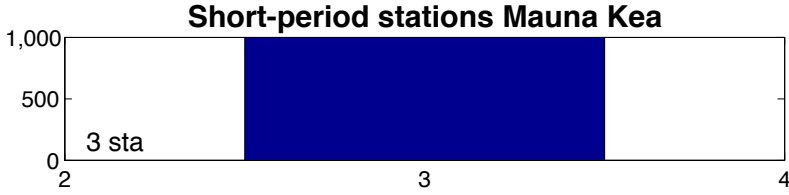

K

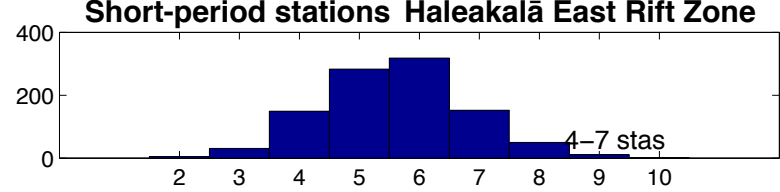

B

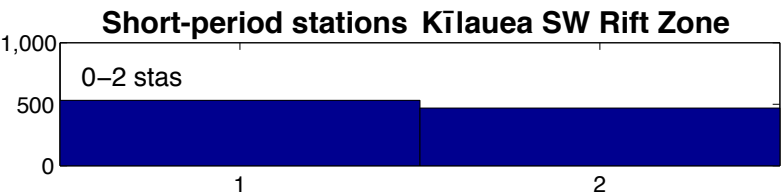

D

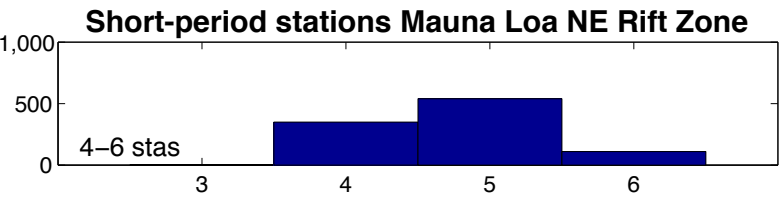

$\boldsymbol{F}$

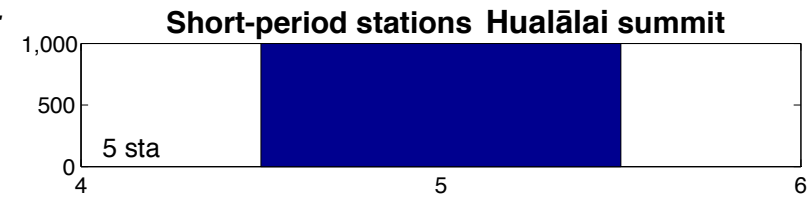

H 500 Short-period stations Hualālai S Rift Zone
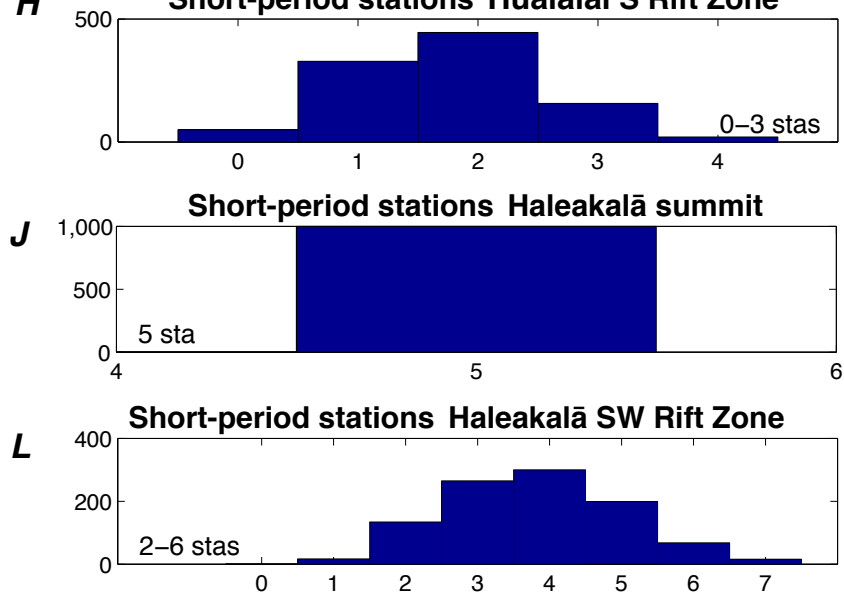

Figure 32. Graphs showing total number of short-period stations needed to meet National Volcanic Early Warning System (NVEWS; Ewert and others, 2005) quality level 4 status in study areas on the Islands of Hawai'i and Maui. The station range given is plus and minus one standard deviation from the mean of the computer simulations. See figure 27 for explanation of individual plots and abbreviations. 
A

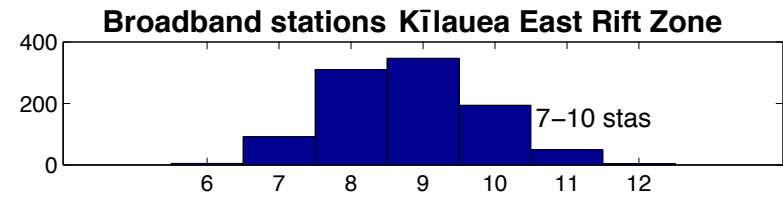

C

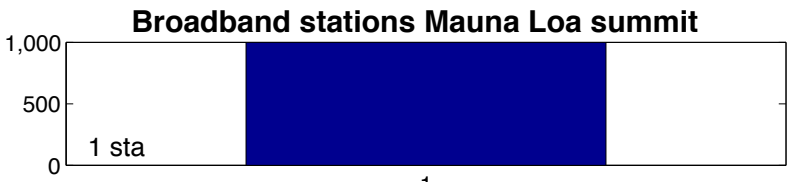

E

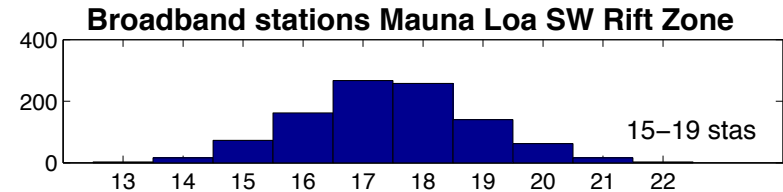

G

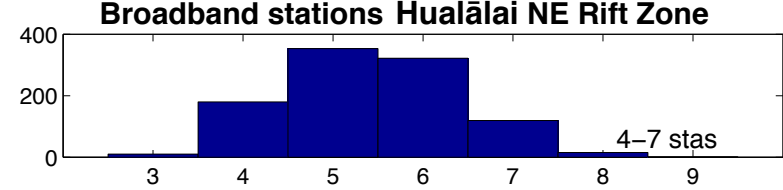

I Broadband stations Mauna Kea

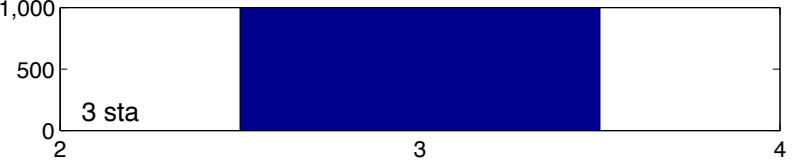

$\boldsymbol{K}$

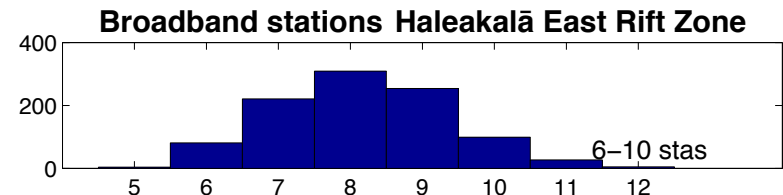

B

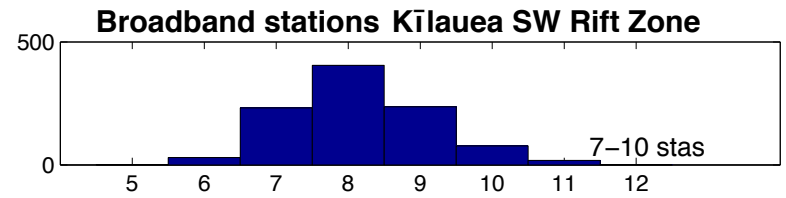

D

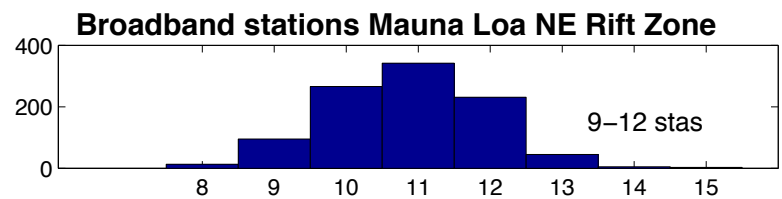

$\boldsymbol{F}$
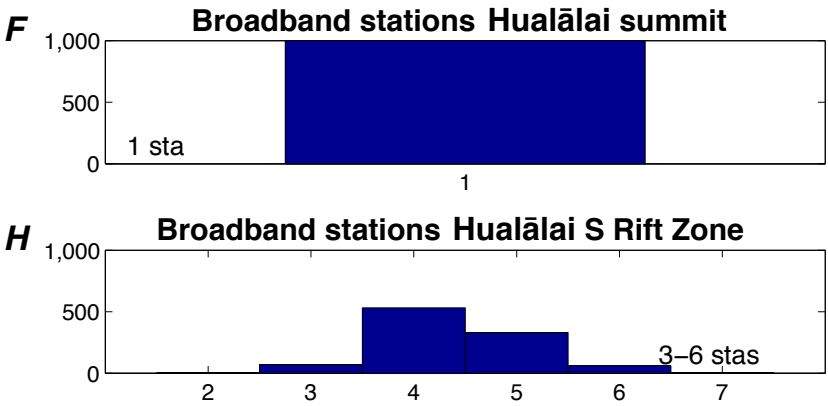

Broadband stations Haleakalā summit
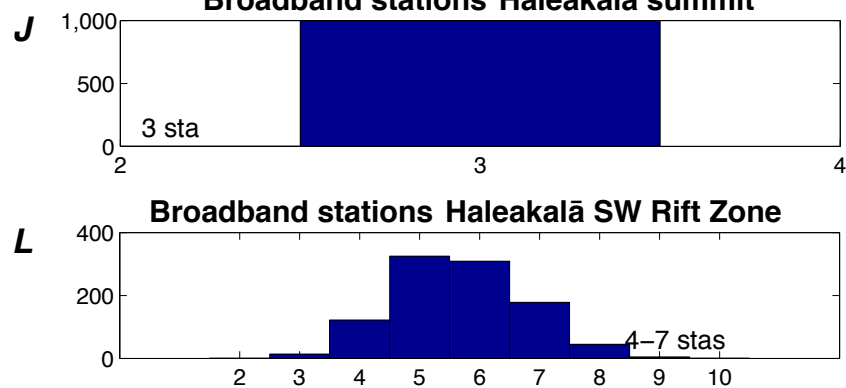

Figure 33. Total number of broadband stations needed to meet National Volcanic Early Warning System (NVEWS; Ewert and others, 2005) quality level 4 status in study areas on the Islands of Hawai'i and Maui. The station range given is plus and minus one standard deviation from the mean of the computer simulations. See figure 27 for explanation of individual plots and abbreviations. 
$\boldsymbol{A}$

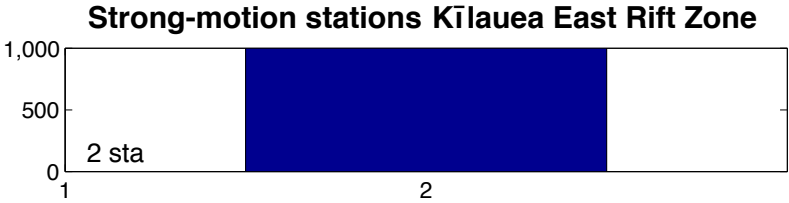

C

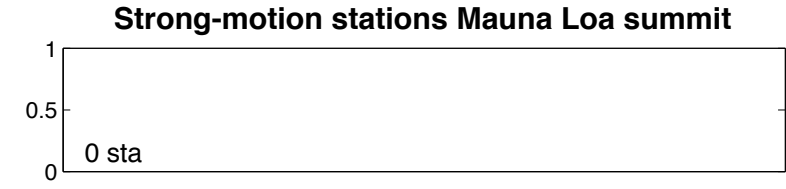

E

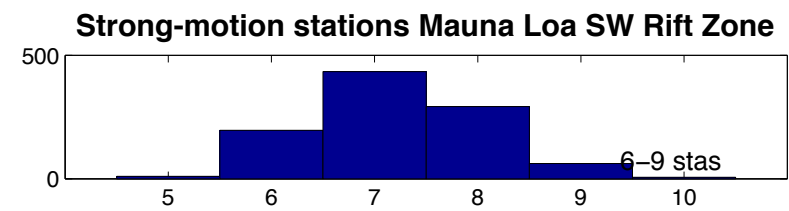

G

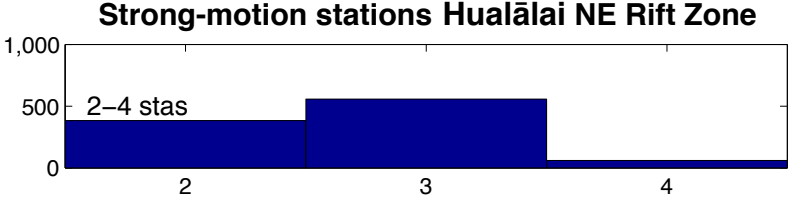

I

Strong-motion stations Mauna Kea

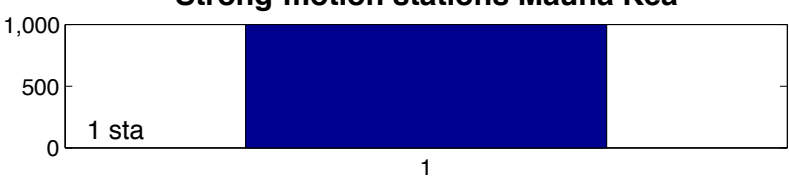$$
\text { K }
$$$$
50
$$

Strong-motion stations Haleakalā East Rift Zone

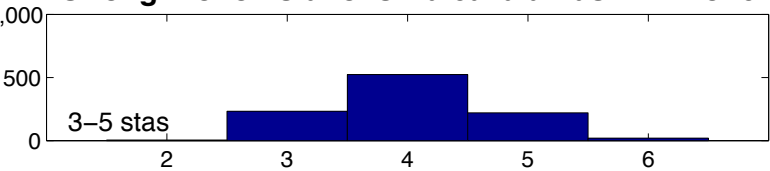

B

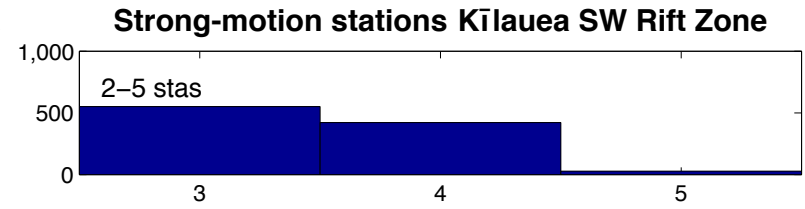

D

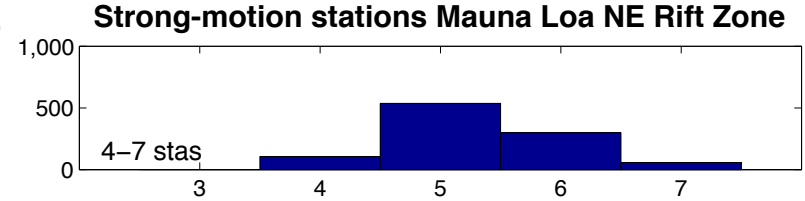

$\boldsymbol{F}$

Strong-motion stations Hualālai summit

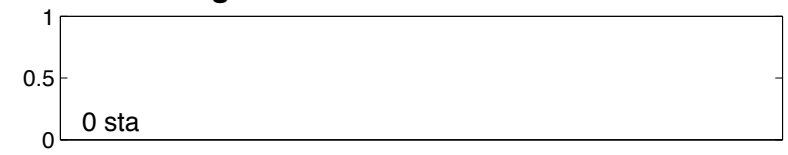

H 1,000 Strong-motion stations Hualālai S Rift Zone
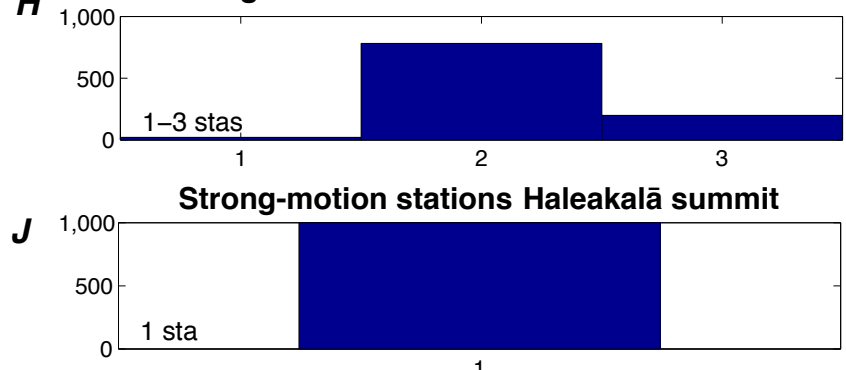

1,000 Strong-motion stations Haleakalā SW Rift Zone

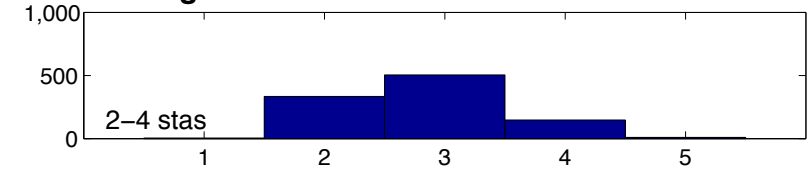

Figure 34. Graphs showing total number of strong-motion stations needed to meet National Volcanic Early Warning System (NVEWS; Ewert and others, 2005) quality level 4 status in study areas on the Islands of Hawai'i and Maui. The station range given is plus and minus one standard deviation from the mean of the computer simulations. See figure 27 for explanation of individual plots and abbreviations. 
$\boldsymbol{A}$

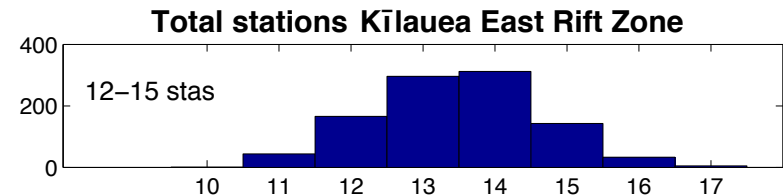

C

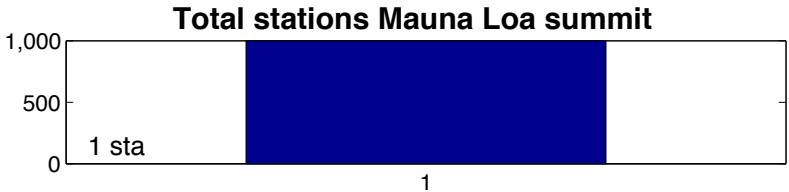

E

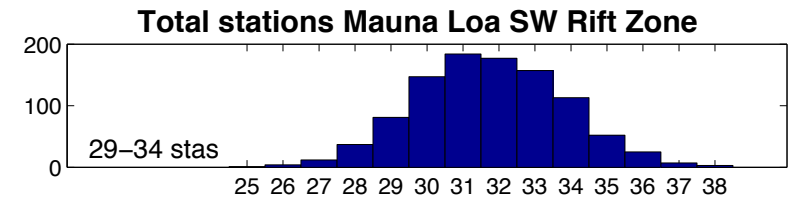

G

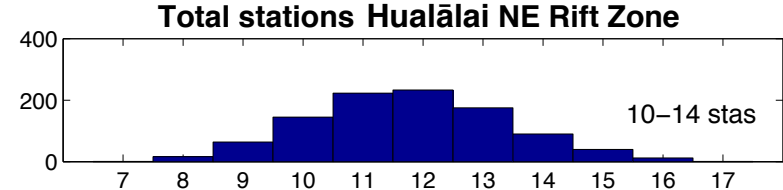

I

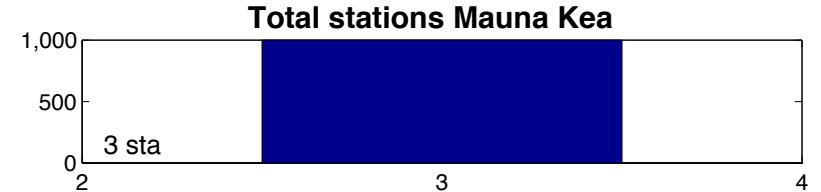

Total stations Haleakalā East Rift Zone

K

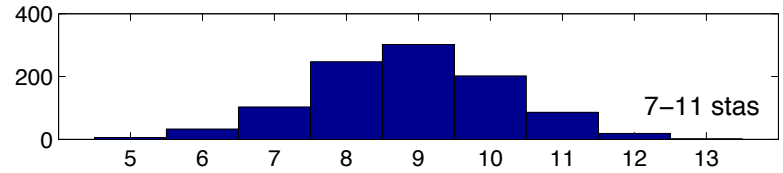

B

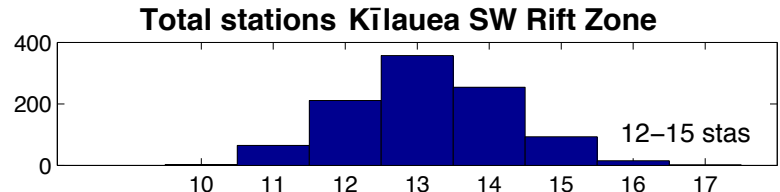

$\boldsymbol{D}$

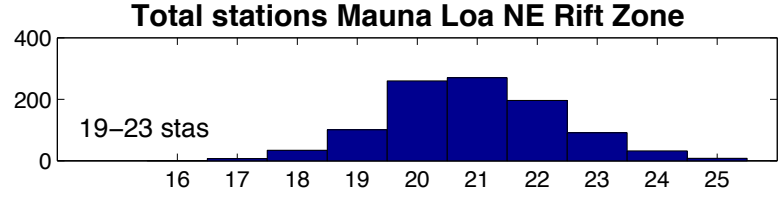

$\boldsymbol{F}$

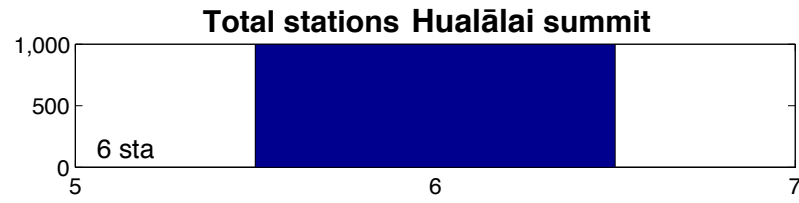

H

Total stations Hualālai S Rift Zone

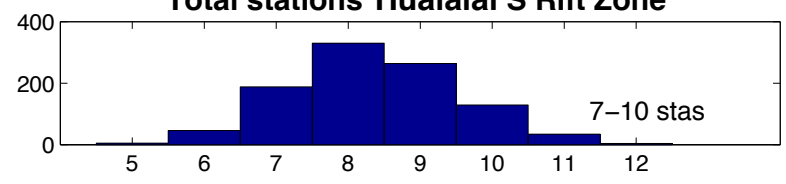

Total stations Haleakalā summit
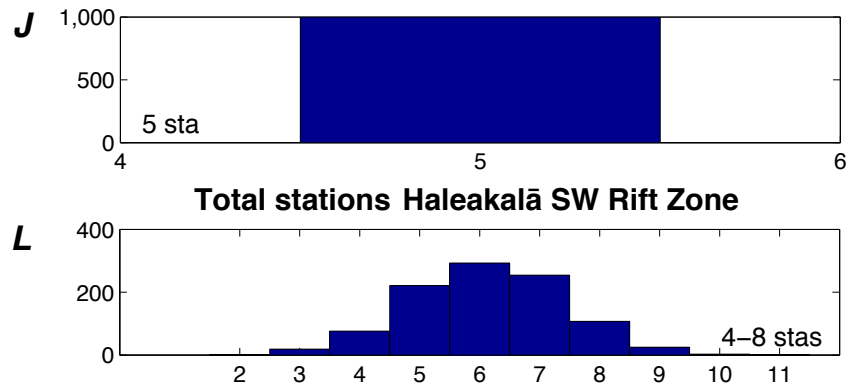

Figure 35. Graphs showing total number of seismic stations needed to meet National Volcanic Early Warning System (NVEWS; Ewert and others, 2005) optimal quality level in study areas on the Islands of Hawai'i and Maui. The optimal quality level is defined in table 2. The station range given is plus and minus one standard deviation from the mean of the computer simulations. See figure 27 for explanation of individual plots and abbreviations. 
A

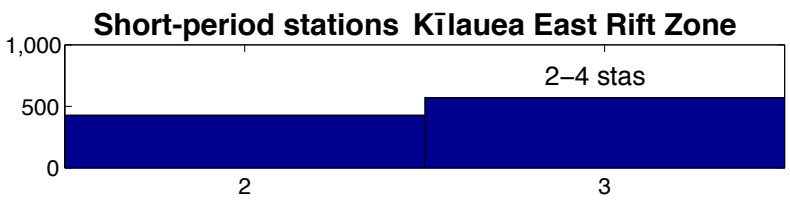

c

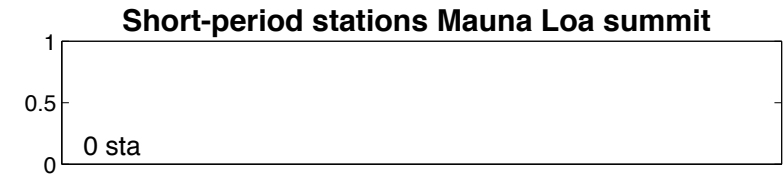

E

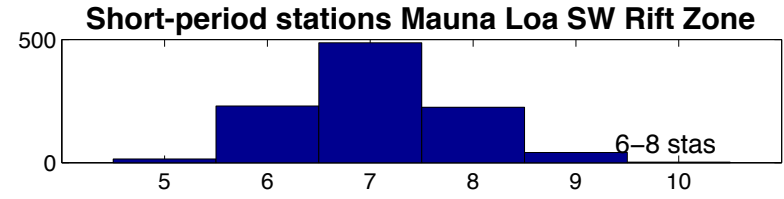

G

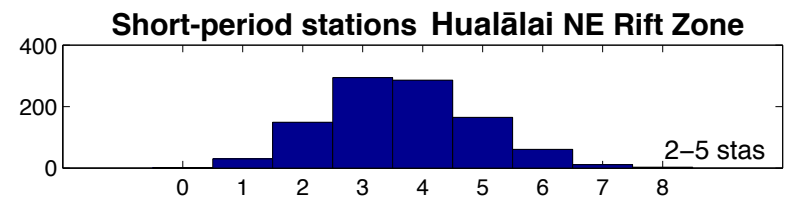

I
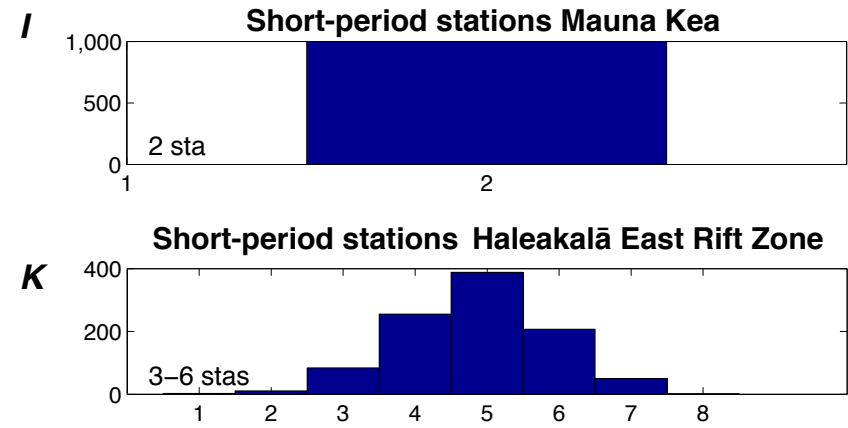

B

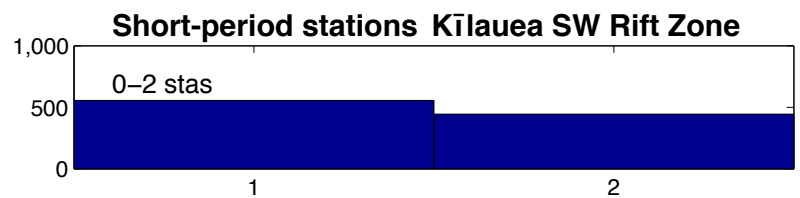

D

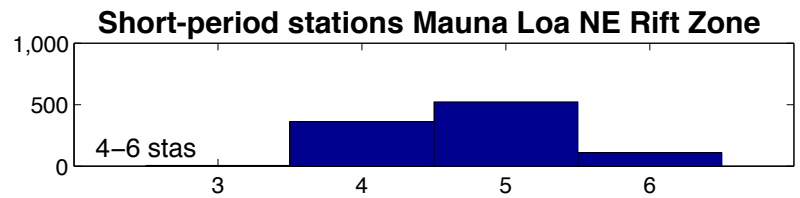

$\boldsymbol{F}$

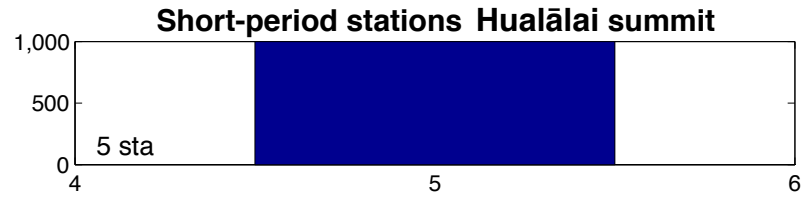

$\boldsymbol{H}$

Short-period stations Hualālai S Rift Zone

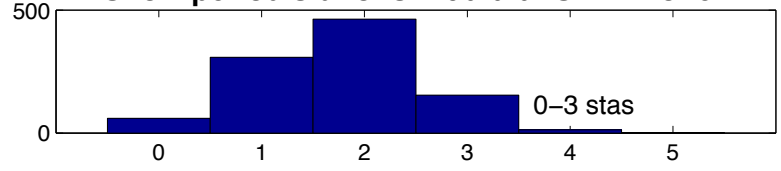

$\boldsymbol{J}$

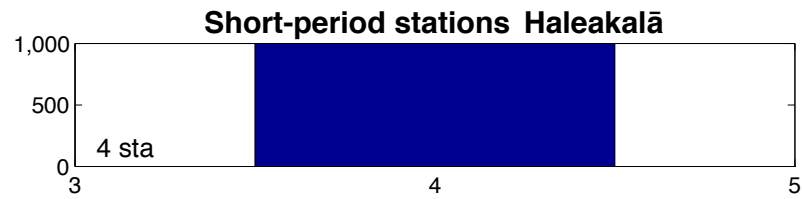

Short-period stations Haleakalā SW Rift Zone

$L$

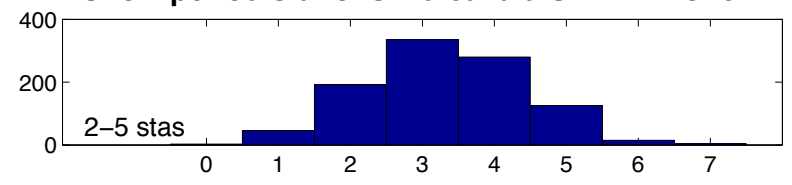

Figure 36. Graphs showing total number of short-period stations needed to meet National Volcanic Early Warning System (NVEWS; Ewert and others, 2005) optimal quality level in study areas on the Islands of Hawai'i and Maui. The optimal quality level is defined in table 2 . The station range given is plus and minus one standard deviation from the mean of the computer simulations. See figure 27 for explanation of individual plots and abbreviations. 
A

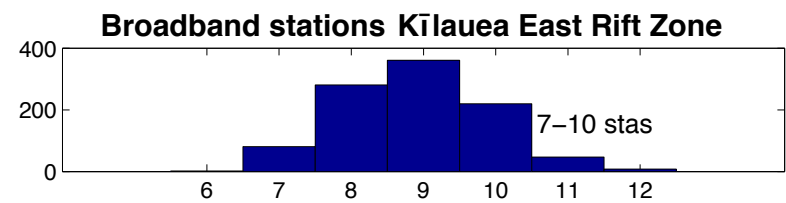

C

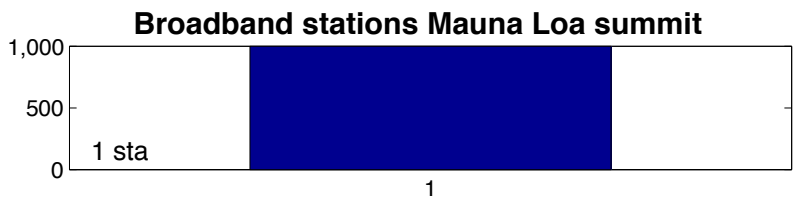

E

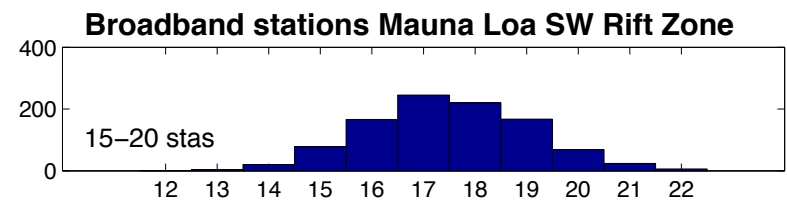

G

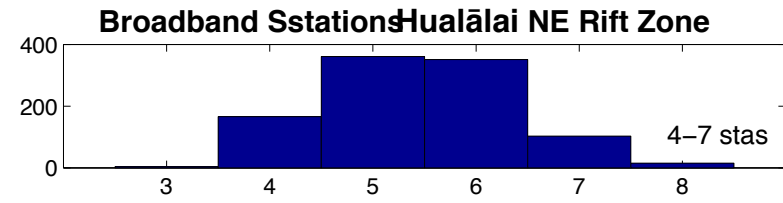

I
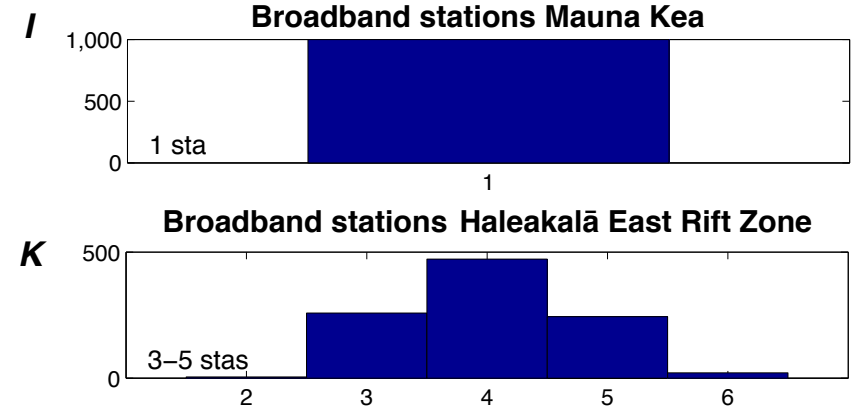

B

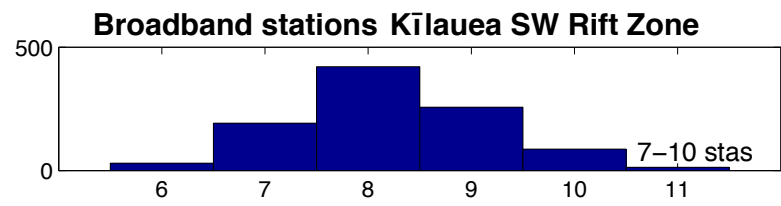

D

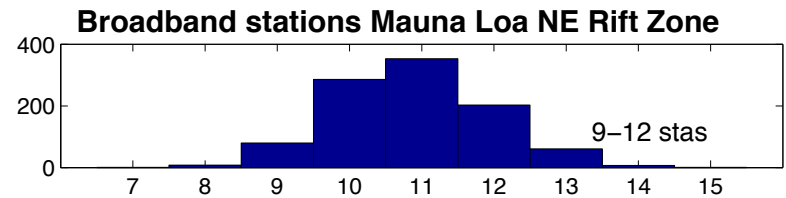

F

Broadband stations Hualālai summit

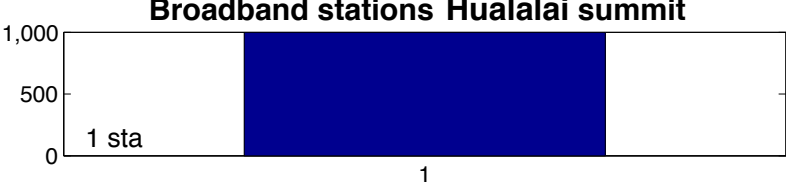

$\boldsymbol{H}$

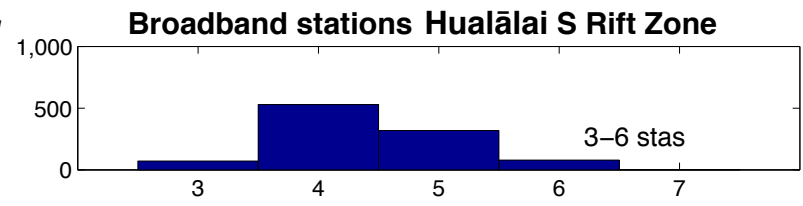

$\boldsymbol{J}$

Broadband stations Haleakalā

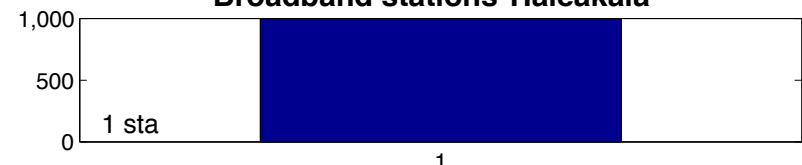

Broadband stations Haleakalā SW Rift Zone

$L$

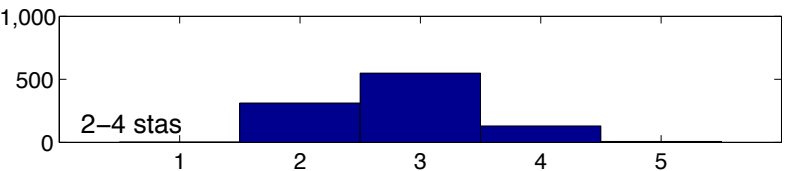

Figure 37. Graphs showing total number of broadband stations needed to meet National Volcanic Early Warning System (NVEWS; Ewert and others, 2005) optimal quality level in study areas on the Islands of Hawai'i and Maui. The optimal quality level is defined in table 2 . The station range given is plus and minus one standard deviation from the mean of the computer simulations. See figure 27 for explanation of individual plots and abbreviations. 


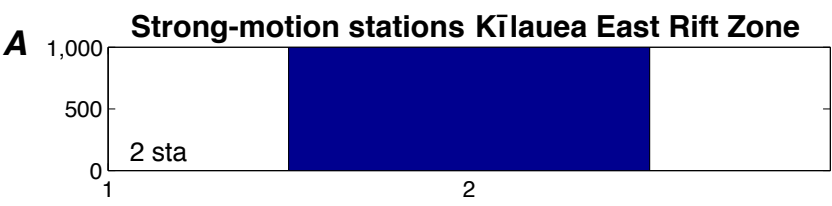

C

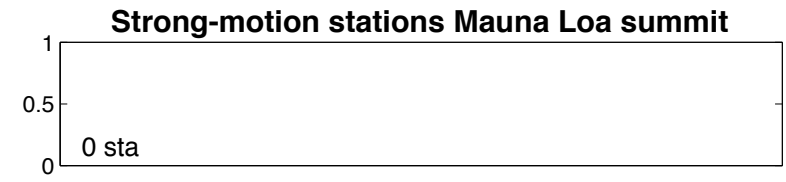

E 500 Strong-motion stations Mauna Loa SW Rift Zone

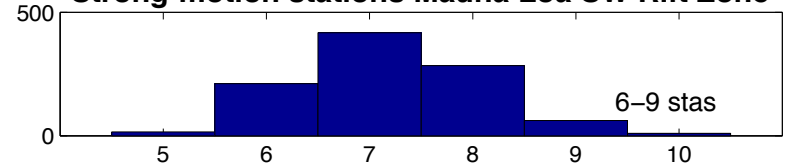

$G_{1,000}$ Strong-motion stations Hualālai NE Rift Zone

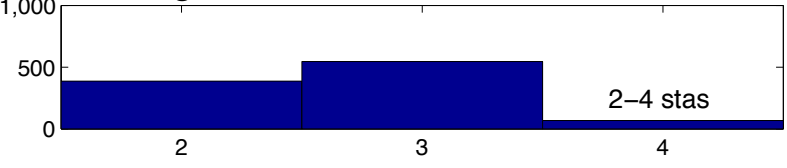

I

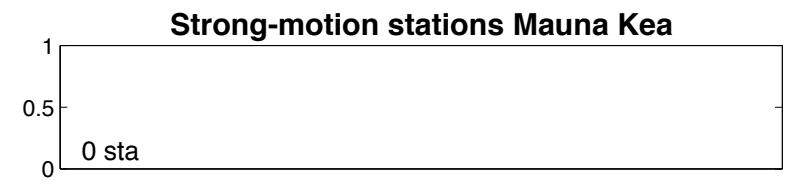

Strong-motion stations Haleakalā East Rift Zone

K

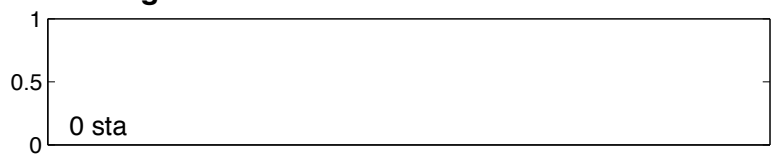

B

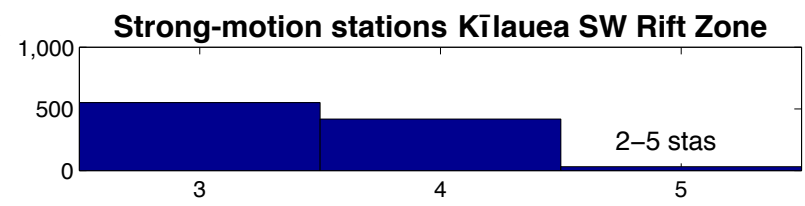

D

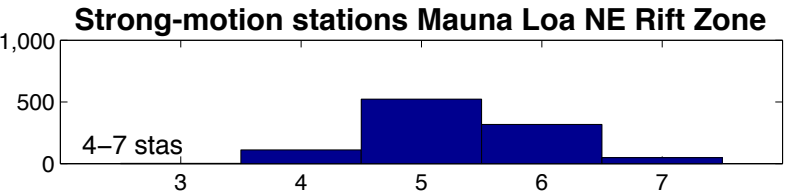

$\boldsymbol{F}$

Strong-motion stations Hualālai summit
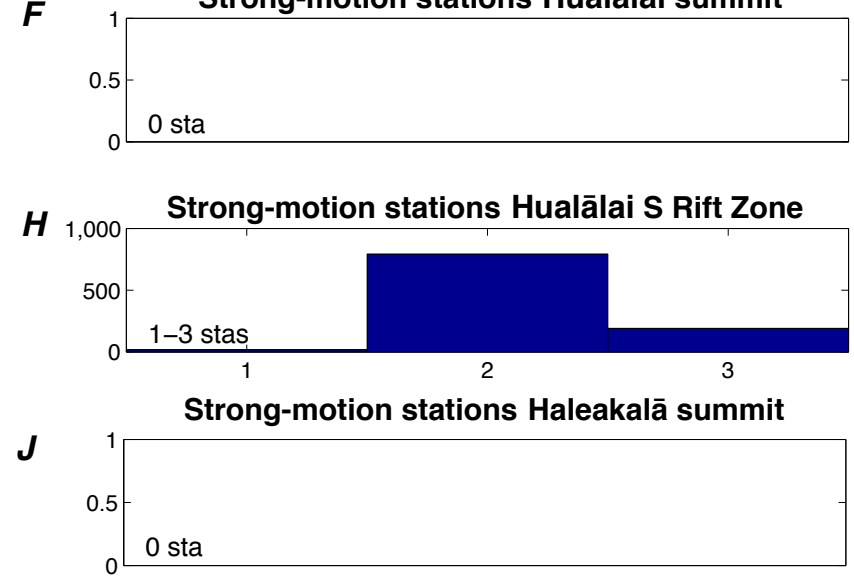

Strong-motion stations Haleakalā SW Rift Zone

$L$

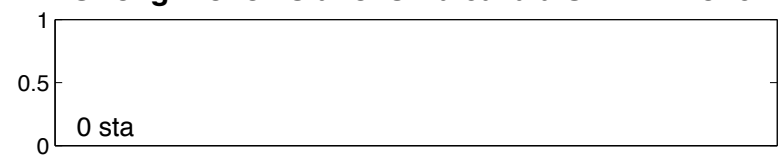

Figure 38. Graphs showing total number of strong-motion stations needed to meet National Volcanic Early Warning System (NVEWS; Ewert and others, 2005) optimal quality level in study areas on the Islands of Hawai'i and Maui. The optimal quality level is defined in table 2. The station range given is plus and minus one standard deviation from the mean of the computer simulations. See figure 27 for explanation of individual plots and abbreviations. 
This page intentionally left blank. 
Menlo Park Publishing Service Center, California

Manuscript approval date September 12, 2014

Edited by James Hendley II

Design and layout by Vivian Nguyen 


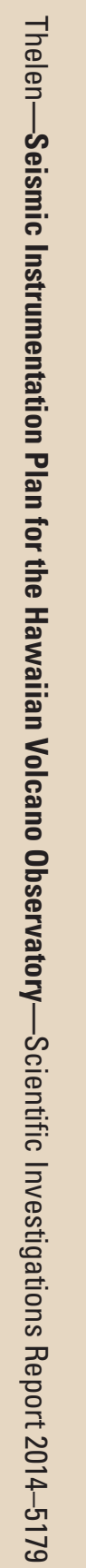

